\title{
Playing Their Song: \\ Developing and delivering a repertoire for use in music therapy on placement with two singing groups of people living with neurological conditions, and their carers.
}

Jenny Gordon

2019

An exegesis presented in partial fulfilment for the degree of Master of Music Therapy Victoria University of Wellington Wellington, New Zealand. 


\section{Abstract:}

This research study uses qualitative, action research methodology to investigate the factors impacting how I can choose and deliver repertoire within the context of my music therapy practice on placement with two singing groups of people living with neurological conditions and their partners and carers. Adhering to the characteristics of action research, this study consists of cycles of learning, and focuses on my understanding of the perceptions and perspectives of clients of the service, plus my own responses regarding the repertoire and how it is used during the music therapy, thus attempting to understand people's preferred repertoire and improve my practice. My clinical practice notes, participatory observations and reflective journals were coded and analysed to develop themes. Following this, inductive meanings were made of what, how and why the particular repertoire was used. There were many insights learned, from the perspective of the researcher (as a student music therapist and beginning researcher), but the most salient seemed, to me, to be that the entire gestalt of the experience shared whilst singing and playing together with the groups was more important than the minutiae of individual factors that go into making up that experience.

Keywords: Group singing; Repertoire; Music preferences; Neurologic conditions; Community Music Therapy 


\section{CONTENTS}

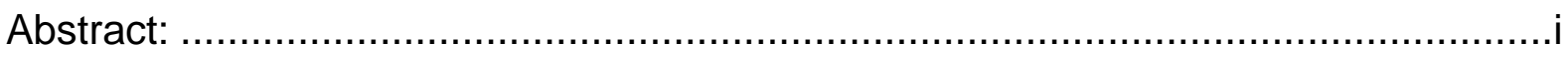

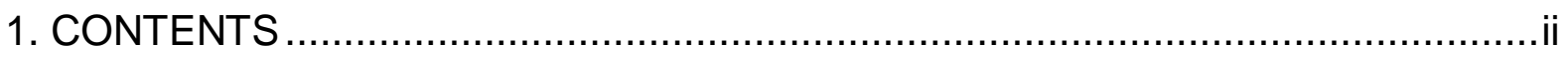

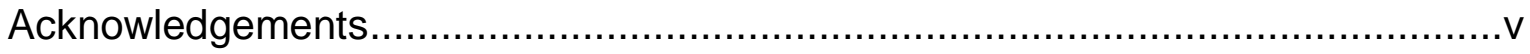

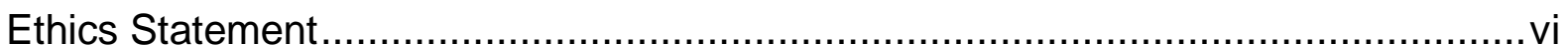

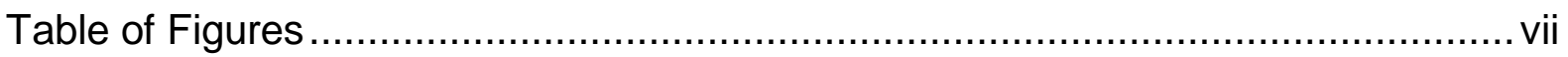

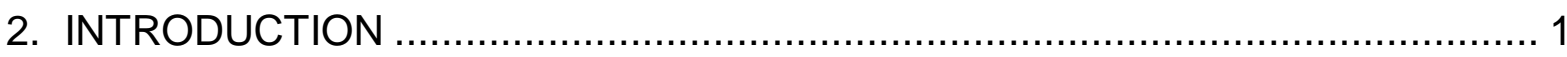

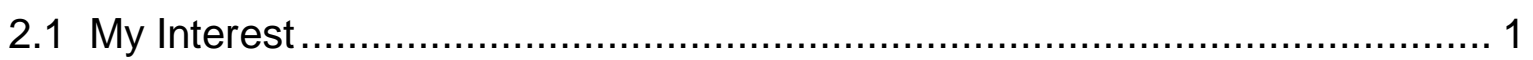

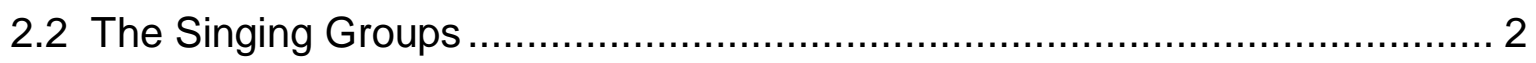

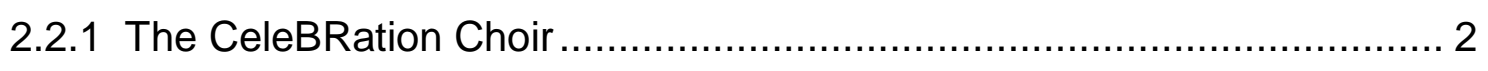

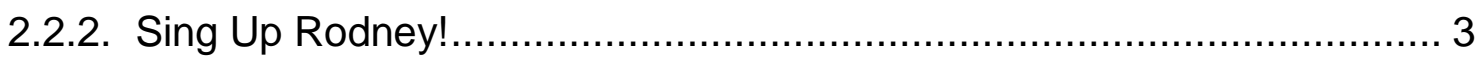

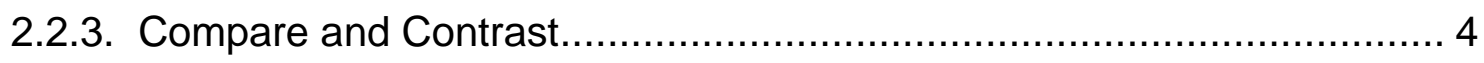

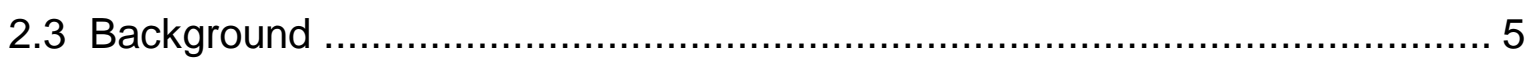

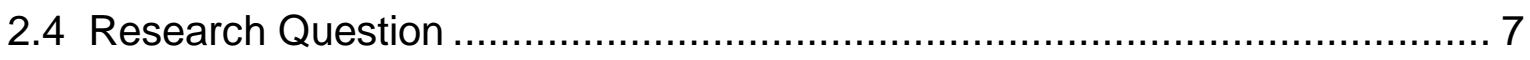

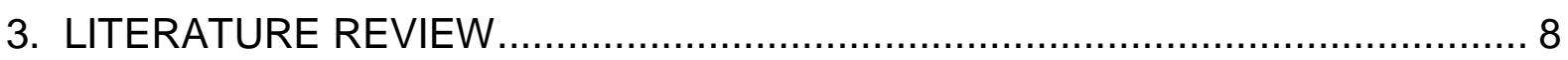

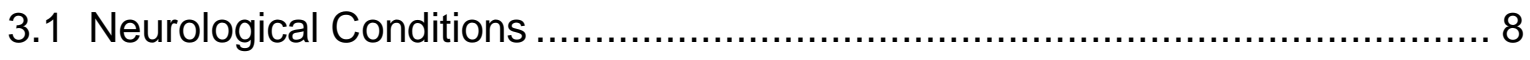

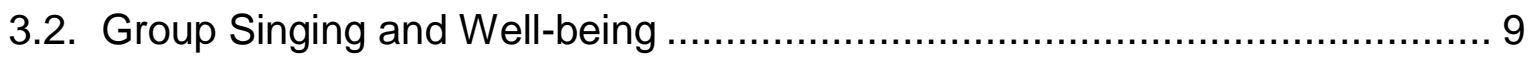

3.3. Communication Rehabilitation for Neurological Conditions ...................... 10

3.4. Music Preferences ......................................................................... 10

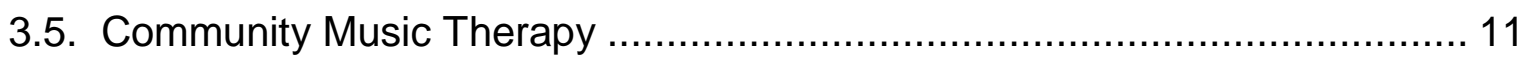

3.6. Summary of the Literature ...................................................... 13

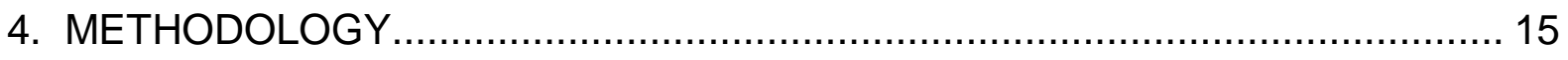

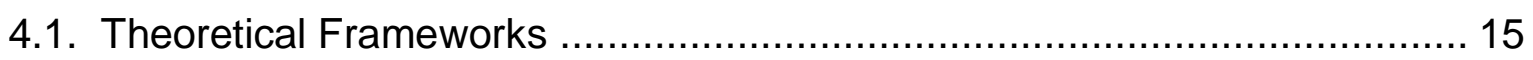

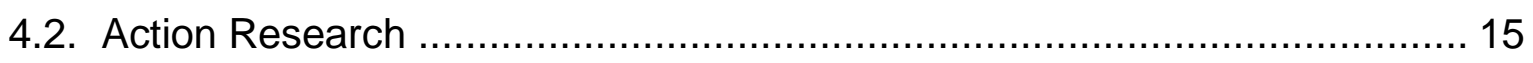

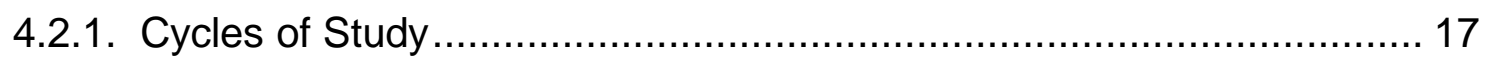

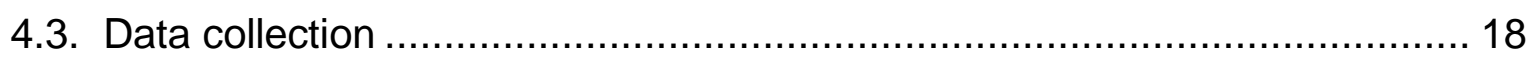

4.3.1. Music Therapy Clinical Notes............................................ 18 


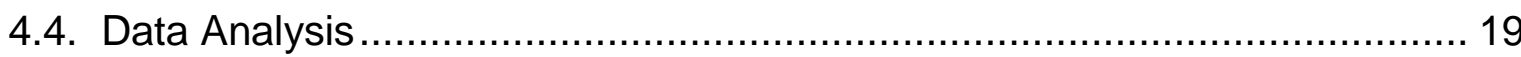

4.5. NVivo computer programme - Coding ……………............................. 20

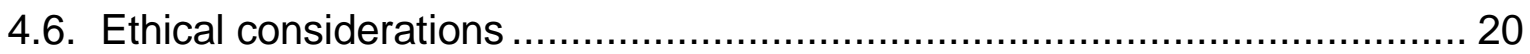

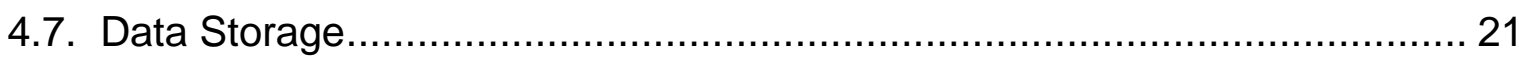

5. FINDINGS

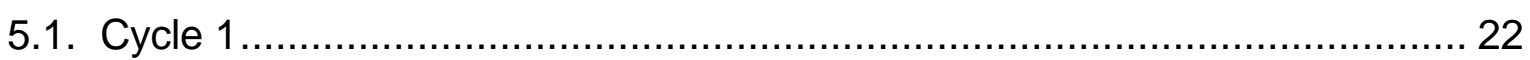

Question: How can I use cueing to support the singing groups? ................... 22

Question: How can I create exercises out of familiar songs and melodies that target communication difficulties caused by speech and language disorders associated with neurological conditions? ........ 23

Question: How do I choose the best key for the choir to sing the song? ........ 23

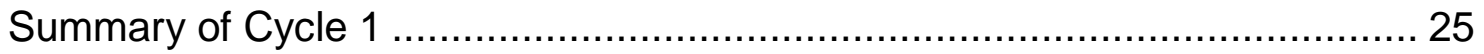

5.2. Cycle 2

Question: How can I make technical decisions about the choir and myself while in the midst of the repertoire activity?................................. 25

Question: How can I dispel unhelpful anxieties to fully allow me to be a natural and open therapeutic presence while making technical decisions in the moment? ...................................................... 26

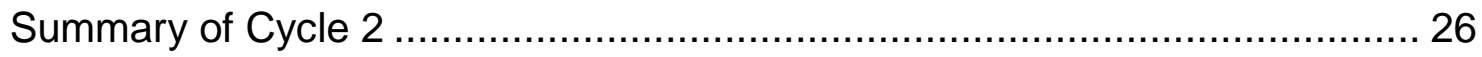

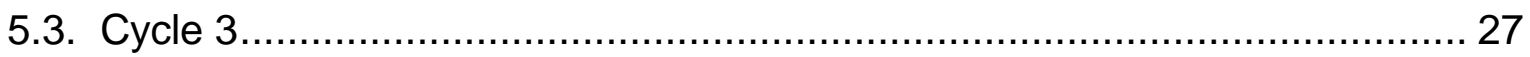

Question: How can I simultaneously facilitate quality musical experiences of the repertoire while responding to the needs of individual participants?

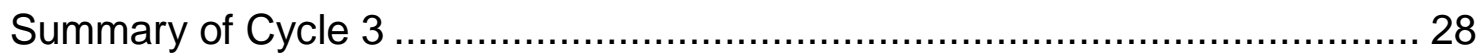

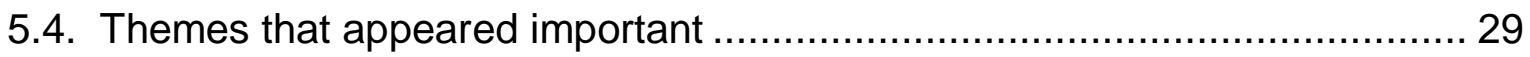

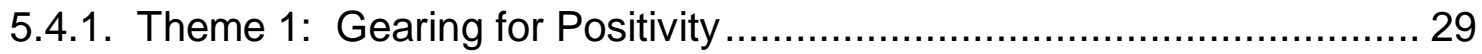

5.4.2. Theme 2: Maintaining the Feel-Good Factor .................................... 44

5.4.3. Theme 3: Managing My Skills and Vulnerabilities ............................ 55

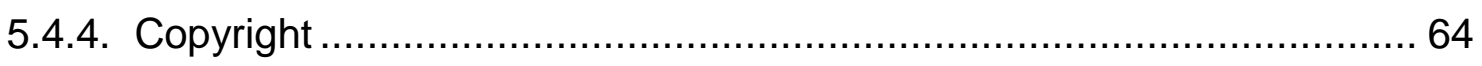

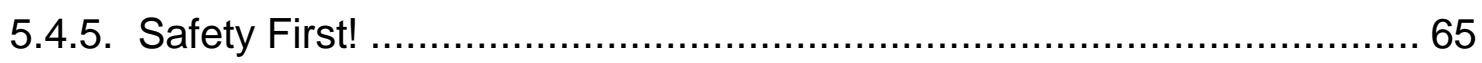




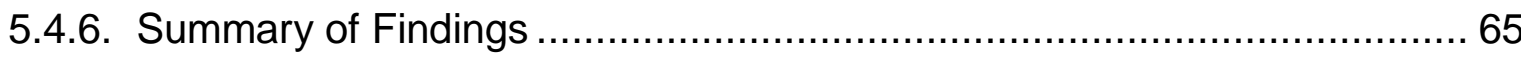

6. VIGNETTE

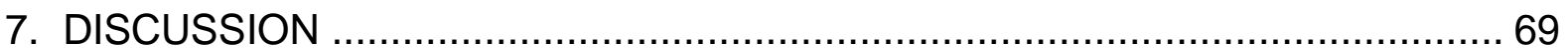

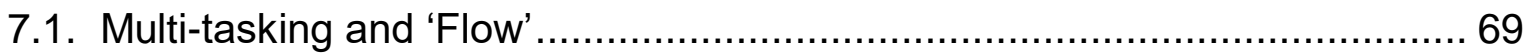

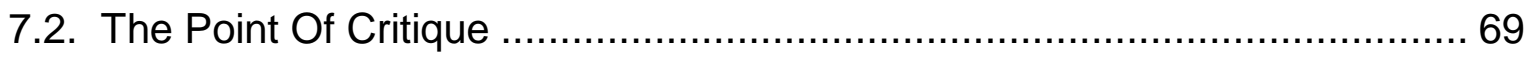

7.3. Speech / Singing Pitches and Aphasia Friendly Printing ............................. 70

7.4. Quality Music Experiences ................................................................... 71

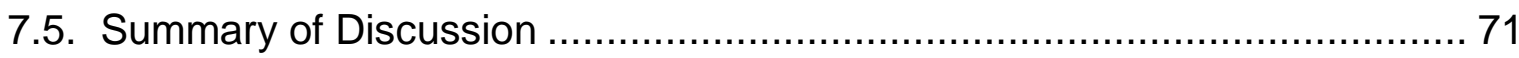

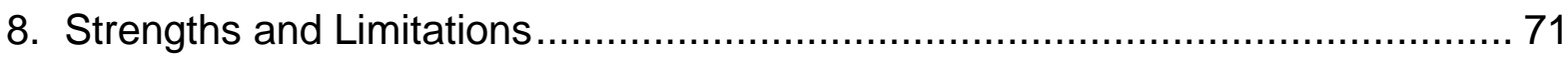

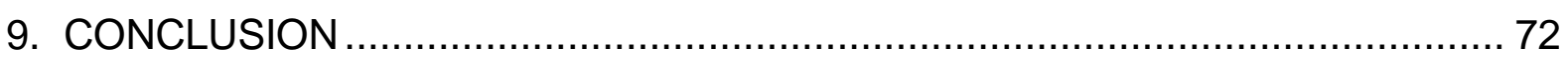

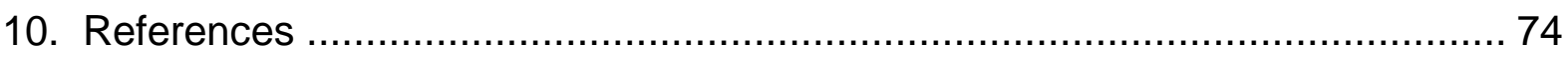

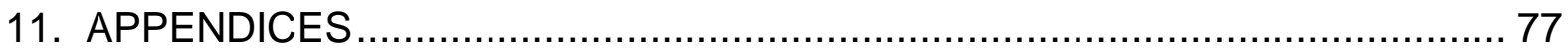

Appendix 1: Two Requests for permission to conduct research .......................... 78

Appendix 2: Information Sheet for singing group participants .......................... 80

Appendix 3: Consent Form for singing group participants ................................ 83

Appendix 4: Consent Forms for Alison Talmage ............................................ 84

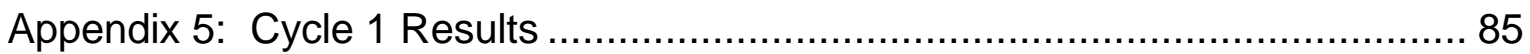

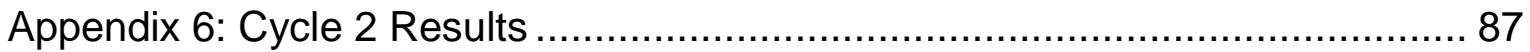

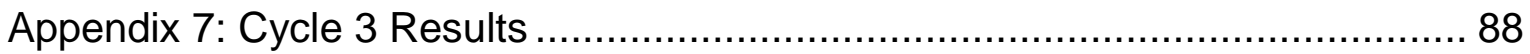




\section{Acknowledgements}

To my wonderful and generous teachers, academic supervisors and music therapy models (amongst other things!), classmates and beloved family:

Your collective wisdom, guidance and encouragement have been inspirational and a force for change.

Associate Professor Sarah Hoskyns: Academic Supervisor. Ever constant, understanding. Thank you for teaching me in music therapy over the past two years.

Dr Daphne Rickson: A calm voice on a sea of confusion, a knowing and a reassuring look here and there. Thank you for teaching me in music therapy over the past two years.

Alison Talmage (RMTh, Doctoral Candidate): Supervising Music Therapist. Calm, generous and very encouraging. A huge thank you, also, for helping with your supreme proof-reading and superb referencing skills. Thank you so much for the opportunity to train with you, watch you work, learn from you and share in this part of your life.

This research would not have been possible without the willingness to participate and encouragement from the participants of the CeleBRation Choir and Sing Up Rodney! singing groups. Thank you all for sharing yourselves with me and letting me share in the singing with you.

I also acknowledge and thank the Centre for Brain Research and the University of Auckland, in particular Professor Suzanne Purdy, for your interest and input into the CeleBRation Choir.

To my classmates who have been on this journey with me for the past two years - you are gangsta!

Last, but not least, to my family: Without your love and support this would not have been possible. Thank you to my husband, Flash, son and daughter, Michael and Grace. You are the best thing I ever did!

I am so grateful to all people named above for their help on my research and practice journey. 


\section{Ethics Statement}

This project received ethical approval from the Victoria University Human Ethics Committee:

Ethics Approval: 22131

NZSM Master of Music Therapy Programme ethical template for student research in NZSM 526 undertaken as observational studies, theoretical or case study research. 


\section{Table of Figures}

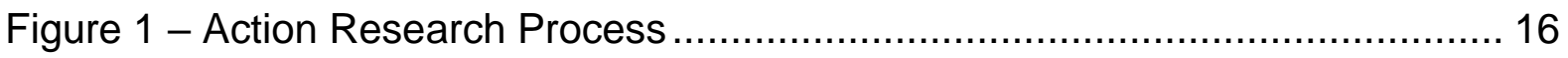

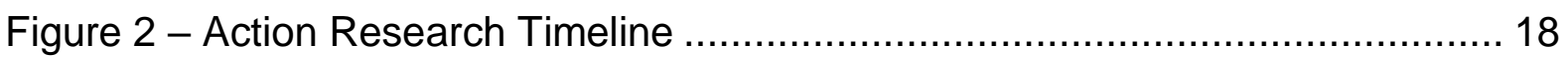

Figure 3 - Scientific Pitch Notation ................................................................ 24

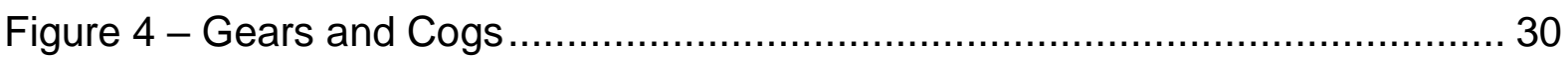

Figure 5 - Coding Map: Gearing for Positivity .................................................... 31

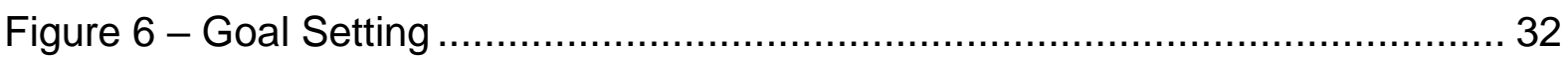

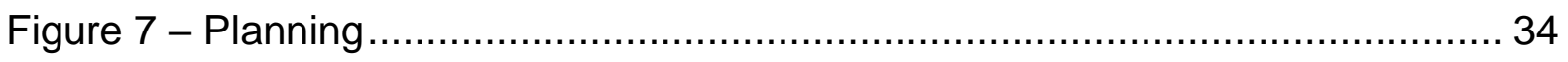

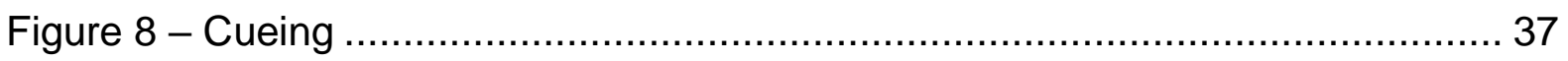

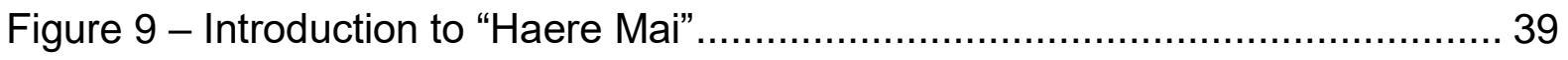

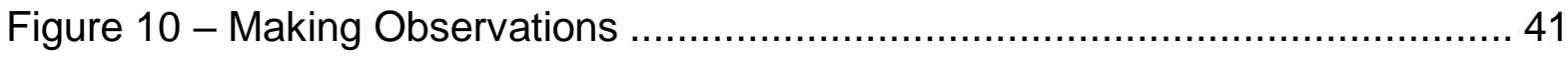

Figure 11 - Coding Map: Maintaining the Feel-Good Factor ................................ 44

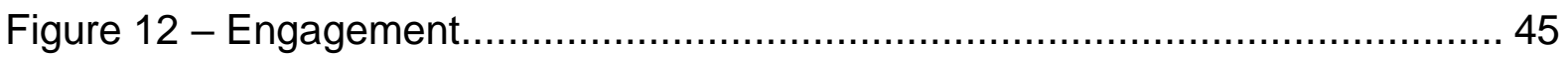

Figure 13 - "Blueberry Hill" exercise - for forward planning of words.................... 50

Figure 14 - "Celebrate CeleBRation Choir" ....................................................... 51

Figure 15 - "Celebrate CeleBRation Choir" with breathing cues ........................... 51

Figure 16 - Coding Map: Managing My Skills and Vulnerabilities ......................... 56

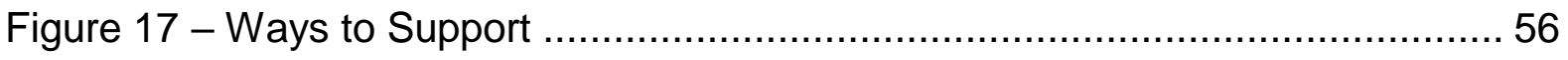

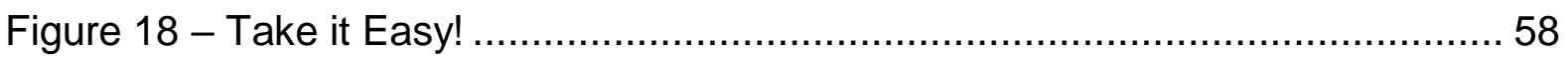

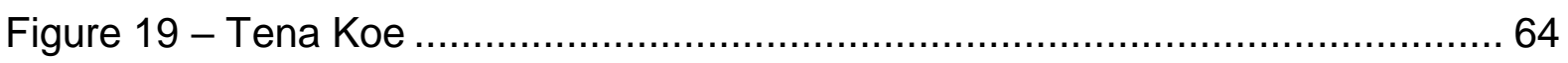

Figure 20 - Horn line for "See You Later Aligator" .............................................. 67

Figure 21 - Speech Pitches (Henton, 1989) …………..................................... 70 


\section{INTRODUCTION}

As students of music therapy, we need to equip ourselves to meet the needs musically, culturally and socially - of those we hope to serve. Along with the requisite musical skills, character traits and 'ways of being', it is also important to consider the music repertoire that we ought to gather for our kete ${ }^{1}$ (basket of 'tricks of the trade'), to make this possible. Music therapists also need to be flexible in their ways of adapting materials, and I am interested in how I can learn and grow to achieve this. I have used an action research methodology to reflect, understand and develop my practice in this area. All my life I have sung songs, in many different groups and choirs, as a schoolteacher, as well as on my own. It is of great interest and highly beneficial to me, as a practitioner of music therapy that I equip myself with repertoire that reflects and responds to the needs of my clients.

\subsection{My Interest}

This research was based on my placement experience with two singing groups of adults and older adults living with neurological disorders, with partners and carers, in Auckland. The groups were run weekly and were $90-120$ minutes long. This included a social time over morning or afternoon tea.

The purpose of this research is not to generalise for people in the study but to gain insight into, and understanding of, how and why I use repertoire, in my practice with this population, to improve said practice. I have a keen interest in and I feel I am philosophically aligned with tenets of positive psychology, particularly the three types of 'happy lives' as they relate to established theories - the pleasant life, (hedonism theory); the life of engagement, (desire theory); and the meaningful life, (objective list theory) (Seligman \& Csikszentmihalyi, 2000, p. 5). Felicity Baker's discussion on how we can promote positive health and wellbeing through music based activities that seek to provide 'authentic happiness', from the positive psychology standpoint (Baker \& Ballantyne, 2012), along with notions of resource-oriented music therapy, which views the individual within their context rather than the medical model which focuses on their

\footnotetext{
${ }^{1}$ Basket, traditionally woven from harakeke (flax) leaves, (Te Reo Maori), used for holding things gathered.
} 
pathology (Rolvsjord, 2010), are also key to my thinking on how I might be able to practice music therapy with this population.

One recent systematic review on reminiscence therapy suggests that the emphasis in included studies was on "measuring outcomes, rather than developing protocol strategies which are not currently standardised, ... (and that) future research should incorporate description and reflection of their practices“ (Istvandity, 2017, p. 24). I intend for this research to be that which will help me develop my own repertoire and lead me to more coherent beliefs and philosophy into what my practice should be.

\subsection{The Singing Groups}

In consultation with my supervisors and placement providers, which included a research centre, we negotiated that it would be valuable to name the places where this research took place. There are particular ethical implications for this, for which we were very mindful, (see 4.6. Ethical considerations, page 20), but overall we felt it would be more beneficial to share the contexts of this work in the exegesis.

\subsubsection{The CeleBRation Choir}

The CeleBRation Choir (CBRC) was formed in 2009 at the University of Auckland's Centre for Brain Research, and offers access, free of cost, to people living with neurological conditions and related speech and language difficulties - and, if they wish, their partners or carers. The CBRC was the first "neurological" choir to be established in New Zealand. This seems unique to new Zealand, establishing inclusive neurological choirs and groups, rather than population-specific groups, e.g. for people with Parkinson's disease (PwP) or stroke survivors or people living with aphasia. The largest subgroups by diagnosis are people post- stroke (PPS), and PwP, while some live with dementia, traumatic brain injury or other neurological conditions. It is an all-ages adult group; however, most participants are older adults (65+), some are in their 50 s to early 60 s, while only a few are around 40 years old. At the time of writing there were usually $50-60$ participants in the sessions. The CBRC is led by 
Alison Talmage, a registered music therapist, supported by $4-6$ loyal and reliable volunteers and behind the scenes support from university speech scientists.

Sessions are one afternoon a week from $1.45-3.15 \mathrm{p} . \mathrm{m}$. in a large, well-appointed lecture/seminar space, with computer and projection system, that is adjacent to a kitchen.

The CBRC is a large group of people with diverse needs, goals, preferences, abilities, and life experiences. Even within the same populations, e.g. PwP, there is a vast range of needs and goals. The participants self-refer to the group and bring their own goals and reasons for attending. With the size of the group there are obvious difficulties in seeing everything at once, and hearing what people say was sometimes difficult, especially with the communication issues common to these populations.

The usual layout was six or seven rows of eight or nine seats (or wheelchair space), with side access and a wide central aisle. Allowing for some mobility issues more space was required between the rows. This meant that there was a reasonable distance from the front of the choir to people in the back rows.

\subsubsection{Sing Up Rodney!}

Sing up Rodney! (SUR) was formed in 2017 in response to requests from former CBRC participants who had moved to the Rodney area. Weekly travel to the CBRC sessions would be onerous due to Auckland area being so large, participants' health needs and mobility or transport barriers. SUR also caters for people living with a neurological condition and includes partners, carers and volunteers. Alison Talmage responded to demand from potential participants, with the support of local branches of non-governmental community organisations, e.g. Aphasia New Zealand and Parkinson's New Zealand, and initial funding from charitable organisations. Situated at Silverdale, north of Auckland, it seems more accessible for people in that area, and extended to a monthly group in Warkworth in 2018. Although partially funded through grants, the participants pay a modest cost per session. The group comprises $20-25$ participants, including partners or carers and usually has the benefit of $3-4$ wonderful volunteers. 
Sessions take place in a rented space with a kitchen attached, one morning a week from 10.30 - 12.30p.m. This includes a 30-minute break for morning tea.

The set up for the SUR group was much different due, largely, to the size of the group. Being only 20 to 25 people, this allowed for a single row of chairs in a circle. Eye contact was easier making for more connections amongst the people in the group. Also, being in a circle made hearing each other's speech and singing much easier.

\subsubsection{Compare and Contrast}

The CBRC and SUR address both psychosocial and communication needs of the participants, and are led by Alison Talmage, who is also my clinical liaison for my practical placement as part of my music therapy studies.

There were four main differences that I noticed when working with these two groups.

Firstly, the size of group. The CBRC is almost three times the size of SUR. While the populations are similar the sheer numbers of the CBRC can make it difficult to learn names and other information about them that make building relationships easier. Although individuals' personal information is recorded on a spreadsheet, it took me some months to learn everyone's names and match names to faces. With SUR, being smaller - a group rather than a large choir - I found I came to know the group much more quickly.

Secondly, the ratio of people with neurological conditions to partners and carers is higher in SUR. Nearly all SUR participants have a support person whereas, for the CBRC, the ratio is significantly less. There is a greater proportion of people with dementia needing support in the SUR group, as well as increased transport barriers in more rural areas.

Thirdly, interactions among the SUR group seem easier because everyone can see, with a small movement of the head, who is speaking. Non-verbal language can add to the communication especially so for those for whom verbal communication is difficult. With the CBRC, sitting often in rows, it was difficult for participants to see 
people talking, especially if they were sitting behind them. Most of the participants are not able to fully turn in their seats to look behind them. It seemed easier to make connections in the smaller group - that is not to say that connections weren't made in the larger group. They were - for example through people choosing to sit together regularly, through social conversation during afternoon tea, and through recruitment of friends from other support groups.

Finally, all these differences impacted the strength of the singing for each group. A smaller number of people produces less volume, however, the higher ratio of support participants in SUR also was a factor, I believe, that allowed SUR to produce more complex arrangements of songs in terms of harmonies and group rounds/partner songs. The high proportion of CBRC participants with Parkinson's, whose voices have a reduced volume, meant that the volume was sometimes less than we might expect from participant numbers.

\subsection{Background}

I first came to the CBRC as a volunteer in 2016. This was before I had decided to pursue training in music therapy - or at least before I had voiced my decision. I enjoyed standing at the back of the seated choir, playing my guitar and singing with them. There was a sense of 'all care and no responsibility' and I perceived, then, my role to be one of social engagement and a support to the choir's musicking efforts by assisting Alison. For me it was all about the psychosocial aspects of being in a singing group. I knew there were physical benefits gained from singing, particularly regarding breathing, and I knew about the emotional well-being derived from doing an activity you enjoyed. I was aware of neurological conditions and that music therapy may be beneficial to people living with these conditions. But I was unaware of the specific issues people living with these conditions face and the myriad ways that music can help.

When I returned to the CBRC as a music therapy intern, on practicum while studying to become a music therapist myself, I noted that my role had changed. I was now standing up the front of the group - talking, explaining, instructing, facilitating, singing and playing - all care and some responsibility. Well supported and welcomed by 
Alison and the group, I still had anxiety about being able to 'perform' the role. Learning the existing repertoire (songs, chords, words), and important information about the 50 or so choir members (names and conditions, situations, likes and dislikes, even where they like to sit and what songs they like) took my efforts for the first month.

Then, as I began to learn and understand some of the things listed above, I was inspired and encouraged to consider the ways that music therapy, and specifically group singing, could benefit the members of the choir. I was given an article to read that helped me immensely to navigate the intersecting worlds of music therapy, neurodisability and neuro-rehabilitation. Daveson's Meta-model of Music Therapy In Neurodisability - MIND (2008), proposes a combination of three approaches to music therapy. Firstly, the restorative approach - therapy involves efforts to regain skills and restore functions that may be lost due to neurological condition. Secondly, the compensatory approach - therapy involves helping the patient develop strategies for maintaining their sense of self despite the irretrievable loss of some functions. The third approach is the Psycho-Social-Emotional approach - therapy involves using music to convery and alter emotions, promote socialisation and psychological wellbeing.

I began to think of my work in terms of this three-pronged model that resonated with me.

Positive Psychology is also a field of knowledge and a way of thinking that resonates with me. There are three basic tenets to Positive Psychology. One is concerned with having positive experiences. For this to occur there needs to be contentment with the past, joy in the present, and optimism for the future. A second basic tenet of Positive Psychology is concerned with fostering positive individual traits such as a capacity for love (interpersonal skills, self-knowledge, forgiveness), resilience (perseverance, courage), creativity (originality, giftedness), future-mindedness, and wisdom. The final tenet relates to creating and fostering positive institutions. This entails strengthening communities through notions of responsibility, tolerance, justice, teamwork and purpose, to name a few.

The field of positive psychology at the subjective level is about valued subjective experiences: well-being, contentment, and satisfaction (in the 
past); hope and optimism (for the future); and flow and happiness (in the present). At the individual level, it is about positive individual traits: the capacity for love and vocation, courage, interpersonal skill, aesthetic sensibility, perseverance, forgiveness, originality, future mindedness, spirituality, high talent, and wisdom. At the group level, it is about the civic virtues and the institutions that move individuals toward better citizenship: responsibility, nurturance, altruism, civility, moderation, tolerance, and work ethic (Seligman \& Csikszentmihalyi, 2000, p. 5).

Positive Psychology and Daveson's meta-model for music therapy for neuro-disability were key theoretical underpinnings of the way I viewed myself in my work for this placement.

Being involved in the study of music therapy and working with two singing groups, one a large and one medium sized, I deemed it pertinent to investigate the development and use of repertoire in these settings and contexts. I wanted my focus to be on ways that I could use my skills in this area, and to further my clinical and theoretical knowledge in this area. I was not looking for lists of songs but more why a song might be valuable in this line of work and how I might best use those songs.

\subsection{Research Question}

How do I develop and deliver a repertoire for use in music therapy on placement with two singing groups of people living with neurological conditions, and their carers? 


\section{LITERATURE REVIEW}

A review of relevant literature has been conducted to provide a foundation of current thinking on the topics concerning this research involving working with singing groups of people living with neurological conditions. This literature review begins with a brief overview of neurological conditions, how these conditions might affect those involved, and how music therapy might be useful. Then some ideas on the relationship between group singing and well-being are discussed before mentioning communication rehabilitation for people with neurological conditions affected in this way. More specific to my research question regarding the development and delivery of repertoire in the singing groups, the literature on people's music preferences is considered and is followed by a review of Community Music Therapy literature.

\subsection{Neurological Conditions}

Neurological impairment - whether through stroke, trauma or other degenerative causes - brings either a sudden or gradual disconnection with a person's previous life. Regions of the brain are left isolated or impaired, affecting bodily functions, but also self-image, relationships and social structures.

Neuroplasticity is evidenced where patients with acquired brain injury, (ABI), are able to re-learn competences even though the area of their brain that normally organises that function is damaged. New neural pathways are formed in the brain through techniques that "facilitate dendrite growth so as to increase the neurotransmission of information within the brain and from the brain to the rest of the body) (Baker \& Tamplin, 2006). Research indicates that repetition of tasks is helpful. Further to this, tasks should be done through a variety of different activities that provide multiple pathways for the brain to achieve that task, thus increasing the neuroplasticity.

"Music therapy has a unique capacity to address many areas of function, including (and perhaps most importantly), emotional well-being" (Baker \& Tamplin, 2006, p. 19). Durham states that "musical structure can help us reorganise and retrieve information $\ldots$ and reminiscence work with patients with short term memory problems shows that singing familiar songs helps access long-term memory" (Durham, 2002, p. 117). 
Of particular interest to this research is the use of group singing and its effects on wellbeing and the communication difficulties that may affect people living with a neurological condition, and their partners and carers. Durham notes that "the patient is not the only casualty; family and friends suffer the loss of the person they once knew" (Durham, 2002, p. 115).

\subsection{Group Singing and Well-being}

Studies have shown that group singing may positively impact healthy aging (Wheeler, 2015) and "can also improve quality of life, well-being, mood, voice and respiration in older adults and people with neurological disease" (Bonihla, Onofre, Veira, Prado, \& Martinez, 2009; Clift and Hancox, 2010; Cohen et al., 2006; Di Benedetto et al., 2009; Gick, 2010; Pacchetti et al., 2000; Wan Ruber, Hohmann, \& Schlaug, 2010; as cited in Talmage, Ludlam, Leão, Fogg-Rogers, \& Purdy, 2013, p. 9). Studies indicate older people are likely to experience positive quality of life outcomes when they participate in social events where music that they enjoy is included (Theorell \& Kreutz, 2012). "Interventions such as group singing may lead to improvements in wellbeing and quality of life for adults with a range of chronic conditions" (Daykin et al., 2018, p. 44). There is anecdotal evidence that people feel better when they are part of singing groups and they relate the psychological well-being to physical well-being (Clift, 2010). Thaut and Wheeler (2010) determine three properties that derive from music and impact well-being - psychophysical (where positive feelings elicited from the music impact the on people's energy levels and excitement); collative (the structural attributes of music help with experiencing order); and finally, the ecological properties of music help elicit memories through association.

One of the roles of neurological choirs and singing groups is to be a community of its members. The groups are an entity in their own right and while the individual members are separate, under the mantle of 'choir' or 'singing group' they become one - part of a socially interactive ecological practice. Together they are able to achieve things they could never achieve on their own. This corresponds to Brusicia's definition of the Ecological approach to music therapy. He states;

the ecological area of practice includes all applications of music in music therapy where the primary focus is on promoting health within and between 
various layers of the socio-cultural community and/or physical environment. While the therapist may work to facilitate changes in the individual or the ecological context, the basic premise is that change in one will ultimately lead to changes in the other. Thus, helping an individual to become healthier is not viewed as a separate enterprise from improving the health of the ecological context within which the individual lives (Bruscia, 1998, p. 229).

It also relates to notions of Community Music Therapy (page 11).

\subsection{Communication Rehabilitation for Neurological Conditions}

Singing and speech are similar in a variety of ways. On a structural level, singing is a blend of music and speech. A spectrum exists from rap and recitative styles of singing on one end to songs and arias on the other. Speech, too, uses musical elements such as pitch, rhythm, tone and dynamics to make it more interesting and intelligible. "Speech and music also share neural networks or are processed in neighbouring networks" (Baker \& Tamplin, 2006, p. 141).

Group voice and singing activities may lead to improvement in singing and slight improvements in speaking, and may also prevent deterioration in production of speech, for people with Parkinson's (Elefant, Baker, Lotan, Lagesen, \& Skeie, 2012).

Singing is a motivating therapeutic medium for patients in neurorehabilitation. Singing exercises may bypass the conscious thought processes involved in more cognitive, traditional speech therapy interventions often used in dysarthria ${ }^{2}$ rehabilitation (Tamplin \& Grocke, 2008, p. 28)

\subsection{Music Preferences}

Studies have shown that preferred music positively impacts people's social well-being by helping regulate emotions and promoting social connection (Papinczak, Dingle,

\footnotetext{
${ }^{2}$ Dysarthria is a speech disorder relating to difficulties in muscular control used for speech.
} 
Stoyanov, Hides, \& Zelenko, 2015), and is more likely to be engaging and motivating, thereby having a more positive therapeutic impact on them (Silverman, Letwin, \& Nuehring, 2016). Studies have identified certain repertoire as bringing about positive changes in behaviour when it is considered to be the clients' preference (CevascoTrotter, Vanweelden, \& Bula, 2014; Vanweelden \& Cevasco, 2010; VanWeelden \& Cevasco, 2007, 2009). This was determined by observation and comments from clients as well as caregivers. There may, however, be other active mechanisms influencing the effectiveness of the therapy rather than solely the song being a favourite of the client (Silverman et al., 2016). The final statement of the Cevasco et al, 2014, article states, "it is imperative that therapists continue to examine song preferences of this aging group of society", (p.176).

\subsection{Community Music Therapy}

International discourse on Community Music Therapy (CoMT) is still comparatively recent, emerging in the early 2000s. Stige described CoMT as "a multifaceted and evolving social practice" and stated that it has been difficult to define (Stige, 2015, p. 233). Developing work with neurological choirs, run in community settings in New Zealand and elsewhere, could be said in some cases to be part of the movement to position music therapy in a less clinical/medical context and more in a community supportive system. Ansdell, when responding to Stige's book (2002), 'CultureCentred Music Therapy', stated, "Rather than focus directly on clients' problems, a Community Music Therapist aims to enlist musicing's ${ }^{3}$ ability to generate well-being and potential in individuals, relationships, milieus and communities" (Ansdell, 2002). In this article he compared and contrasted, through four main themes, CoMT with 'other music therapy to date', which he referred to as "The Consensus Model". The themes cover the identity, role, aims and working practices, as well as their underlying attitudes of music therapy, and are briefly outlined in Table $1^{4}$.

\footnotetext{
3 "Christopher Small coined the word 'musicking' (some refer to an alternative spelling of 'musicing') to convey that music brings people together, creates relationships, and that places and events are transformed by it", (Pavlicevic, 2013). "To music is to take part in any capacity in a musical performance, and the meaning of musicking lies in the relationships that are established between the participants by the performance", (Small, 1999).

${ }^{4}$ This table is my own creation
} 
TABle 1 - A Comparison and Contrast of CoMt and the Notion of 'The Consensus Model' Of Music Therapy (ANSDELL, 2002).

\begin{tabular}{|c|c|c|}
\hline Themes & Consensus Model & Community Music Therapy \\
\hline $\begin{array}{l}\text { Who am I as a } \\
\text { Music Therapist? }\end{array}$ & $\begin{array}{l}\text { The therapist is not a } \\
\text { music educator, a } \\
\text { community musician or a } \\
\text { music healer. } \\
\text { There are clear } \\
\text { boundaries and roles, } \\
\text { ('therapeutic frame') } \\
\text { between the Therapist and } \\
\text { Client(s) in which the } \\
\text { therapeutic relationship } \\
\text { can develop thus avoiding } \\
\text { social relationships. }\end{array}$ & $\begin{array}{l}\text { CoMT - balance between being a } \\
\text { therapist and musician. }\end{array}$ \\
\hline $\begin{array}{l}\text { What am I } \\
\text { expected do } \\
\text { I do as one? }\end{array}$ & $\begin{array}{l}\text { The therapist should aim } \\
\text { to know about the client. } \\
\text { The therapist's role is to } \\
\text { facilitate psychological } \\
\text { insight (where possible) in } \\
\text { the service of the client } \\
\text { processing the therapeutic } \\
\text { experience. }\end{array}$ & $\begin{array}{l}\text { Promote music's ability to help, } \\
\text { musicing/musicking, remove barriers to } \\
\text { the access of these. Relationships } \\
\text { negotiated to suit the people and the } \\
\text { context and regarded 'moral' rather } \\
\text { than 'professional' }{ }^{5} \text { and equal as } \\
\text { possible }\end{array}$ \\
\hline $\begin{array}{l}\text { Sites and } \\
\text { Boundaries } \\
\text { Where do I work } \\
\text { as a Music } \\
\text { Therapist? } \\
\text { Where are the } \\
\text { limits to this work? } \\
\text { What are the limits } \\
\text { on what I do } \\
\text { there? }\end{array}$ & $\begin{array}{l}\text { Usually clearly defined, } \\
\text { 'containing' spaces, often } \\
\text { private and behind closed } \\
\text { doors. }\end{array}$ & $\begin{array}{l}\text { The sites where this occurs are } \\
\text { wherever the therapist is with the client } \\
\text { and music making is required. "The } \\
\text { overall aim being to increase the } \\
\text { musical spirit of community" } \\
\text { (accounting for cultural differences in } \\
\text { definitions of private vs communal,) } \\
\text { "and to enhance people's quality of life } \\
\text { within it". There are usually, but not } \\
\text { always, public performances } \\
\text { showcasing previous therapeutic work } \\
\text { that has been carried out in private. }\end{array}$ \\
\hline $\begin{array}{l}\text { Aims and Means } \\
\text { What am I trying to } \\
\text { do as a Music } \\
\text { Therapist, } \\
\text { and Why? } \\
\text { How do I go about } \\
\text { achieving these } \\
\text { aims? }\end{array}$ & $\begin{array}{l}\text { The 'therapeutic } \\
\text { relationship' between } \\
\text { Therapist and client (or } \\
\text { group of clients 'and the } \\
\text { process' is the aim, and } \\
\text { 'music' is the means to } \\
\text { help client live more easily } \\
\text { in the external world. }\end{array}$ & $\begin{array}{l}\text { The ultimate aim is to cultivate musical } \\
\text { communities - 'musicing' is the aim } \\
\text { while 'music' is the means - getting } \\
\text { people to use music to feel 'weller' } \\
\text { even when they are 'ill'. Working } \\
\text { towards psychological well-being } \\
\text { through "qualitative change in people's } \\
\text { experience of themselves, and } \\
\text { themselves-in-community". }\end{array}$ \\
\hline
\end{tabular}

\footnotetext{
${ }^{5}$ Term coined by Spinelli (2001) signifying that the relationship boundaries are humanly rather than theoretically generated, (Ansdell, 2002).
} 


\begin{tabular}{|l|l|}
\hline $\begin{array}{l}\text { Assumptions and } \\
\text { Attitudes }\end{array}$ & $\begin{array}{l}\text { Ecological i.e. 'in context', } \\
\text { phenomenological, therapy works as } \\
\text { music does in individuals' lives and } \\
\text { their social lives. "Music Therapist aims } \\
\text { to enlist musicing's ability to generate } \\
\text { well-being and potential in individuals, } \\
\text { relationships, milieus and communities" } \\
\text { (Ansdell, 2002). }\end{array}$ \\
\hline
\end{tabular}

CoMT has evolved and coalesced as time has gone by and Stige and Aarø developed an acronym, PREPARE, that identifies seven features of Community Music Therapy (Stige \& Aarø, 2012). These are:

- Participatory (valuing and encouraging democratic participation in activities)

- Resource Oriented (drawing on and developing people's abilities and interests)

- Eccological (recognising the importance of the collaborative relationships between individuals, and in groups)

- Performative (acknowledging the "focus on human development through action and performance of relationships in context”) (Stige, 2015, p. 239)

- Activist (being aware of power imbalances in society and actively working to rectify deficits in equilibrium)

- Reflective (involving notions of reflecting and moderating of processes practices and outcomes, usually but not exclusively involving others)

- Ethics Driven (driven by human rights rather than the medical model - that of focussing on ailments and treatments).

\subsection{Summary of the Literature}

This brief literature review shows there is much that has been written in these areas to guide me in my research. Group singing is a well-researched music therapy intervention for people with neurological conditions, that may assist in communication difficulties, improve well-being, provide opportunities for choice, social interaction and performance than can benefit participants. 
I used this knowledge to guide me through the action research cycles when considering how I develop and deliver repertoire to the two singing groups of people living with neurological conditions, their partners and carers. 


\section{METHODOLOGY}

This qualitative, action research study investigated how I can improve the development and delivery of music therapy repertoire within the contexts of my placement practice with two singing groups of people living with neurological conditions and their carers.

\subsection{Theoretical Frameworks}

This study came from the position of constructivism where reality is constructed from the multiple realities we come across and not simply 'discovered'. Social constructivists hold the assumption that individuals construct reality in seeking to understand the world in which they live and work. Closely linked with this is the theoretical perspective of interpretivism where meaning is derived from the subjective, lived experience of the individual. Coming from an interpretivist stance I recognised that not all choices, especially regarding repertoire for the purposes of this study, can be described as stereotypical. While some generalisations can be made as a starting point, for logistical and management reasons, for choosing repertoire for groups, it cannot be said that all people of a certain age, gender, ethnicity, religion, (or any other demographic discriminant), will prefer the same music. Personal preference is very subjective. Also, simply recording someone's selection as 'their choice' does not consider any possible power imbalances that may exist or context as to why that choice was made. In this research I considered carefully the different perspectives of people involved in the two singing groups, as interpreted through my own lens firstly as a music therapy student practitioner, and secondly as a beginning researcher investigating my own practice.

\subsection{Action Research}

One of the main characteristics of action research is that it is based on what Kurt Lewin (1946/1948) described as proposed steps that constitute a cycle of action, and that these cycles of action be repeated as long as necessary, or "until sufficient outcomes have been achieved" (Stige \& McFerran, 2016, p. 434). The action research approach is useful for people who are looking to improve their practice. They are "willing to 
submit that practice to critique" (Rickson, 2009, p. 5) and, therefore, it is a good approach for this study. For each cycle, I planned, acted and implemented an action(s), reflected on, and then evaluated the effects of the interventions. As expected the findings of each cycle produced a new question, or questions, or focus of study. This prompted a new cycle of the research (Figure 1).
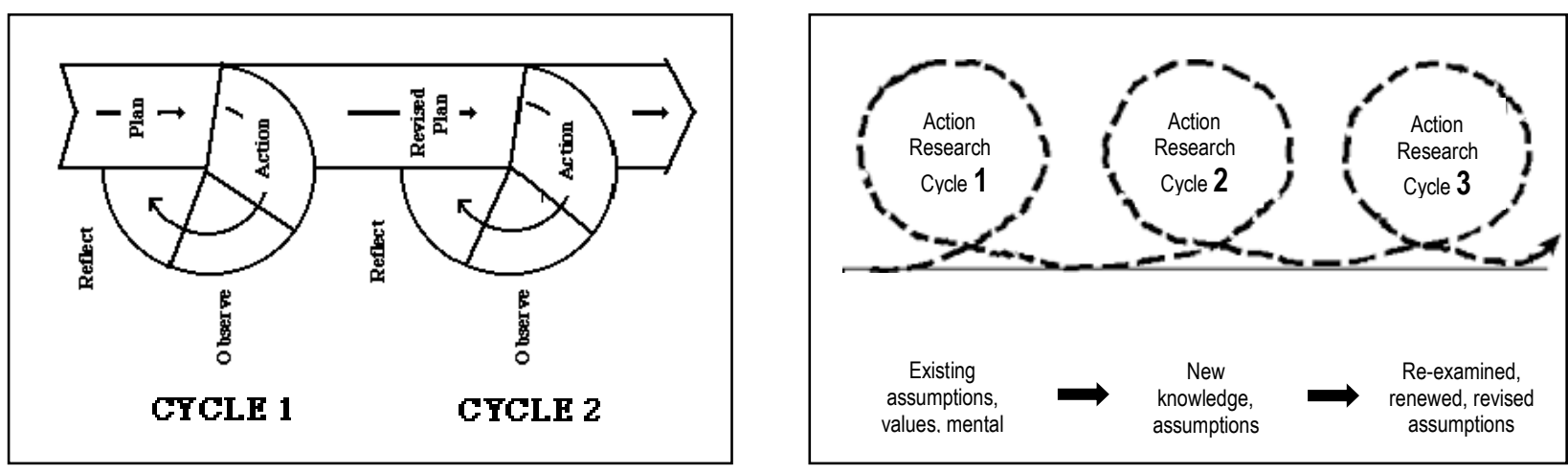

\section{Figure 1 - Action Research Process}

I intended to study developing a repertoire of preferred musics with and for my clients of music therapy and develop methods to deliver it to them in meaningful ways. This is an important part of my ongoing practice - to negotiate and develop shared music with clients that supports their needs. This study aimed to reveal the process across a variety of sessions and settings.

The settings of practice were the spaces where the two singing groups rehearse each week. Occasionally one group or the other would sing in a public space, a rest home or community gathering, during the usual time for that group. The data consisted of my observations of the participants as well as of myself and my practice as part of the clinical notes for the sessions. I undertook to be a reflexive participant researcher, reflecting on how my predispositions, values, and personal background, such as gender, history, culture, and socioeconomic status, influence my interpretations of events which, in turn, informed my judgements and feelings formed during the study. The design was an emergent, pragmatic one that evolved as new learnings and insights came to light throughout the process. This enabled the study to give a holistic account of events as they occurred. This felt authentic and valuable to me as a new practitioner in this complex field. 
Lonergan stated that the Action Research process:

"presents the structure of knowing as a dynamic, heuristic three step process: experience, understanding, and judgement. First, I attend to my experience. Then I ask questions about my experience and receive an insight (understanding) and I follow that up by reflecting and weighing up the evidence to determine whether my insight fits the evidence (judgement)" (quoted in Coghlan, 2008, p. 355).

Lonergan also argues that the making of judgements about whether the insights gained through an experience fit with the evidence is what elevates the insights into the domain of truth or reality.

This study entailed carefully reviewing my own practice with the two singing groups to see how I could develop helpful and creative methods of using repertoire for my clients during the course of my placement. The usual cycles of action research (where I review the current context and my use of repertoire, critically enquire what I might need to change, plan my action, execute my planned action, then review and analyse data, and then refine my next cycle), were implemented in this project. As a natural part of my music therapy practice, I talked with some participants, in my work with them, about their preferred music. In my notes I recorded reflections about preferences and usage of the repertoire, as well as how this developed, as appropriate.

\subsubsection{Cycles of Study}

The length of this study was from Mid-May until the end of October in 2018 and involved three cycles of action. The first cycle evolved after a period of reflection and planning for a few weeks after joining the singing groups. Other cycles developed organically throughout the process of the research. Each cycle involved several weeks of action and observation of interventions followed by a further several weeks of reflection, analysis and planning for the next cycle. 


\section{Cycle 1}

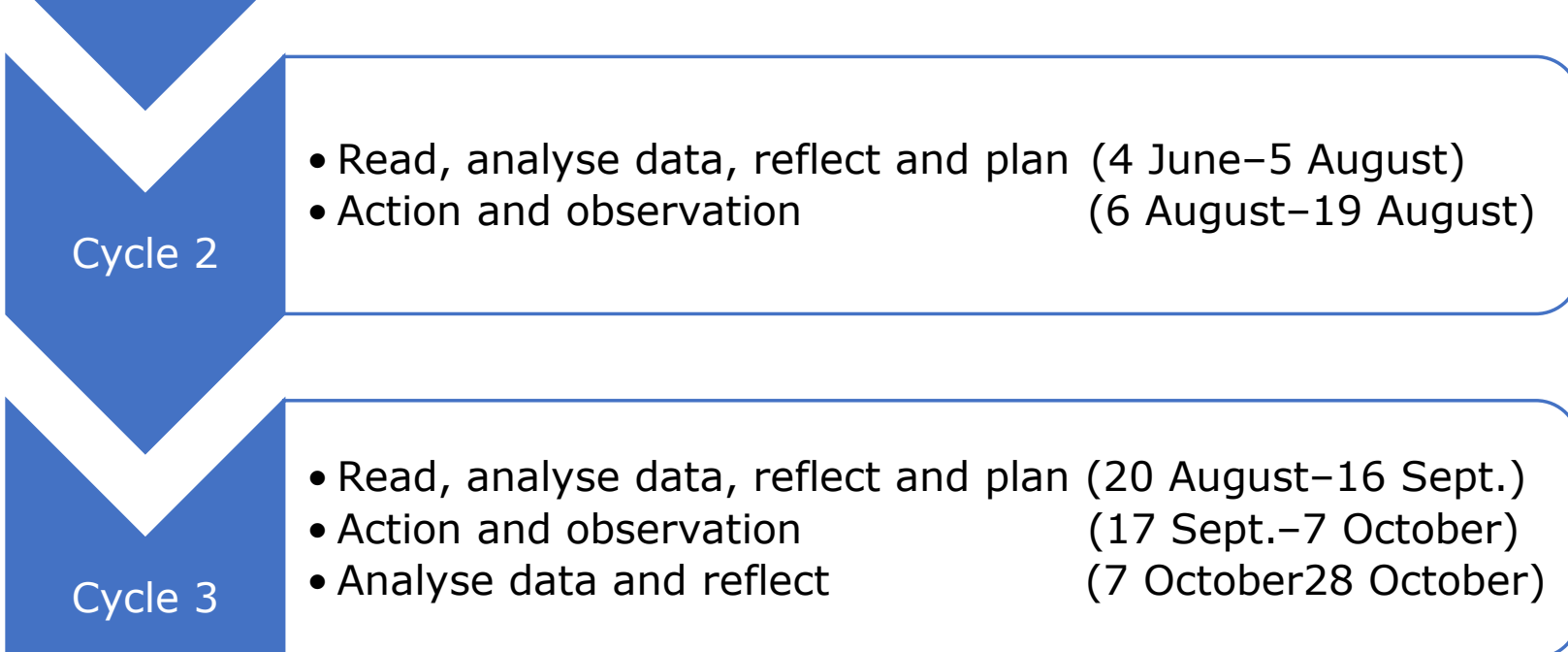

FIGURE 2 - ACTION RESEARCH TIMELINE

\subsection{Data collection}

\subsubsection{Music Therapy Clinical Notes}

The clinical notes were specific to the music therapy sessions for each of the two groups. They used a formatted template and were initially generated as a plan for each session. Once the session was completed, Alison or I would add to the plan (renamed as 'Notes'), a description of what had happened throughout the session. There were places below to write reflections on the session. These included the layout, the response of the group, as well as how we thought the songs, activities and exercises had gone. There was also a space to share information between Alison and I that we had not had a chance to share in person. Once one of us had written our notes we would email the file to the other, so both our notes were recorded in the same file. The second person's notes often had responses to queries from the first person's writing. The notes were sometimes procedural and bullet-pointed, precise and 
sparsely worded, and at other times, quite detailed descriptive passages of what turned out to be a written conversation about what both Alison and I saw, thought and felt was occurring in those sessions. Once there were two poems.

I further wrote a hand-written personal journal of observations and recollections of my experiences in response to my action research planning. I condensed these and put into the tables of results for cycles $1-3$ (appendices $5-7$ ).

\subsection{Data Analysis}

After each cycle I analysed the data gathered, in preparation for next cycle. Thematic analysis (TA) was carried out on the data using a six-phase outline (Braun \& Clarke, 2006), as follows:

1. Familiarising myself with the data,

2. Generating initial codes,

3. Searching for themes,

4. Reviewing themes,

5. Defining and naming themes,

6. Producing the scholarly report

Following Clarke and Braun's aim of TA I summarised the data "to identify and interpret key, but not necessarily all, features of the data, guided by the research question" (Clarke \& Braun, 2016, p. 297). I identified and established code categories and themes during repeated readings of the data (Atkinson \& Hammersley, 1998, as cited in Silverman, 2017).

When I first began to work with the CBRC and SUR I began my research almost at the same time. I did not allow myself enough time in the early stages of analysis as I was busy with the practical and technical aspects of working with the groups, as well as learning the personal information of participants in order to form the necessary relationships. I wrote summaries of the cycles as they occurred and sought advice and guidance from both supervisors, Alison and Sarah, as to my next steps in the research. 
The data was coded inductively - to find new understandings since I have no prior experience. While there is some research on preferred musics which made deductive coding possible, time was short, and I chose to leave this out. It is an area that I can revisit in the future and cross reference my data with previous research.

\subsection{NVivo computer programme - Coding}

I used the NVivo programme to code my data. I then was able to produce maps of the codes for each of the three main themes identified through the analyses of the data. Periodically I reviewed my coding and restructured the hierarchies as the themes became meaningful to me. I wrote the findings section according to the maps as they developed.

\subsection{Ethical considerations}

While engaged in this action research study regarding my work with two singing groups of people living with neurological conditions and their carers, I performed the multiple roles of researcher, music therapy student/practitioner and participant, while the members of both singing groups were indirect participants. As a student of Music Therapy at Victoria University of Wellington I was bound by the university's Human Ethics Policy and I also consulted the Music Therapy New Zealand Code of Ethics (2012). I developed informed consent forms (see Appendix 3: Consent Form for and Appendix 2: Information Sheet for singing group participants) following the templates approved for the NZSM Casework and Research paper. I asked for consent to write vignettes about specific people (pseudonyms used) in specific situations (things that unfolded in the course of the work). I also asked for consent to make audio and/or video recordings, to be used as a reliable record of what occurred in the sessions. Any recordings were deleted once transcription had occurred.

Participation in this study was voluntary. Due to both singing groups' engagement in research, the organisations involved deemed it to be positive and generally beneficial for the groups to be acknowledged in this study. While the two groups are named, individuals' names and identifying information has been changed to protect their 
privacy and anonymity. There were potentially more risks to exposure because of the rarity of such singing groups in New Zealand, but participants were informed of this and time was taken with participants and family members to be informed and to choose if they wished to give consent for data pertaining to them to be used. Those that have consented have participated knowingly. I have not written specifically about any person who has not consented to this study.

Regarding the redacting of names in the examples of notes provided in the findings section I have attempted to make the size of the redacted names the same for all examples for further disguise (see page 54 for an example). The size of the redacted name in this script is not representative of the actual size of the name the example pertains to.

\subsection{Data Storage}

All computer files regarding this project were password protected. Hand-written journals and notes used pseudonyms. The data will be stored in a locked cabinet, in my supervisor's office at Victoria University in Wellington, for a period of ten years after library publication of the research, after which it will be destroyed. 


\section{FINDINGS}

This section presents the findings of this action research project. Each of the three action cycles are outlined and described (including the specific questions/actions I planned, and a reflective summary) followed by descriptions of the major themes that emerged throughout this project. In order to guide the reader around the section on themes, I have introduced each of the three core themes (Gearing for Positivity, Maintaining the Feel-Good Factor, and Managing My Skills and Vulnerabilities) and provided a diagram from NVivo to show the subthemes. In the text I highlight each subtheme and I quote sections of my data sources to provide examples, and to add detail and richness to my text. The findings section ends with a summary of findings.

\subsection{Cycle 1}

I chose three practical actions that I thought would improve my ability to support the singing groups as I worked on developing and using repertoire with this population (Appendix 5: Cycle 1 Results).

1. Using ways of cueing - the signals and prompts for stimulating memory for actions (see page 37) to support the group singing.

2. Using familiar songs and melodies to create exercises that target communication difficulties caused by speech and language disorders associated with neurological conditions.

3. Considering the key of a song.

Question: How can I use cueing to support the singing groups?

I considered the different kinds of cues that might be useful to support the singing groups when they were singing the songs. These included musical imperatives such as song introductions, and physical, verbal and visual cues.

By employing more musical introductions to songs and stronger cueing techniques throughout the sessions I would be a more supportive member of the groups. These cues provided surety for the singers and helped bring confidence to their participation. Sometimes, however, the group just wanted to sing and not be concerned with such things. It was a balancing act. 
In my preparation for the sessions I considered each song - my reasons for including it, what I intended doing with it, as well as how I would deliver it to the group. I rehearsed the style of delivery, including cueing because I found it can be difficult to accurately accompany one part of the song while giving advance cues for the next part.

JG: I rehearsed at home ways of cueing the intake of breath and hold during the introductions - I think I could have been much stronger in this but at least I am thinking about it and I want it to become second nature.

(1.3 CBRC 28.05.18)

Question: How can I create exercises out of familiar songs and melodies that target communication difficulties caused by speech and language disorders associated with neurological conditions?

Some participants of the choir will say that they don't want to do exercises or talk about why something might be helpful for them, and that they "just want to sing"! I investigated using short bits of familiar songs and melodies as exercises to target areas of voice and speech production that needed strengthening or maintaining. Given the diverse range of people and needs in the choir it is likely that some participants need specific exercises to assist their voices that other participants do not. The choir participants are cognisant of this and are patient with regards to other's needs, but it can be tricky keeping the engagement and interest up across the entire choir.

It was time-consuming to plan, create and prepare the resources ${ }^{6}$ needed for the singing sessions. In my notes I observed that I need to keep a check on the time I spend doing this so that it is sustainable going forward. I also noted that I enjoy this sort of creative activity. It will be an on-going task - to continue creating and gathering these resources for my kete, toolbox.

Question: How do I choose the best key for the choir to sing the song?

There are a number of aspects to consider when selecting the key of a song. These concern the pitches that are comfortable for singing or are needing to be strengthened

6 Physical items (lyric sheets, chords for accompaniment, video clips) used in the work. 
and maintained by the choir to aid communication through speech and language; my skills on various instruments; and the personal preferences for certain keys from an aural- aesthetic perspective.

\section{Pitch Range}

Some of the broader goals of the choir are to rehabilitate or maintain vocal strength to help facilitate conversation and communication. The pitch range for these groups is generally $A$ below middle $C$ to the $A$ above - A3 - A4, Scientific Pitch Notation (Figure 3). However, we do also sing outside this range occasionally.

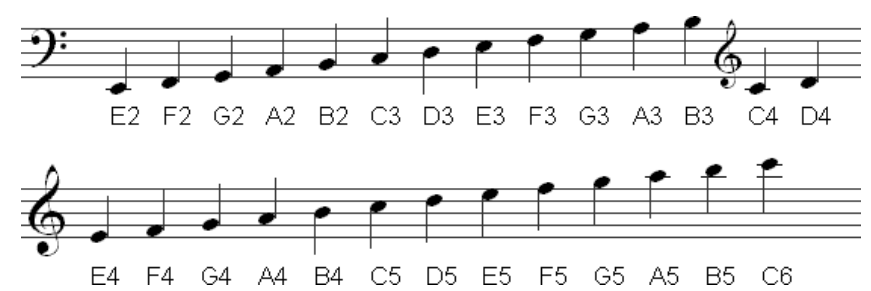

Figure 3 - Scientific Pitch Notation

\section{My own playing skills}

I considered my variable skills on the three main accompanying instruments used in these groups - piano, guitar and ukulele. I was aware in my notes of having some limits of keys I can play on these various instruments (guitar was most flexible but sometimes other instruments were more suitable for the song). I became particularly aware that I needed to conserve energy and time, so I often chose the pragmatic option - a near enough key but one that I could play relatively easily. When I could I did practise, and I did notice that I was becoming more proficient. Finally, I began to give myself permission to say there was nothing wrong with singing a cappella when I wasn't able to accompany the group.

When I was really enjoying the playing and singing and was happy with how it was going for myself, then, I felt, the experience must have been going well for the singing groups too. So maybe there is some flexibility about the key, but I needed to be happy with it to bring it off well. 


\section{Personal preferences: The aural-aesthetic perspective}

In addition, some songs sound better in certain keys. I observed in my reflections that some keys sound 'brighter' or reflect the mood of the song better than another similarpitched key. I am aware of expertise in other fields about synaesthesia, and acoustic properties of sound. There could be connections with other music fields of psychoacoustics and musicology. This could be something for further research.

\section{Summary of Cycle 1}

As these three actions were largely skill and knowledge-based, any time that I put into these actions improved my ability to be a support to the singing groups. It also increased my enjoyment of the sessions and helped to lessen any performance anxiety I might have been feeling. This, in turn, allowed me to attend more fully to the participants of the choir. When I was leading the exercises, and even the singing of songs later in the sessions, I reported in my notes that I was focused on my performance of the 'leader' role - accompanying and singing and cueing. I found it difficult to listen to the choir and make judgements about the quality of their singing in the moment'. It was a multitasking role - leading and cueing, accompanying. Furthermore, assessing and making judgements informs further thoughts for leading and cueing.

\subsection{Cycle 2}

For this cycle, whilst necessarily continuing to consider and refine my practice of the technical and practical skills outlined in the actions of Cycle 1, I realised I needed to spend some effort considering my thought processes and emotional/psychological obstacles I was experiencing whilst carrying out this work. Tables outlining the actions, outcomes and queries arising, for each of the two actions, can be found in Appendix 6: Cycle 2 Results.

Question: How can I make technical decisions about the choir and myself while in the midst of the repertoire activity? 
In order to make technical decisions about the choir in the midst of our repertoire activity I realised I needed to be more aware of the choir. I felt I needed to be able to see and hear them, so I could critique for the qualities that would align with our therapeutic goals. It took me some time to learn to move my head left and right as we sang and try to take in as much as I could visually. When I was working with Sing Up Rodney! the fact that I, too, was seated in the circle allowed me to feel 'less on show' than when standing up in the front for the CeleBRation Choir. (This notion is related to the $2^{\text {nd }}$ action for cycle 2 ).

Question: How can I dispel unhelpful anxieties to fully allow me to be a natural and open therapeutic presence while making technical decisions in the moment?

I found that I allowed my performance anxieties to interfere with my thought processes, particularly in the early months of my practical experience. This is reflected in regular entries in my clinical/reflection notes. I have always suffered from performance anxieties but have mostly been able to manage them in the course of my teaching and performance work. These anxieties are what compel me to prepare and rehearse and this is a good thing. Preparation and rehearsal lead to a certain confidence in delivery. I observed (Appendix 6: Cycle 2 Results) that I don't mind making mistakes or 'not knowing' when the session is in progress if I have done the requisite rehearsing. It's the pre-session nerves that I need to learn to manage as it's not always possible to do all the rehearsal necessary to gain 'performance confidence'. Further to this, as stated in Planning, (page 34), there were many times throughout the sessions that we sang songs selected from our repertoire folders as a 'People's Choice' segment to the session. As my practicum progressed, I wrote in my notes that I was more comfortable with this aspect as I became more familiar with the songs and how to play them.

JG: I now have the confidence to 'manage' the 'people's Choice' portion.

(2.1 SUR 09.08.18)

\section{Summary of Cycle 2}

While working on cycle 2 it became apparent that the two actions I had selected to focus on were both big issues for me. I will be working on gaining these types of knowledge and insights for the rest of my life. I found it difficult to critique the choir's 
sound with regards to clarity of consonants and vowels, being some of the speech and communication goals. I preferred to be positive - not to appear disingenuous with my praise as this is not my intention - but to respond to what I felt was the effort expended by participants to participate at all.

I did begin to manage my anxiety more successfully during impromptu parts of the sessions (where a song was selected that I was unrehearsed for). I developed more self confidence in this as my practice and practise progressed. I felt I had to work on being prepared to stop the song, to go over some aspect of it, or repeat instructions etc in order to support the choir's efforts in their experience of 'quality music', but that this invariably interfered with the 'flow' of the moment - at least for some people. Due to the spectrum of the group some people needed less instructions and take less time to process instructions or have less difficulties with diction etc and for some of them, it's less about diction and more about memory.

\subsection{Cycle 3}

As my confidence in working with both groups grew, I began to take on more responsibilities with each of the groups and I felt accepted as both a member and cotherapist. I continued to work on clinical knowledge of the population as well as technical and practical music goals with regards to developing and using repertoire, with the support and encouragement of my supervisors and the participants. I also continued to make connections with people and form relationships. There were any number of goals and actions I could have tackled for cycle three, and, even though time constraints were tight, I decided to take on the weighty challenge of considering the musical experiences of the groups whilst simultaneously considering the needs of the individuals therein (Appendix 7: Cycle 3 Results)

Question: How can I simultaneously facilitate quality musical experiences of the repertoire while responding to the needs of individual participants?

Firstly, I had to contemplate just what a 'quality musical experience' was for me and see if it corresponded with what I perceived might be the groups' notions of a 'quality musical experience'. I felt music with some added complexities of harmonies, and 
even counter-rhythms, made for a quality music experience. I sought participants' opinions, periodically, on what their preferences might be and how they felt about the repertoire we had just sung. These, however, were ad hoc conversations and in no way could be construed as representative of the whole group's views. This could be a consideration for further study.

There are many different versions of many of the hugely popular and long-lived songs, often decades apart, that the participants selected for singing. It was considered necessary to define this group's or the other's version, for unity purposes, as there are likely to be many differing versions within the participants' prior experiences. Having to 'un-learn' one way of singing the song and learn a potentially new version, slight though the differences may be, is difficult for anyone to do. I wondered if the polyrhythms and slight differences in melody, from individuals singing the tunes and rhythms 'their way', would detract from the quality of the musical experience? If the effort of learning the 'group way' was worth it? Was there a difference in the quality of experience for the individuals? These questions could warrant further study.

Further to this, I introduced split group activities that included basslines and harmonies, but some participants told me that they preferred to sing the melody, with everyone in unison, to the general agreement of the group I was with at that time. This was a revelation for me and indicated to me the type of musical experience they were looking for. One of the participants (a person with Parkinson's Disease), told me that there was "power in everyone singing the same thing at the same time". Perhaps, to them, a quality musical experience prioritises loudness and togetherness? I then realised that everyone has their own notion of what a quality music experience is, and it's worth pursuing.

\section{Summary of Cycle 3}

My initial thought at the beginning of this cycle was that everyone would have a different idea of what a quality music experience was. I didn't, however, expect that the singing group participants' concept of a quality musical experience would differ significantly from my own. 
I will continue to seek other people's concepts of this - particularly those people I work with - to enable me to be open-minded and more accommodating about such things.

\subsection{Themes that appeared important}

As my work on this project unfolded, I became aware of, from my analyses, of three major themes that appeared important. They evolved over the process of my research with the two singing groups and have been through several transitions as I modified and refined the coding of my data. The three themes are 'Gearing for Positivity', 'Maintaining the Feel-good Factor', and 'Managing My Skills and Vulnerabilities'.

\subsubsection{Theme 1: Gearing for Positivity}

The name for this theme, Gearing for Positivity (Figure 5, page 31) came to me out of my previous experience as a music teacher in an intermediate school. In the school some of the professional development discourse was around "Gearing for Success". We often considered how we could facilitate students' achievement to attain certain levels according to some pre-ordained 'line in the sand' or 'bar to jump over'. When considering my work with these singing groups I came to the realisation that, while I did want to support the groups reaching their goals, I did not want to be concerned with hierarchies of attainment as there are in education. My search for a word to replace 'success' eventually led me to 'positivity'. Dictionary.com ${ }^{7}$ defines Positivity as "the state or character of being positive: a positivity that accepts the world as it is", and Merriam Webster ${ }^{8}$ defines it as "1: the quality or state of being positive", and positive ${ }^{9}$ as "6a: marked by or indicating acceptance, approval, or affirmation, 8a: having a good effect”. Although, on a therapeutic level, helping people with neurological damage manage their grief necessarily includes working through and managing the 'un-positive' sides to life, I think it is important to support and provide positive energy. This is especially so in a group setting because, if you are personally not feeling good about your situation in that

\footnotetext{
${ }^{7}$ https://www.dictionary.com/browse/positivity

$8 \mathrm{https}: / /$ www.merriam-webster.com/dictionary/positivity

${ }^{9} \mathrm{https}: / /$ www.merriam-webster.com/dictionary/positive
} 
moment, if there are enough around you that are feeling positive then it can rub off on you.

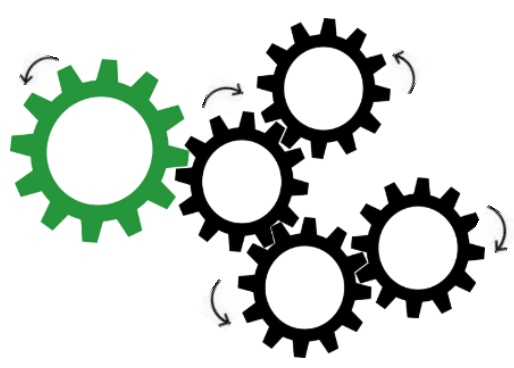

Figure 4 - GEARS AND COGS

The notion of interlocking gears (wheels) and cogs (teeth) interacting on each other (Figure 4), all necessarily connected, with one common purpose, seemed to fit as an analogy for the myriad of conditions and actions that need to be in place to help us all reach our goals. All the forces need to be synchronous to have the desired effect. If one of the gears stops turning - it seizes up or the cogs become worn down, so they don't interact with other cogs - it will interfere with the whole machine or even stop it. Neurological damage can cause a range of difficulties. Consider the brain as a machine made up of many gears. Each gear represents an area of the brain and the human functions it is responsible for. The cogs are the many facets of each of those functions. Take, for example, the gears that are required to make intelligible speech. Some are related to phonation ${ }^{10}$, others might be related to oro-motor ${ }^{11}$ movements, while yet others relate to the ability to regulate the airflow between nose, mouth and lungs. If there are some cogs missing on your oro-motor gear, the connections with the phonation and airflow gears will be intermittent at best if not absent altogether. Managing these gears is particularly sensitive due to how important the 'speech machine' is to communication. We aim to keep the engine going as best we can, repairing the cogs that are able to be repaired and oiling up the gears that may be seized up and need a little encouragement to begin to turn again.

When I asked myself the question of what repertoire should I choose and how could I use it I found that much of my thinking was around the following questions: What are the goals of the singing groups? Do they align with the goals of the individual

\footnotetext{
10 Making sounds with the larynx

${ }^{11}$ Mouth and jaw, nasal cavity and pharynx
} 
participants? What do I need to do to support the singing groups in working towards those goals? These questions are all intertwined and, as such, like the interlocking gears, are concerned with why we come to the singing groups to do what we do. These actions are: Goal Setting, Planning, Preparing, Cueing, Observing, and Teaching and Learning Repertoire (see Figure 5).

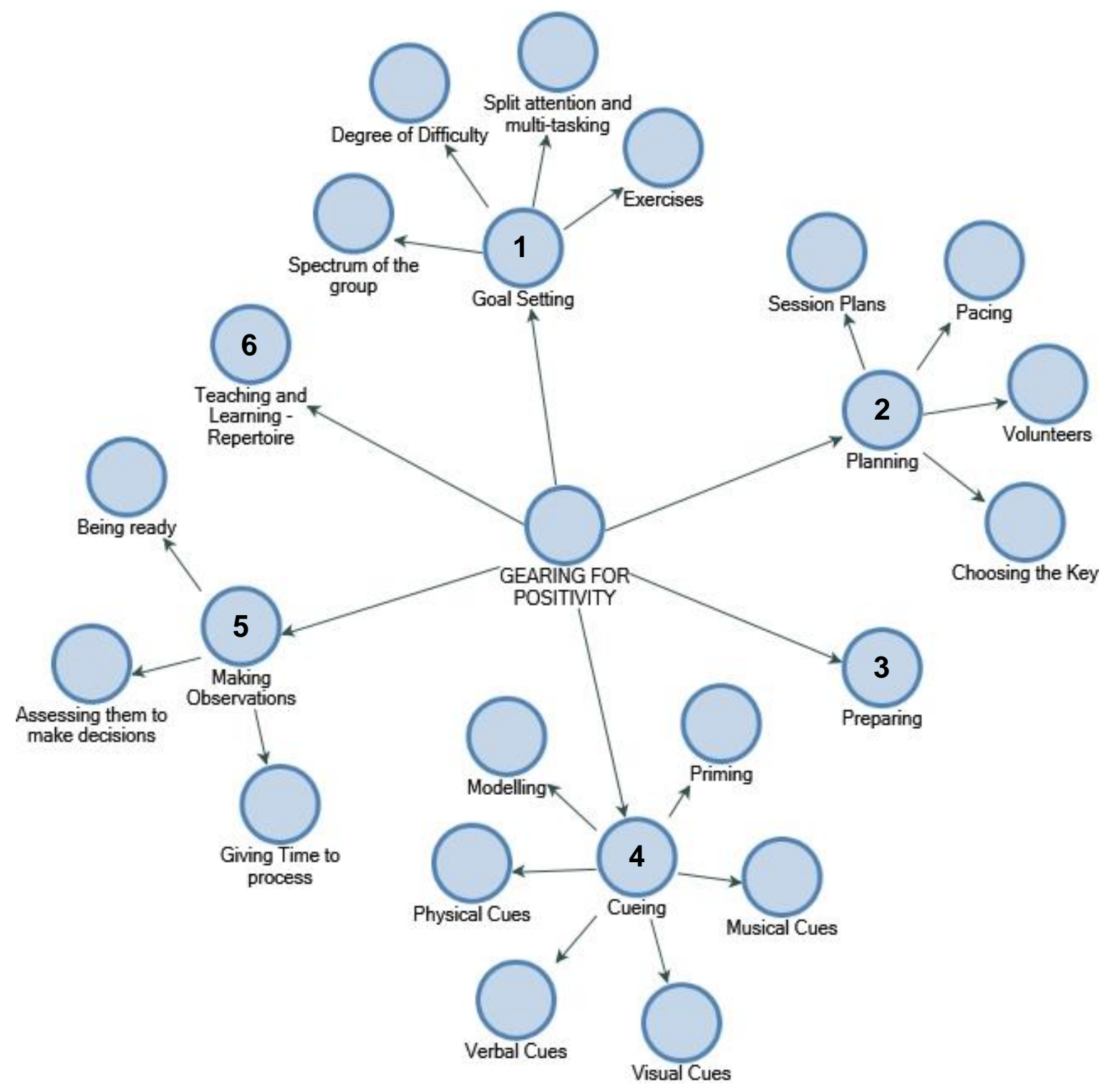

Figure 5 - Coding MaP: Gearing for Positivity

\subsubsection{Goal Setting}

Goal setting is the vital first step in Gearing for Positivity. Participants are self-referred to the singing groups and most of their joining paperwork refers, in one way or another, to any or all three of Daveson's 'MIND' meta-model (2008) approaches, Psychosocial/Emotional, Restorative, and Compensatory (see Figure 6). 


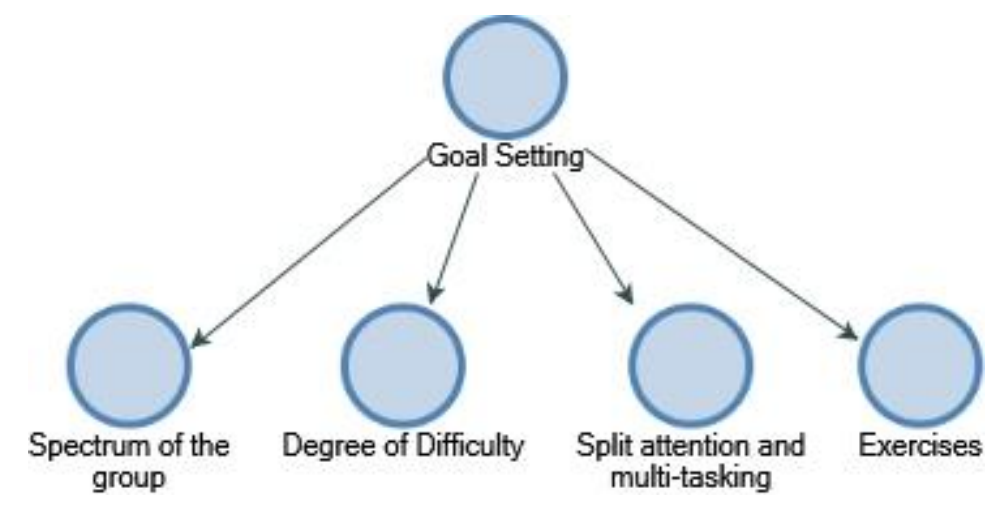

Figure 6 - GoAl Setting

The Spectrum of the Group is a major consideration in goal setting. For these groups the spectrum is broad in terms of medical condition, progression of that condition, the symptoms that are emphasised in each person, the abilities, hopes and aspirations of participants, age range and other demographic signifiers, right down to, "Is this a good day for this individual or not so good?". Selecting repertoire to address any of the myriad of personalised goals pertaining to all the individuals can be challenging. What suits one person will not necessarily be engaging or useful to another. The groups operate well under communal guidelines where common curtesy prevails. They understand that 'it is not always about them - sometimes it is about others.'

JG: With this group some need more time to process receptive language; others have difficulty controlling what they do with their mouth, lips, teeth, tongue etc; some have difficulty reading so lyrics on a page are not particularly helpful; some get mixed up with only, in my opinion, a small level of complexity (this could be due to my instructions being too complex or long, a poor choice of words, or not giving them enough time to process).

(3.1 CBRC 24.09.18)

I found that pragmatism in goal setting led me to select repertoire that addressed multiple and varied goals across the groups - that what might be addressing restorative or compensatory goals for some may also be providing psychosocialemotional benefits for others at the same time. I found that tapping into the 'feel-good factor', most particularly the 'engagement' (see page 45), in the first instance became necessary throughout the sessions as much as possible.

AT: This was an enjoyable session - well prepared with lots of variety and attention to the spectrum of group goals, resulting in good choir engagement and many lovely moments.

(1.1 CBRC 14.05.18) 
The Degree of Difficulty of the repertoire activities became a factor due to the spectrum and abilities of the groups. In order to be inclusive of all participants it was desirable to start simple and build the complexity, ensuring that there was always some way that everyone could be engaging in the activity.

JG: Is it worth having some feeling inadequate/over-faced to allow others to push towards their capabilities?

AT: More helpful to start simple so that everyone has some success - e.g. just patting the beat on your knees? "And if you're ready for some more challenge, try this..."

(1.1 CBRC 14.05.18)

Planning activities that had the added cognitive and physical aspects of actions while singing, singing in parts and multiple rounds - requiring Split Attention and Multitasking - needed to be carefully considered. Confounding participants may lead to a certain level of disengagement and some questioning feedback from some participants about the purpose of said activity or song.

AT: I noticed couldn't copy the 2-beat pattern and changed it to one of each and a few others did no actions - but some others did more than last week. Keep an eye on progress with familiarity.

(1.2 CBRC 21.05.18)

JG: ... and added the kazoo part for the clap afterwards. The kazoos are somewhat confounding - add a layer of complexity. Quite a cognitive exercise sing and then kazoo!

AT: I find it's always helpful to start simple and recap on past work - especially when not a famous song.

(2.1 CBRC 06.08.18)

Exercises that focused on posture and body awareness, breath management, articulation of speech, including vocal warm-ups were something I spent quite some time considering. I felt strongly that exercises were helpful but also that many members did not enjoy doing them. I sought out songs that were familiar, and even favourites of some members, and used part of the songs as an exercise to target the areas itemised above.

(Regarding 'Bohemian Rhapsody' - we sang it through at $100 \%$ tempo, then $80 \%$ tempo to give us all a chance to get the words out).

JG: The middle part of the song we worked on for rhythmic speech and 'tonguetwister-ness' and articulation.

(3.1 CBRC 10.09.18) 
Knowing what exercises were required was important but equally when it was appropriate to be working on exercises.

(Regarding 'Goodnight Irene', a farewell song, in key of C, D, then E. PLAN: Sing 3 times with a key change up a tone each time - to check which key might be better. Maybe it might act as an exercise for increasing range? Is this something (range increase) we need to consider or not?)

JG: I liked doing this - going up a tone each time. It might be a way to get them used to singing higher notes?

AT: Yes - but be aware that voices are tired at the end of the session. l'd regard the transpositions and range exploration as fun at this stage of the session - I'd listen carefully to see what they manage but wouldn't introduce it to them as an exercise.

(1.1 CBRC 14.05.18)

For other examples, see Exercises in songs add to engagement page 48.

\subsubsection{Planning}

The planning was done by considering the set goals - both group and individual. Four codes seemed important when reflecting on my notes. They are Session Plans, Pacing of the sessions, Volunteers as a resource, and Choosing the Key of the songs (Figure 7).

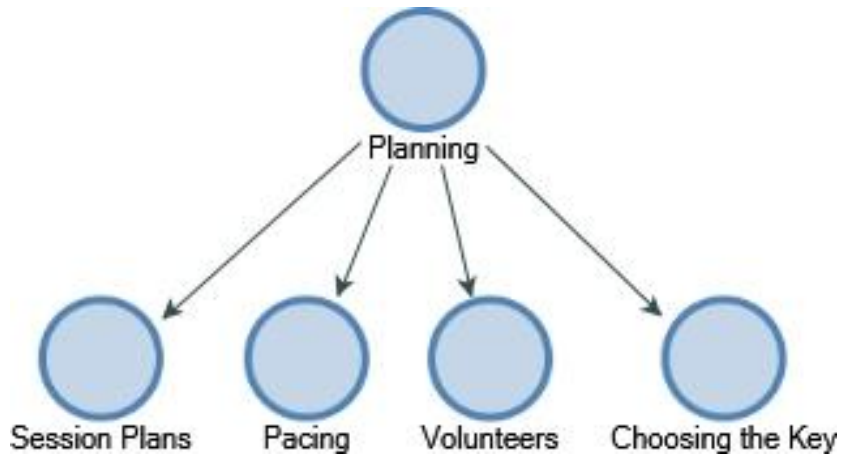

Figure 7 - PlanNing

The session plans followed existing templates for both groups founded on the Choir Protocols (Talmage et al., 2013). This included activities for warm-ups of body and voice, posture, breathing, consonants, vowels, rhythmic speech. Finding ways of achieving this through singing rather than just talking was a priority. Humming well known tunes gently and Call and Copy songs with instructions of movements increased body awareness whilst simultaneously warming the body and the larynx. 
The session plans also included page numbers of the lyric folders and song keys so that these things could be considered in advance. This said, the sessions themselves were always about the people in front of us at the time and the 'plan' was constantly evolving as the sessions progressed. Sometimes everything went 'according to plan' and at other times we might not sing a song that had been in the plan (due to it being a particular favourite of a group member deemed to need inspiration, encouragement, or who simply hasn't 'made a choice' for a while), if that member was absent on that day. Unless of course it was a favourite of other participants.

Having a plan allowed for consideration to be given to the pacing of songs and activities. This would ensure that enough time was allowed for participants to process instructions and manage differing energy levels. It would also ensure that consideration was given to how the volunteers might be able to help with the singing of rounds and partner songs by leading a group or section, managing other aspects of the session such as lyric projection.

Having a plan prompted me to consider choosing the key for these songs with each singing group. Firstly, I considered the pitch range of song. A general rule of thumb, I had been advised, is that for songs that begin on the dominant below the tonic, e.g. "Skye Boat Song" (A3 - A4), a good key for these singing groups would be D, maybe $\mathrm{C}$ or $\mathrm{E}$ if we were wanting to push our range boundaries. For songs like "Danny Boy", which has a larger range (from G3 - D5), most of the song is above the tonic so a better key for these two singing groups would be A. This key would already push our range boundaries and would usually be sung after a successful warm up session.

Having a plan also gave me something specific to prepare and practise musically for the sessions.

\subsubsection{Preparing}

I would spend some time before each of the sessions searching for chords to songs, creating resources that I could see from a distance thus allowing me some freedom in the session to move away from the song sheet. The aim is to be able to sing and play these songs without the resource and I can see that this is already starting to happen 
for some of the songs. I also felt less anxiety if I was well resourced and rehearsed. I didn't mind making mistakes when I was rehearsed - it was often quite funny and we all know that 'none of us are perfect', but I was hard on myself if I made mistakes because I hadn't prepared well (see Ways to Support, page 56). This is something that I will need to work on as it is not always possible to rehearse as other priorities may take precedence over my time.

JG: (About 'People's Choice' part of the session) Struggled a bit with this section wanted to be more supportive of them but they supported me! I got a little lost and flustered but it wasn't the end of the world! I will have some up my sleeve in case they don't make choices.

AT: Good

(1.1 CBRC 14.05.18)

JG: I put lots of time into the preparation of this session (being my first to lead on my own) but I feel I now have the confidence to 'manage' the "people's Choice" portion - it's OK to not play everything and it's OK to only play $10 \%$ of the chords of a song (the first and the last!). I think people enjoyed sharing the lead and having choices.

(2.1 SUR 09.08.18)

I thought carefully about the reasons for including each song in the plan and how I would deliver it to the group. Included in my preparation was practise of the style of delivery which included cueing.

\subsubsection{Cueing}

The $4^{\text {th }}$ code I identified concerning Gearing for Positivity is the cueing of the singing. This was a significant code and was a considerable focus in my practicum. The techniques of cueing that I considered and practised were Modelling, Physical Cues, Verbal Cues, Visual Cues, Musical Cues and Priming (Figure 8). 


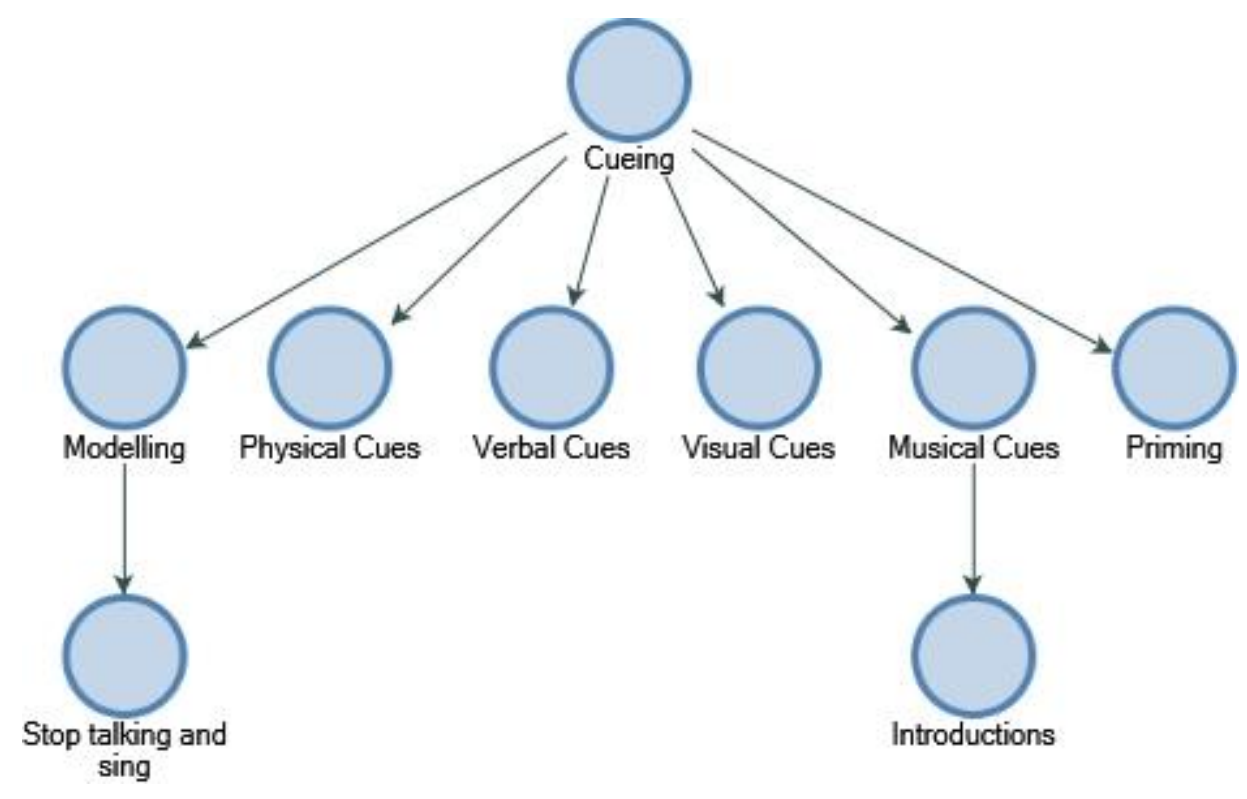

FIGURE 8 - CUEING

Modelling was the most consistently used of my cueing techniques as it conveys many different types of cues simultaneously. I would demonstrate some action, such as taking a big breath, opening my mouth wide, and screwing up my face. Mostly my modelling was a strong vocal delivery of the song we were singing at the time. Sometimes it was clear that actually 'doing it' was more effective that 'talking about doing it'. At these times I noted that I should Stop talking and sing.

JG: (Regarding singing 'See You Later Alligator' as a session-ending song) I felt we ran out of time? Was I a bit rushed through this? I did the call and copy version, so we didn't sing the "do do do dos". This might have been a better option - just to ask them to do the do dos?

AT: Perhaps a more concise verbal intro would give you more time. They became more confident and livelier the second time through.

(2.1 SUR 09.08.18)

Sometimes there were unintended, but not altogether unhelpful, consequences to the modelling.

JG: I stopped playing as I laughed about it but thankfully Ali and others continued so I started playing again. It didn't seem to matter.

AT: I thought you used it as an opportunity to model that mistakes / misunderstandings aren't the end of the world.

(1.3 SUR 31.05.18)

Physical cues such as gestures and arm-waving and facial expressions, the head bobbing that accompanies the beat are good for helping to indicate changes in tempo 
or to keep the group in time with each other. I often used my head and torso movement to indicate tempo changes especially pauses/tenuto/a slowing of the pulse when I felt we needed to allow time for participants to process cues and to breathe.

JG: I rehearsed at home ways of cueing the intake of breath and hold during the introductions

(1.3 CBRC 28.05.18)

Verbal cues I used were the standard calls of, "Sing up" and "Big breath", as well as the advance calling out of lyrics.

(Regarding 'Sing Up Rodney!' song for session starting, written by AT).

JG: We just sang as written today but I didn't announce it. I just called out the words of the next verse. It seemed to work and certainly is a nice way to start.

(1.3 SUR 31.05.18)

Visual cues such as words and pictures, available for the CeleBRation Choir, due to the overhead projection facilities in our usual rehearsal space, (but not so for Sing Up Rodney!), became more pertinent to me as I learned about 'Aphasia Friendly Guidelines' for typing displays of instructions and lyrics. There are specific fonts, and font sizes that are easier to read and pictures can also help to convey meaning effectively (Rose, Worrall, Hickson, \& Hoffman, 2014). This could be an area for further study. For some participants reading is difficult so other forms of cueing must simultaneously be available to them.

JG: (Regarding 'Hokey Tokey'). Nice harmonies, clear words. I stopped playing guitar to encourage movement and clapping.

(2.1 SUR 09.08.18)

Musical cues were also a major part of my consideration and preparation for the sessions. They included song introductions where sometimes I would hum or "La" the last two lines or phrase of a chorus or refrain, and other times strong rhythmic strumming with an emphasised 'stop' became the cue to sing (see Figure 9). Cadences were good for cueing the key we were singing in, and especially if we were singing exercises that moved up a semi-tone or tone each time to warm the voice and extend range. I would often play a $\mathrm{V}^{7}$ chord - (dominant 7th), stop and look up at the groups, my head and torso moving up and down to the beat, with the expectation that people would join in. Similarly, anacruses were helpful for supporting choir entries by providing a sense of anticipation, prompting for lyrics (as the anacrusis words were used), and, therefore, motivation to sing. The Oxford Dictionary of Music defines 
anacrusis as an unstressed note or group of notes at the beginning of a music phrase (Kennedy \& Bourne, 2013). An example of anacrusis is in the song "She'll be Coming 'Round the Mountain When She Comes". The words, "She'll be" that precede the stressed words falling on the first beat of the bar, "coming "round the mountain" serve as reminders for what is about to be sung.

Participants appeared more confident to sing at the appropriate moment, after I had sung or played my introduction. I had rehearsed the introduction before the session and I was playing more confidently and rhythmically. For example: "Haere Mai” with CBR choir on Monday 07 May 2018 (Figure 9).

\section{Vignette}

This group knows the song, "Haere Mai", very well, but they are not yet used to me leading it. This song does not particularly lend itself to the last two linestype intro' so I just played a chord for a few bars and they seemed a little uncertain and made a muffled sound on entry. Perhaps it was that some of them came in when I did (maybe they had quicker reactions or mental processing ability) and others joined after we were singing. I stopped, apologised for the lack of clarity. We all laughed that it wasn't a good start to the song. I then started to play the guitar with a stronger sense of beat, bobbing my head in time as I looked down throughout most of the first three bars of the introduction. I raised my head in the third bar, raising my eyebrows and widening my eyes in what I perceived as a 'questioning look', getting good eye contact as I scanned the choir, then played a muted 'Stop' strum on beat 1 (to indicate the rest beat) of bar 4 and highlight the anacrusis, "Ha-e-re". This time the choir's entry was a clearer, "Ha-e-re" on beats 2, 3 and 4 respectively of bar four, and people seemed more confident. I think they felt more sure of what they were doing. Perhaps they felt more confident that I knew what I was doing?

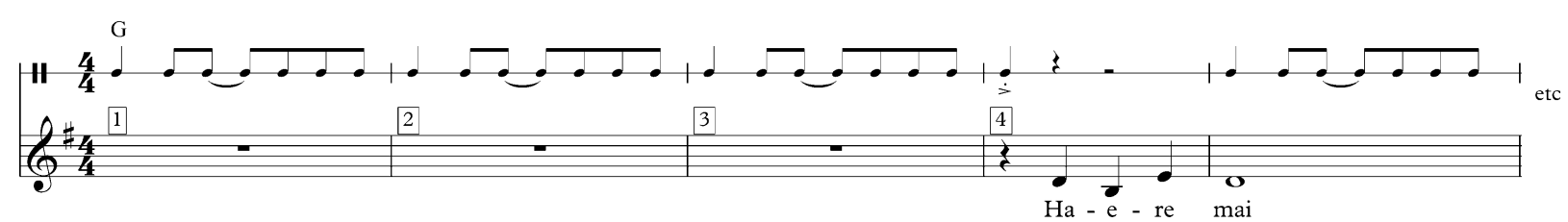

FIGURE 9 - INTRODUCTION TO “HAERE MAI" 
Priming was another form of cueing that I was familiar with, from my experience as a classroom music teacher. This involved mentioning and, in the case of The CeleBRation Choir, playing a sound or video file of the songs 'coming up after the break'.

(Regarding playing some film clips before the session and during the break) 'Camptown Races', 'Play a Simple Melody', 'K K K Katy'

AT: Good idea - perhaps "priming"?

(2.1 CBRC 06.08.18)

The stronger, musically clearer song introductions helped to get everybody starting to sing at the same time. Cueing is something that occurs with the introduction but continues throughout the song if one is actively considering how the group is doing at any one moment. It was sometimes necessary to cue for more volume, a 'rounder' tone, or clearer vowels and consonants, as well as the form of the song when switching from verse to chorus and reminders of 'trickier' bits in the song as they occurred.

I found it easier to stop modelling the singing in order in order to provide the cues. I rehearsed a version of the song that contained the cues.

AT: Perhaps accompany less, sing less when they know something well. (1.1 CBRC 14.05.18)

The songs we knew well were easier to cue because I felt I could stop singing and cue. The irony is, that by that stage, fewer people needed cueing. Although nothing beats a good, consistent 'intro' to a song to ensure a good start, being able to observe and consider what you've observed to make further decisions regarding cueing for the remainder of the song is necessary.

This can be difficult to accurately do while accompanying one part of the song and giving advance cues for the next part. A notion of stopping modelling the singing to model the cue ... this is what I rehearsed.

\subsubsection{Making Observations}

There were three main actions that presented in my data when considering making observations - Being ready, Assessing the groups to make decisions, and Giving them time to process, (Figure 10). 


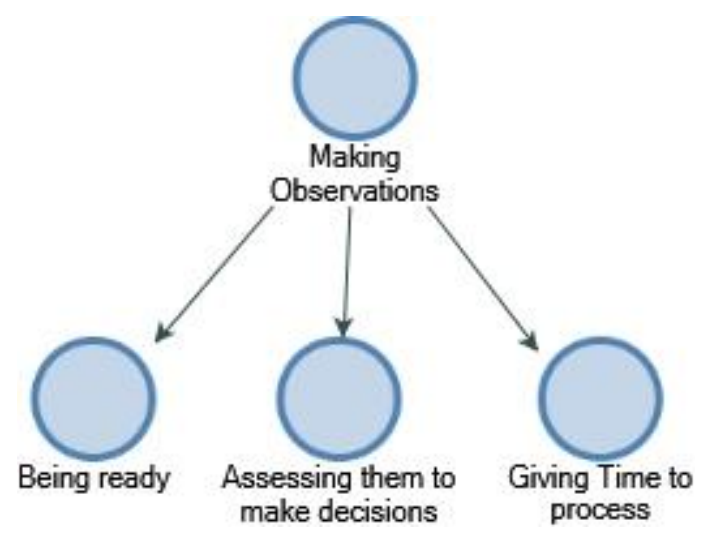

Figure 10 - MAKING OBSERVATIONS

For me, being in a position to visually take in and hear the whole group depended on the size of the group and how we were seated. I needed to assess that the group was collectively ready to sing before starting.

AT: Good. Just check everyone is looking before you start.

(1.3 CBRC 28.05.18)

When Assessing them to make decisions I needed to be able to visually take in the groups' collective posture, mouth shapes etc and give encouragement and prompts when I thought they were needed (to help with projection/breath control). This was more difficult with the CeleBRation Choir due to its size and usual layout. I noted that I found this aspect of my work challenging.

JG: (Reflecting on the CeleBRation Choir layout of two rows of large circles with four aisles for access). It is easier to see more people at one glance, but I still find it difficult to assess things (like their increased participation) 'in the moment'.

(1.2 CBRC 21.05.18)

Also, a difficulty for me was interpreting facial expressions - people living with Parkinson's or post-stroke can have difficulties with facial movement that shows expressions. It was not always apparent to me that there was a consensus (or enough of a majority at least) to repeat a song - either as a chance to work on some aspect or just for the enjoyment of it. Often the second time through was better than the first.

JG: (Regarding 'Summertime' by Gershwin). The singing was very lovely by the end of the $2^{\text {nd }}$ time through.

(3.2 CBR 08.10.18)

Sometimes I would ask the choir directly if they were enjoying a song or activity. Occasionally, even then, it was not clear to me. Perhaps they needed more time to 
process my questions than I gave them? Or they may have found it difficult to express a preference and I would have to intuit their intent and make the decision (see Engagement - Making Choices, page 46).

Stopping singing but continuing to accompany the choir allowed me to hear more clearly but invariably I would re-join the singing as I felt that is how I could best support the group (see Ways to Support, page 56). I found that when we were singing rounds it was easier for me to concentrate by turning my back on one group and focussing on the group I was leading. This was only possible when we were in a co-therapy situation and the other group(s) had good support from Alison and the volunteers. This did allow us to achieve more technically difficult music activities although it did not occur often because it sometimes excluded some of the participants due to difficulty.
AT: Perhaps accompany less, sing less when they know something well, and yes the recording process is helpful.
(1.1 CBRC 14.05.18)
AT: (Re: singing 'Blueberry Hill') "The wind..." People who didn't already know the song stopped/mumbled at this point - did you hear the difference from the choir? I suggest saying that there's something different next and modelling it - some people will still attempt to sing with you, but it's helpful to insist sometimes on everyone listening.
(1.1 CBRC 14.05.18)

\subsubsection{Teaching and Learning Repertoire}

The final code I identified as being important from my notes for Gearing For Positivity was the Teaching and Learning of Repertoire. Call and Copy activities are a great way to teach and learn unfamiliar or forgotten songs. When I introduced a new Maori song, "E Toru Nga Mea", the choir produced a good, solid sound. I heard later that some still found it difficult but singing in another language can be difficult whoever you, and whatever your circumstances are.

JG: (Regarding 'E Toru Nga Mea'). The choir very familiar with Call and Copy so were pretty good at singing this.

(3.2 CBRC 05.10.18).

JG: (Regarding 'Banks of the Ohio')."I thought they sang this nicely. I'm busy modelling and singing in support so I find it difficult to really assess how they are sounding. I'm guessing it took some pressure off them. I hope it did!

AT: I thought this went really well, with people really listening to your version of the tune.

(1.2 CBRC 21.05.18) 
Some members liked a challenge -

JG: (Regarding 'I got rhythm'). A simpler bassline (two minims followed by a semibreve rest, - "I Got" over $G$ and A) and joining with "who could ask for anything more". One man said he liked this. "Found it manageable". Sang out (it was just me and him 'against' the others). $\quad$ (3.1 CBRC 17.09.18)

While others wanted to do what they know -

JG: They said they liked it, but I feel quite strongly that they would prefer to just sing the song and not learn another way of doing things. It could be easier for them and they are conserving energy, and/or it might bring more joy to them to sing the words. Singing words that they know might help them to feel more empowered than trying new things? These are confronting questions and I didn't feel I should ask them as a group. Maybe one or two individually?

(3.1 CBRC 24.09.18)

Sometimes a little modelling and or priming was all it took -

JG: (Regarding 'Ring of Fire'). A few knew it without any melody prompting. Once I was back in my seat, I sang the 'Do Do Do Do Do Do Do Dooo' line and they were able to sing it quickly. We sang it twice. Then I started to sing the verse slowly and deliberately. They began to join me, and I was pretty sure that the melody was prompting their memory of the song. By the time we got to the chorus we were singing at the correct speed and the tone was good, words were clear.

(2.1 SUR 09.08.18)

Once, when trying to achieve something complex, by splitting the activity into what I perceived to be manageable tasks, we were confounded.

JG: I tried to initiate two groups (red and blue lyrics) as both a cognitive acuity exercise (sing / don't sing / listen / come in at the right time - they knew the rhythms very well) as well as splitting the workload of getting the lyrics out - even Queen had to multi-track the recording to achieve the sound ... This was more difficult for them I think (this could be due to my instructions being too complex, long or poor choice of words, or not giving them enough time to process). I would like to investigate this further - learning new ways of doing things to achieve the same effect.

(3.1 CBRC 17.09.18)

Backwards chaining was a new process for me, but it is very effective when trying to be inclusive as it focuses the first learning in the repetitive parts of the song (the last two lines) and so more people can join in from the beginning of the activity.

AT: (Singing 'E tu kahikatea') Jenny's prior suggestion, led by Ali, then Jenny. Not very familiar, but always a good effort. As we sing this only intermittently, I find today's process is often needed each time.

Reminder of my process (backward chaining): 
1) Sing to the group (all listen)

2) Practise last line - listen and just sing this line

3) Practise penultimate line, then last two lines - listen, sing last 2 lines

4) I went on to verses 3 and 4 without announcing this all singing last lines

5) All sing (led by Jenny) - trying (harder) lines 1 \& 2 if confident

(1.1 SUR 17.05.18)

While I considered Gearing for Positivity in my work with the groups, I was also concerned with Maintaining the Feel-Good Factor that participants either arrived with or was generated in the sessions. The next section discusses this.

\subsubsection{Theme 2: Maintaining the Feel-Good Factor}

This is the second of the three main themes that appeared to be important (Figure 11). This theme is predominantly related to the psychosocial elements that align with the 3 Pillars of Positive Psychology - positive experiences, positive individual traits and positive groups.

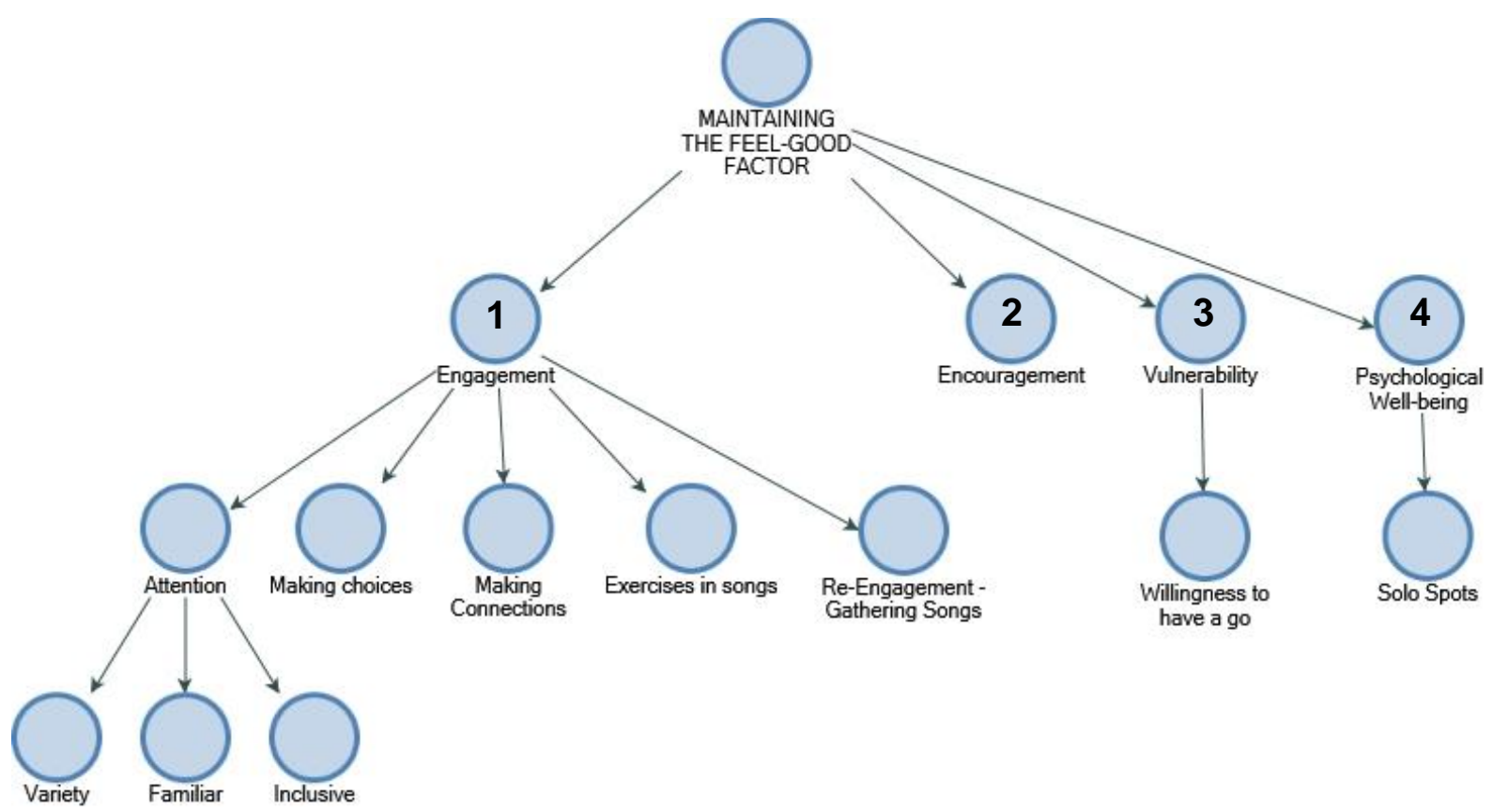

\section{Figure 11 - Coding MAP: MAINTAINING THE FEeL-Good FACtor}

I found several aspects relating to the repertoire in the sessions that impacted on maintaining the feel-good factor. These were Engagement, Encouragement and Vulnerability. I further noted that the Gathering Songs, used to 'call the group back 
together' after the tea/coffee break in the sessions, i.e. re-engagement, were linked to this notion. Maintaining the Feel-Good Factor also had an impact on participants psychological well-being.

\subsubsection{Engagement}

I noted a number of factors that were helpful in gaining and maintaining engagement in the repertoire (Figure 12). These included getting Attention, Making Choices, Making Connections, Exercises in songs, and Re-Engagement - Gathering Songs.

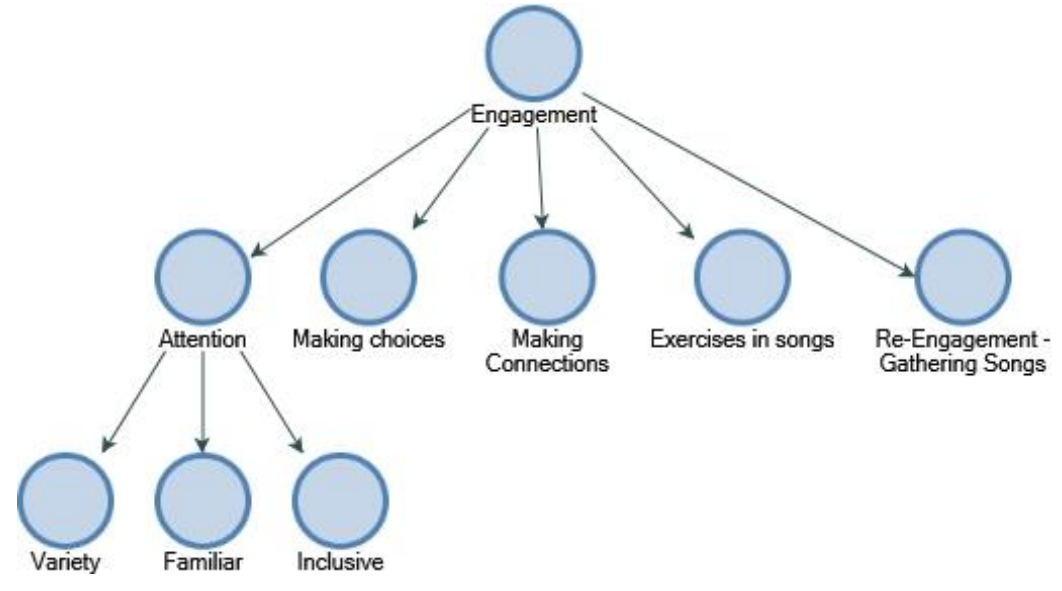

FIGURE 12 - ENGAGEMENT

Gaining and maintaining the group's Attention helps with engagement and I noted that using a variety of familiar songs and activities that are inclusive of all members is likely to hold the group's attention for longer.

JG: ('Feet on the Floor' written by AT). If they get used to 'not being $100 \%$ sure of what's coming it might encourage sustained attention? Then keep enough of the very familiar to give them some respite throughout the song.

AT: Excellent - held everyone's attention well and incorporated a lot of body / facial / oro-motor aspects.

(1.2 CBRC 21.05.18)

Variety helps by providing interest.

JG: The singing was very lovely by the end of the $2^{\text {nd }}$ time through. We discussed how the choir had done this song 'to death' (?) in the past, and it has been out of the usual repertoire for a decent while. So, while it was very familiar, well known yet it was relatively fresh, not tired and stale for them.

(3.2 CBRC 08.10.18) 
Including familiar songs provides the security of 'knowing'.

JG: (Regarding 'Haere Mai'). I confused them initially because I was trying to get them to hum (I was mixed up with one of the later songs) but we found our feet quickly because I felt they KNEW what they were doing.

(1.3 CBRC 28.05.18)

The song, 'Feet on the Floor', composed by Alison, is designed to encourage participants to connect with their bodies by providing reminders of correct posture for singing and movement of various body parts. It is a call and copy song, has a standard 12-bar blues form, and a repeating and catchy refrain. There is a logical and preferred order of sequence (starting from the feet and moving up gradually to the head, neck and oro-motor) ${ }^{12}$. There were also opportunities for the element of surprise through using a 'different' hand movement from usual. This added variety and humour, encouraging active listening and participation.

JG: ('Feet on the Floor' by AT). This went well. I think they managed to 'not know' exactly what I was going to come up with. I wanted for there to be enough that was familiar and to offer some challenge as well. This was quite a long one though. AT: Very effective - they were very attentive and enjoyed the variety. Use of rhyme was good (nose and toes).

(2.1 SUR 09.08.18)

JG:(When singing 'Ying Tong' by The Goons, and 'Witch Doctor' for the silly words after some SLT exercises). I feel they enjoyed the songs and seemed to be more lively when singing them - perhaps they were into known territory rather than the unknown exercises and face shapes?

(3.1 CBRC 10.09.18)

Having inclusive activities in the songs helps with a sense of community and wellbeing.

JG: (Regarding 'Waltzing Matilda' after the break). There were a few problems with some of the words (doing from memory) but very rousing chorus each timethis was my point. Something most could sing all the chorus to, even the volunteers working to tidy up.

(2.1 SUR 09.08.18)

Involving members in making choices regarding the repertoire was one way to elicit engagement in the sessions. Sometimes I would ask the choir directly if they were enjoying a song or activity. Even then their response was not always clear maybe needing more time to process than I gave them? I wondered how far I

\footnotetext{
12 I learned early on that it could be more difficult than necessary to jump from toes to nose and patting your knees to waving your arms high in the air!
} 
could or should encourage the participants for 'their' choice as it may have been difficult to make a choice or made them feel uncomfortable.

JG: was happy to sing 'what we wanted to sing' but did not want to have to make a choice when asked. Is this something that I could encourage? She seemed to be (only) a little uncomfortable being asked directly.

AT: has dementia and is likely to find initiating and decision making difficult. Perhaps try browsing through the book and offering a choice of two?

(2.1 SUR 09.08.18)

Sometimes participants may have found it difficult to express a preference and I would attempt to intuit their intent and make the decision.
JG: (Regarding "Moon River"). I had heard and (joined by others in the SUR 'café') sing this at the break and knew this. She had a beatific look on her face - very noticeably enjoying the song. I resolved to include it in the $2^{\text {nd }}$ half despite not having word sheets. The group seemed to enjoy singing this and the singing was lovely.
(2.1 SUR 09.08.18)

Offering too much choice was sometimes confounding to participants. It could be more effective to offer a smaller or more familiar selection.

JG: In my urgency to offer as many songs/options for them on 'my last day' I overloaded the situation with many bits of paper and too much choice. I talked about singing songs off the sheets and added, as an after-thought (because I had proposed it on the plan but not included it in my instructions), that they could choose songs from the Red folders that they usually sing from - THIS SHOULD HAVE BEEN THE FIRST THING I SAID! They seemed not to be able to make a choice until I said 'Red Folders' then the choices started flowing! Choices from what is familiar is easier for them, I think.

(3.1 SUR 04.10.18)

Making connections with other people added to the engagement. This was one of the reasons for joining the singing groups that people indicated on their forms. People in the groups connected in many ways for different reasons.

AT: I have been thinking about what makes it possible for friendships to develop here, for people to feel confident to make suggestions / challenge the group, intersectionality (e.g. combined impact of disability, ethnicity, gender, age, other positions of power)...

This also prompted me to reflect on songs (in and beyond current repertoire) that might nurture this spirit among the choir - beyond empowerment through enabling choice.

(1.1 CBRC 14.05.18)

Adapting songs that are familiar to include names is one way of encouraging people to make connections. 
AT: (Regarding an activity with one greeting song). People look across the circle, make connections, choose a name. No pressure to 'solo' but encouraged to select someone. Includes everyone.

Being seated, instead of standing, in one circle made it easier to feel part of the group.

JG: I much prefer being 'in the round' and being seated 'with them'. I could see more of what was going on - connect more with looks and smiles.

(2.1 CBRC 06.08.18)

Sitting opposite another, instead of side by side, produced some encouraging and pleasing results.

JG: was a revelation - he did the ascending chromatic run at the beginning of each line of Imagine and began to copy him (sitting directly opposite across a small table). Then in another song sang a lower harmony and copied him again.

(3.1 CBRC 01.10.18)

AT: Surprised response to the circle, but most enjoyed this. There seemed immense energy today - in response to the seating. I wonder if this is because it's more inclusive and or it is easier to see everyone else and connect ... It creates more opportunities for visual interaction and to encourage projection.

(1.2 CBRC 21.05.18)

Making connections does not depend on being able to communicate verbally.

JG: One of the staff asked me to translate a conversation between her and I said I would be happy to try to. I told her he understands everything, and his eyes lit up and he said his usual "yeeeah". Big smiles and laughs. She told him how much she enjoyed it (the concert) and she asked him some questions. We all 'conversed' in a kind of bumbling camaraderie! It was great.

(1.3 CBRC 28.05.18)

Exercises in songs add to engagement in the session.

Using aspects such as lyrics and rhythms of familiar songs as exercises was one of the techniques I used to work on speech and language goals. I found it helped with the engagement in the exercises.

(Regarding 'Alive, alert, awake, enthusiastic': Participants perform an action with their hands for each of the words, (to the tune of "If you're happy and you know it") - learned from Kim Wade RMTh and lead by AT).

JG: This was great. Easier than "Caractacus" because well-known tune, more repetition and not such 'stupendous' words. A great exercise.

(3.1 SUR 04.10.18) 
JG: He told me that the exercises we were doing seemed to go for longer and were more helpful/made him work harder (I don't remember his exact words, but I thought he was trying to say the exercises were "more than scratching the surface of working at something"). He also said he thought he could do more and go for longer (at the exercises) with the music and it was much more fun!

(3.2 CBRC 08.10.18)

I noted that the surprise of doing something that was familiar in a new way only lasted a while, and that it would be good to have a varied array of different 'exercise' activities that could be rotated often to avoid over-use. I also found that some members would want to sing the whole song. This was an issue if it led to exclusivity because the whole song's lyrics made it difficult for many to participate in the full singing of it.

JG: (Regarding "Blueberry Hill" exercise). I could tell they were listening and trying to follow instructions - even though it is difficult to 'not sing' some of it.

(1.2 CBRC 21.05.18)

Call and copy, or echo singing, as a way of singing, is something that the CBRC and SUR do as a warm-up. Participants didn't have to read the lyrics and the phrases are short. I used "Be-Bop-A-Lula" as a call and copy exercise for diction and consonants. It is also rhythmically strong and consistent while the melody is relatively stepwise. These two things mean the choir may be more likely to be able to focus on the diction and consonants rather than the rhythm and melody. I led strongly with my voice for each phrase and played on guitar a single note, crotchet accompaniment.

Most of the choir seemed familiar with the song, "Be-Bop-A-Lula". Also, being familiar with the concept of call and copy was helpful. Most members seemed to enjoy it. We sang various versions of this for several weeks. I don't know if it is the "something new" aspect or the "we remember that and really like that we remember it and can still do it". I have also introduced "Little Brown Jug" and panting "Ha $\mathrm{Ha} \mathrm{Ha"} \mathrm{and} \mathrm{"Hee}$ Hee Hee" as diaphragm exercises. I asked them to work hard on the panting and just hum/sing/catch their breath for the "Little Brown Jug how I love thee" part. "Blueberry Hill" was another song I used as an exercise to encourage forward planning of the word "Thrill". One needs to get the consonants "TH" (linguadental-fricative) then "R" (linguapalatal) out before the vowel sound of "l" on the beat before tacking on the "LL" (lingua-alveolar), (Speech and Language therapy terms in parentheses - Baker \& Tamplin, 2006, p. 140). There are many processes required to make this possible. 
We practised saying it first in the rhythm of the song - $\underline{\mathrm{THi}} \mathrm{Ri}-\mathrm{i}-\mathrm{ILL}$ (Exercises in songs add to engagement, page 48).

\begin{tabular}{|l|l|l|l|l|l|l|l|}
\hline L: & I found my & Ch: & THR-ill & L: & On blueberry & Ch: & Hill \\
L: & On blueberry & Ch: & Hill & L: & When I found & Ch: & You \\
L: & The moon stood & Ch: & Still & L: & On Blueberry & Ch: & Hill \\
L: & And lingered un- & Ch: & Til & L: & My dream came & Ch: & True \\
\hline
\end{tabular}

FIGURE 13 - "BLUEBERRY HILL" EXERCISE - FOR FORWARD PLANNING OF WORDS

Participants seemed to find this fun for a while but then I got the sense that they just wanted to sing the song (those that knew it). I thought it might be helpful for them not to have to sing all the words and just concentrate on the rhythm of the "THi Ri-I - IL". However, it seemed it may have been harder not to sing the 'lead-in' words. It seemed to become more of a cognitive exercise in 'not to sing' rather than what it was that I intended. I have a sense that the choir will try anything and do enjoy trying new things but, like any of us, they get bored or tired if things are repeated too much. Keeping the ideas flowing so there are new, fresh exercises is time-consuming and adds to the time needed in planning and resource development. I noted in my reflections that I should endeavour to build a selection of exercises-in-songs that target similar goals and, thus, be able to rotate the use of them.

I devised a warmup exercise for the CeleBRation Choir based on the first part of the 'William Tell Overture' by Rossini (Figure 14). 


\section{CeleBRate CeleBRation Choir!}
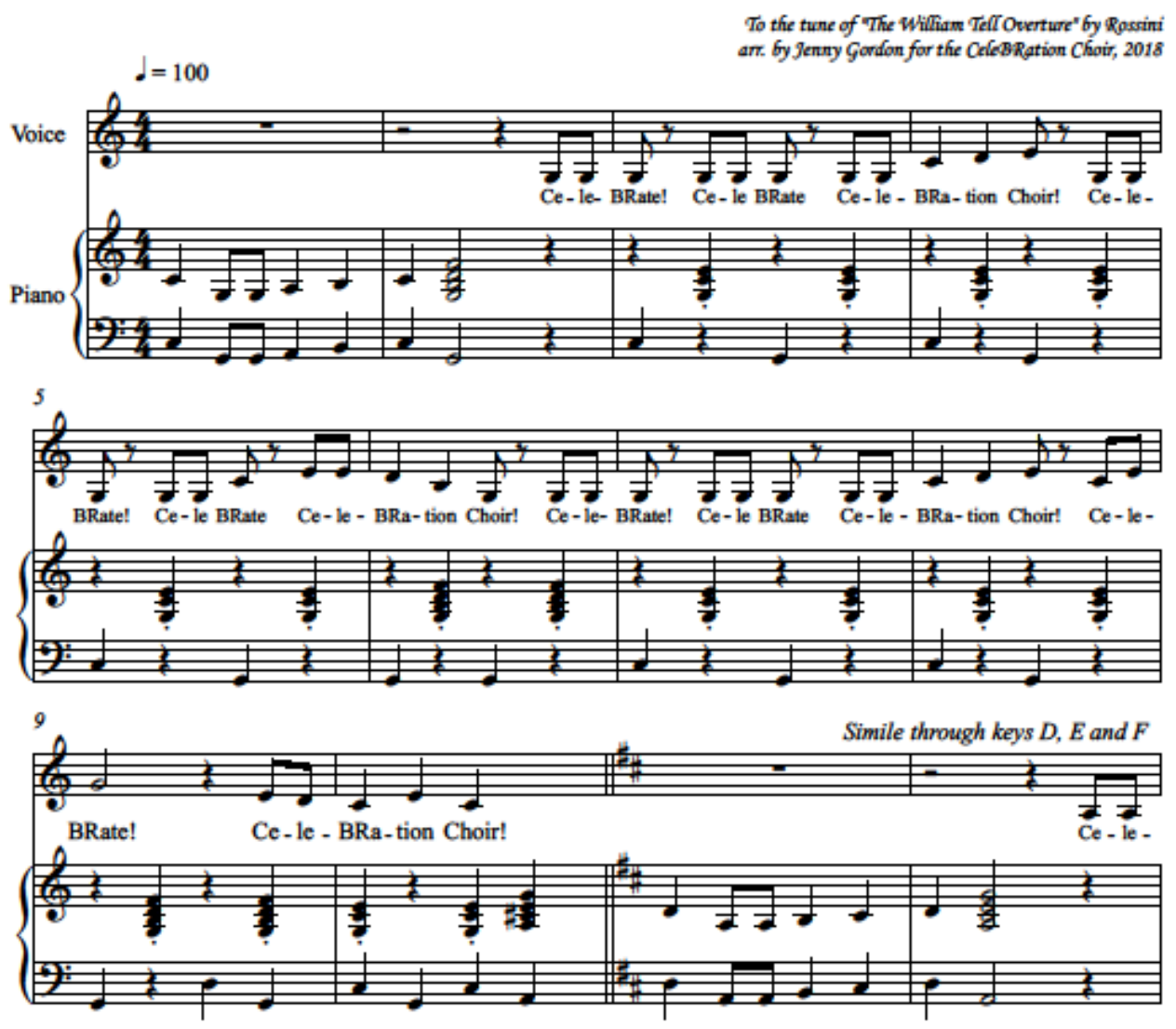

Figure 14 - "Celebrate Celebration Choir"

It is primarily for articulation of particular consonants and vowels, but there is, also, an element of warming the range of the voice as well. This involves repeating the melody of the exercise a semitone or tone higher each time. Between each of the main melody parts is an a 2-bar introduction that is designed to cue for breath inhalation before singing.

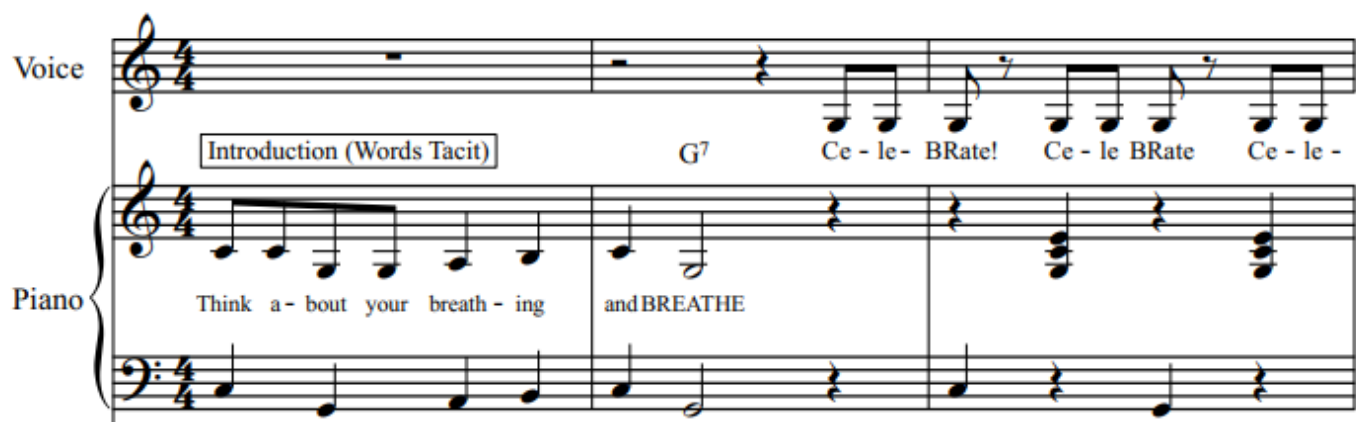

Figure 15 - “Celebrate Celebration ChoiR” With breathing Cues 
I sang the first introduction with the "Think about your breathing and BREATHE (held 2 beats) Ce-le-BRate! ..." (Figure 15). Then I repeated it. This may have been superfluous for some members, but I am confident that some in the group required a second hearing and needed more time to process instructions and the unfamiliar material. Then I played the introduction without words and modelled a loud nasal inhalation instead of saying the word "BREATHE". I asked them to try the introduction with me which we did successfully.

Another aspect of working with choirs that I became aware of was the planned use of Gathering Songs for the purposes Re-Engagement after the social breaks in the sessions. There is something that is special about the gathering songs after the break. They have the difficult task of reconnecting everyone back into the group and if people are having a lovely time chatting and socialising, as we would hope that they do, it can be difficult to 'want' to break that up. However, while the tea break is a vital part of the session, it is only one part and we try to manage the length of the breaks so that they are appropriate to each group.

I took my lead from Alison on this and I quickly found it to be much more calming and satisfying, I think for everyone, rather than shouting out, "Come back" or "Let's get singing".

JG: Difficult to get people back after the tea/coffee. I stopped the videos at 2.40 and we started swapping seats etc. It took about 5 mins to get people back. MAYBE IT WOULD BE HELPFUL IF I SAID "PLEASE BE BACK IN 15 MINS" ETC?

AT: It always is a challenge - actually I thought it was OK today. I often view the first session after tea as a time to gather, rather than insisting on everyone being seated, which favours those who got their tea first (or had it brought to them first)!

(1.2 CBRC 21.05.18)

The songs that were effective 'gathering songs' were those that people knew at least the chorus well enough to sing without the lyric sheets. This enabled participants to sing on their way back to their seats, and the volunteers could join in while they tidied up after the break.

Plan: (Regarding 'We Shall Overcome'). Use as a 'call back' from morning tea. Just sit down with whoever is handy and start singing with them. People will come back as and when they can.

JG: "This worked well". $\quad$ AT: " $Y$ " 
JG: (Regarding 'Waltzing Matilda'). I think this works well as a gathering song. We all know the chorus and it's a little exercise to get the verses some challenge and some familiar.

(3.1 SUR 04.10.18)

\subsubsection{Encouragement}

Encouragement, I noted, was something we all need. I enjoyed giving encouragement and I found it difficult to critique the groups' sounds.

JG: I am not very good at being critical (in a good way) - it's much easier to say, 'that was fabulous'. Very difficult to be specific about what is needed.

(1.2 CBRC 21.05.18)

I found that I, too, needed and enjoyed encouragement. I am very grateful for the encouragement I received.

JG: came up to me and told me how much she appreciated how positive I was about the singing.

(1.2 CBRC 21.05.18)

To Jenny (An 'immediate response' poem by way of reflecting on the session, Jenny's reflections and notes - by AT)

So much to do,

So much to learn,

So much to remember.

So much you already do well,

So much openness to learn,

So many experiences you will remember.

So much evidence of reflection and learning,

So many people experienced joy today,

A day to remember.

(1.2 CBRC 21.05.18)

\subsubsection{Vulnerability}

We are all subject to vulnerability, particularly of the emotional kind. This is generally something that we put on ourselves. The Merriam Webster online dictionary ${ }^{13}$ defines vulnerable as, "1: capable of being physically or emotionally wounded; 2 : open to attack or damage". While the singing groups are very friendly and supportive situations to find ourselves in, we can still be afraid of showing weaknesses and even

\footnotetext{
${ }^{13} \mathrm{https}: / /$ www.merriam-webster.com/dictionary/vulnerable
} 
of failure. I found this equalising early on in the relationship, at the start of my practicum with the singing groups. I thought while I felt vulnerable 'in my newness to the role', as student music therapist, maybe they felt vulnerable having a new person, who doesn't know them and whom they don't know, come into the groups and start asking them to do this and that. The reality was that the participants were totally trusting and seemed prepared to try everything.

JG: (Regarding 'The Court of King Caractacus' - stupendous words, long phrases and actions). They seemed to enjoy this song although I was very busy doing the words and actions myself, I noticed as I looked around the circle that people were engaged and prepared to give it a go.

AT: A challenge for some, but most open-minded / keen to try.

AT: (Regarding 'Hine E Hine' - for NZ Music Month). Yes - a good choice and enjoyable. I thought everyone relaxed and didn't mind making mistakes.

(1.1 SUR 18.05.18)

There were times when I needed to show a willingness to have a go, despite some trepidation.

JG: called out and asked for "You Raise Me Up". I said I didn't think I could play it but that we could try it without accompaniment. ... In the end I had the chords and it wasn't too bad from my point of view - I thought they sang it nicely and enjoyed doing it.

AT: Good - and a cappella is fine too, as you'd suggested.

(1.1 CBRC 14.05.18)

At times I felt the anxiety of my lack of clinical and practical knowledge, with these populations, interfered with my ability to support the groups to having quality musical experiences.

JG: I am distracted or put off when I see things I don't understand eg facial expressions. There is so much that is unfamiliar to me and I start wondering if she's alright etc. I stop concentrating on the song and then worry about doing a good job with it when I muck up a bit.

(3.1 SUR 04.10.18)

\subsubsection{Psychological Well-being}

Psychological well-being can be enhanced by meaningful activities, healthy relationships, and independence (Wall, 2010). I was able to convey enjoyment in the 
music and the groups. This further strengthened the relationships between me and choir members.

AT: You appeared relaxed and well prepared, and engaged well with the group throughout, conveying enjoyment of the music and the group's participation - this would have been clear to the participants too, through your body language, facial expressions, comments and music. They experience the social context (interactions with you and one another) as well as the music - and of course these intertwine.

(1.3 SUR 31.05.18)

Some participants gave an occasional spontaneous solo performances, and these were well received. I felt that these solo spots were beneficial for the soloist and the rest of the group.

JG: " solo of yodelling song. Appreciative applause.

(2.1 SUR 09.08.18)

\subsubsection{Theme 3: Managing My Skills and Vulnerabilities}

The third major theme that became important to me over the course of this study was managing my skills and vulnerabilities (Figure 16) in developing and using repertoire with this population - the two singing groups, 'The CeleBRation Choir' and 'Sing Up Rodney!'. I noted in my reflections that, while I did have many skills in this area, there were times when I felt I did not have the right skills, or that the skills I had were not adequate at that time. All codes related to this theme are concerned with either my skills or my vulnerabilities regarding the lack thereof. These include Ways to Support, Teaching and Learning - Relationships, The notions of 'Performance' vs 'Rehearsal' vs 'Therapy' Session, Multi-tasking, and finally notions related to Csikszentmihalyi's (1996) concept of 'Flow' (Livesey, Morrison, Clift, \& Camic, 2012). 


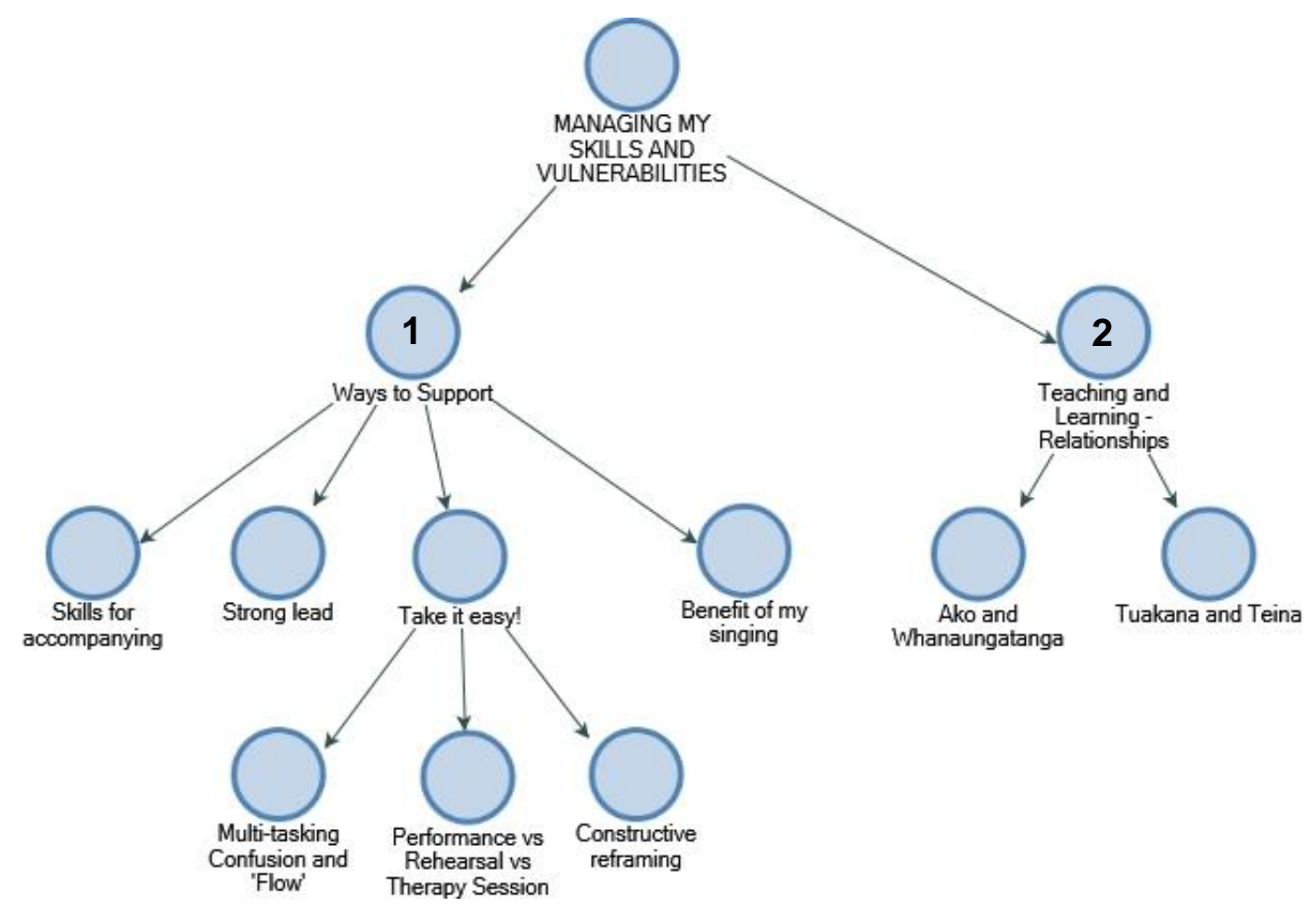

Figure 16 - Coding MaP: MANAging My SKills ANd Vulnerabilities

\subsubsection{Ways to Support}

There were several ways, I noted, that I could support the singing groups - using my Skills for Accompanying, by taking a Strong lead in the singing, by Taking it Easy! (on them and on myself), and finally adding the Benefit of my singing (Figure 17).

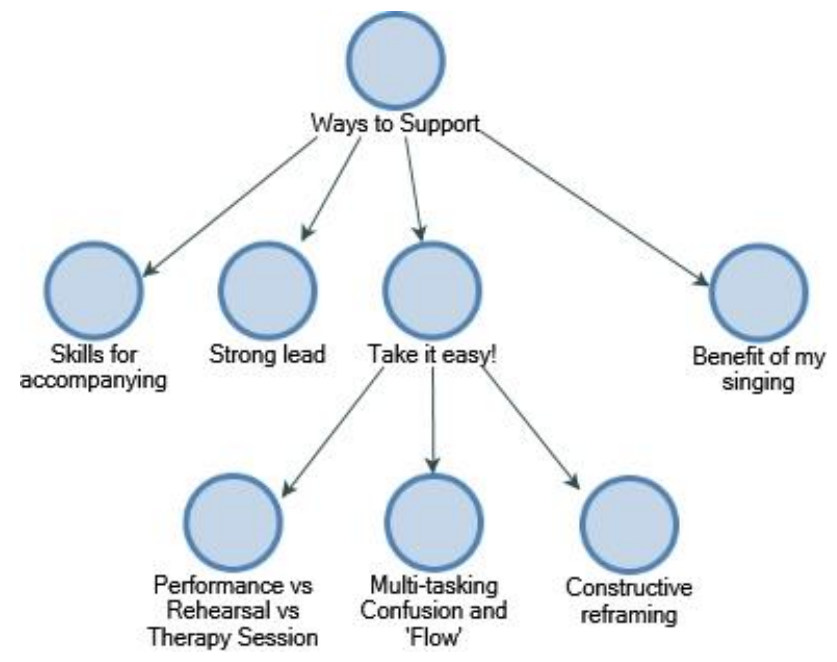

FIGURE 17 - WAYS TO SUPPORT

One way I could support the groups was through my Skills for Accompanying. These include a reasonable proficiency in 3-and 4-chord songs on guitar, ukulele and 
piano. I could usually play these songs by ear, although I did require printed lyrics. I tended to have the chords written and referred to them when playing songs with more complicated chord progressions, and particularly those that modulate in and out of keys. I played barre chords on guitar and because of this I had the best chance of being able to change a key by semitones or tones, if it suited the choir better to do so. There was also the use of a capo if one was readily to hand. On the piano I was more comfortable playing in the keys of $B^{b}, D^{b}$ and $E^{b}$ than $I$ was in $B, D$ and $E$. On the ukulele I found the keys of C, D, G and A the easiest although, through practise, I improved in my skills in all instruments. I liked to practise the songs in a couple of keys, but I found some keys easier, depending on the instrument I was playing. One might assume that I 'had the bases covered' over the three different instruments, as far as the song keys go, but I found that not all songs were best accompanied by either a ukulele, guitar or a keyboard - the way that I played them at least. The instruments have different qualities that can seem important to some of the musical experiences, sometimes. Different instruments suit different songs and I did begin to swap out instruments for the different songs eventually. Sometimes, however, this wasn't an option, due to either availability or handiness of another instrument, or me sensing the choir feeling like we should 'just get on and sing'.

I found it interesting that I was more confident in one key or another depending on the instrument. For this to change I need to practise playing songs in new keys. This can be time consuming and so I also need to know what I like and try to be assertive about what is realistic for me to do.

Another way to support the groups was by providing a Strong Lead in the singing. This was something I felt I was able to do when I knew the song well.

JG: (Regarding ' $59^{\text {th }}$ Street Bridge Song/Feeling Groovy' - the first time singing this song): This one is more difficult with rhythms, melody in places and word scanning. Requires a strong lead but there were enough of us that knew it to provide that.

(2.1 SUR 09.08.18)

The third way to support the groups was to Take It Easy! (Figure 18). This code refers to me giving myself permission to relax throughout the proceedings and not work myself, or the participants, too hard. Notions of Performance vs Rehearsal vs Therapy Session, Multi-tasking confusion and 'Flow', along with Constructive 
Reframing were also related to this code in that any vulnerability I felt I had in any of these areas could be aided by 'taking it easy'.

JG: I felt flustered when I realised I had to hand out the sheets but I think the break was WELCOME (for the choir and me). I had been cracking a fast pace to get through before the break. Remember to take some time to 'just BE'. ... I need to not panic when there is a gap in proceedings - these can be lovely and restful if I'm relaxed but could be awkward and clunky if I'm uptight! I think people need to 'sit up, feet on the floor, work, concentrate' then relax and not work for a little.

(1.2 CBRC 21.05.18)

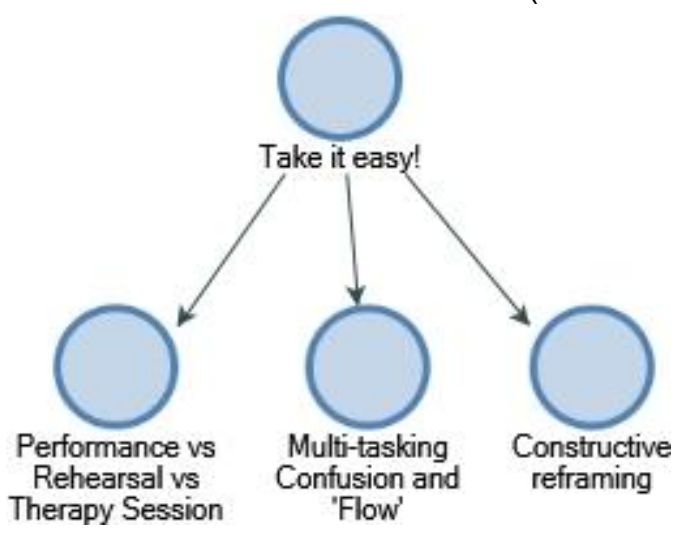

FIGURE 18 - TAKE IT EASY!

\section{Performance vs Rehearsal vs Therapy Session}

There were a number of modes of operating that were used in our singing 'sessions'. These were 'Performance', 'Rehearsal' and 'Therapy'. The parameters of these modes were sometimes quite fluid and during the sessions I found that we would move from one mode to another, due to subtle changes in the groups' goals that impacted how the session operated at that particular time.

Performance mode, while it seems, on the surface, as easily definable, I found this to be the most complicated for me to internalise. At least at the beginning of my practicum with these groups. On the one hand we, as a group, were (mostly) not performing to an audience, yet I felt I was performing. I wanted to play and sing well because I believed that, due to these being my skills, this was how I could best support the group. This eased as I came to know the repertoire and, indeed, the individual participants. 
At other times we were 'performing' to others in the community although, these were further complicated by the fact that we encouraged our 'audiences' to sing with us. Often we included warm-up exercises in these 'performances' because everyone needs to warm up to sing.

The sessions prior to 'performances' were more like rehearsals and we would repeat songs and part of songs to go over certain aspects of them in preparation for the 'performance'. We also reiterated exercises in some parts of our sessions to work on a particular component of speech - Respiration, Phonation, Resonance, Articulation and Prosody - much like a therapy session.
AT: ... It depends what your aims are - is it important to have a go and improve, or to get it right? (especially when "in-house", not a community performance).

(1.1 CBRC 14.05.18)

I performed with both singing groups at various events in the community and one thing is very clear to me - they sure know how to perform! There was magic about being together, demonstrating to others, despite vulnerability. Was it due to increased strength in the moment or, perhaps, people are normalised and enthused by the experience they share?

AT: (Regarding a 'Performance - Session' at a retirement village). I was surprised how robust the singing was today with a lesser emphasis on warming up - the choir always seem to rise to the occasion on performance days!

(1.3 CBRC 28.05.18)

\section{Multi-tasking Confusion and 'Flow'}

I often worried about making mistakes when I was delivering the repertoire to the singing groups. There seemed to be many things to do at once - singing and playing, the 'cueing-observing-making decisions-further cueing' cycle, eliciting their engagement, and giving encouragement. I found I panicked overly when I was too aware of such things and the sessions appeared more enjoyable when I was not thinking so much of all these things.

JG: I was trying to be more aware of things as the session progressed but then I think the times the session 'flowed' best were the times when I wasn't thinking too much.

(2.1 CBRC 06.08.18) 
Learning new clinical knowledge and, of course, becoming more familiar with playing and singing the repertoire, will help me with some of these anxieties.

JG: I am distracted or put off when I see things I don't understand eg $\square$ facial expressions. There is so much that is unfamiliar to me and I start wondering if $s$ (that person is) alright etc I stop concentrating on the song and then worry about doing a good job with it when I muck up a bit.

(Nvivo memo - 2.1 SUR 09.08.18)

I decided that I would just try to 'be myself' and let other learnings come gradually rather than trying to do everything at once. Focussing on the psychosocial goals was easier for me, however, I was also aware of speech and language goals.

\begin{abstract}
JG: The problem can be that I'm not really able to recollect what actually happened because l'm not very cognizant of what's happening and why 'in the moment' when singing and playing. Trying to be a natural and open therapeutic presence is easier if my goal is 'to be a nice person to be around at that moment', but there are other goals to work towards. When I start trying to think about those sorts of things my 'flow' gets interrupted, I THINK. ... Hopefully when I am much more familiar with the repertoire I'm using (both playing and singing) it will be easier to start thinking about other goals without losing the flow.
\end{abstract}

(2.1 CBRC 06.08.18)

There were times when I felt I was experiencing some kind of 'flow' where I seemed able to facilitate the session, make observations and provide responses.

AT: You appeared relaxed and well prepared, and engaged well with the group throughout, conveying enjoyment of the music and the group's participation - this would have been clear to the participants too, through your body language, facial expressions, comments and music. They experience the social context (interactions with you and one another) as well as the music-and of course these intertwine.

(1.3 SUR 31.05.18)

Trying to juggle all the needs and goals with the processes involved is difficult indeed but I began to feel that, while it was a balancing act, I was not on a high wire without a net, I was on the ground and I had a lot of great encouragement and support.

Constructive Reframing of feedback is a technique that Alison brought to my attention. It concerns changing negative language and reframing things positively when I respond or give feedback in the sessions. I found it was very helpful in relieving some of my performance anxiety pressure that I placed on myself. I don't have to know and be able to play every song that comes up (not that anyone else is expecting 
me to) - there's always another time that we can sing the song and that gives me a chance to prepare.

AT: An interesting moment with half-remembering the verse-might be good to reframe feedback e.g. "I'll find the words for next time" rather than "I haven't got them." Splitting hairs perhaps, but constructive re-frames can be helpful.

(2.1 CBRC 06.08.18)

The fourth way I found I could support the groups was to offer the Benefit of My Singing. Stopping singing but continuing to accompany the choir allowed me to hear more clearly but invariably I would re-join the singing. I regarded my voice as my first instrument and I felt that singing along was how I could best support the group at that time.

JG: I think she smiled when I would turn my head sometimes and my singing was in her direction.

(2.1 SUR 09.08.18)

There were times when I misjudged this and missed the opportunity to truly observe and reflect.

AT: ... there is still some benefit in sitting in the group some of the time when l'm leading - to observe the group and really focus on listening to them - rather than always accompanying.

(1.2 CBRC 21.05.18)

I felt strongly that my motivation for doing this work was to use my skills and manage my vulnerabilities to support the groups towards their goals.

\subsubsection{Teaching and Learning Relationships: The Tuakana/Teina Model and the Concepts of 'Ako' and 'Whanaungatanga'.}

Another of what I considered to be my skills was in the teaching and learning of repertoire. These are equally elemental in some of the processes of singing groups. There can be no teaching of songs without the learning of them and vice versa. Because of this, the interrelationships between teachers and learners is an integral part of my work with and within these singing groups.

The Maori concept of 'ako' is described as “a reciprocal learning relationship (where) teachers are not expected to know everything. In particular, ako suggests that each 
member of the ... learning setting brings knowledge with them from which all are able to learn" (Keown, Parker, \& Tiakiwai, 2005, p. 12).

One Maori model of learning and teaching that has the concept of ako as a central tenet is that of Tuakana / Teina. The Māori term, tuakana, is defined as "elder brother (of a male), elder sister (of a female), cousin (of the same gender from a more senior branch of the family), prefect", and teina is defined as "younger brother (of a male), younger sister (of a female), cousin (of the same gender) of a junior line, junior relative" as found in the Te Aka Online Māori Dictionary ${ }^{14}$. In education circles the Tuakana/Teina model became synonymous with a 'buddy' system of knowledge transfer. There are various forms of this:

- $\quad$ Peer to peer - teina teaches teina, tuakana teaches tuakana.

- Younger to older - the teina has some skills in an area that the tuakana does not and is able to teach the tuakana.

- $\quad$ Older to younger - the tuakana has the knowledge and content to pass on to the teina.

- $\quad$ Able to less able - the learner may not be as able in an area, and someone more skilled can teach what is required", (TKI website $\left.{ }^{15}\right)$.

The tuakana is a mentor who supports and advises the teina while the teina affords opportunities for the tuakana to learn new things. While the term 'tuakana' literally means 'older', the model is often understood as the tuakana is more knowledgeable and consequently mentors the younger, less knowledgeable, teina.

AT: ... also the tuakana/teina relationship Jenny discussed at the start of the year (RMTh/MTS). ... I understand older/younger here to mean experience - and my experience of the session was that I also continue to include "learner" among my roles.

(1.1 CBRC 14.05.18)

\footnotetext{
14

http://maoridictionary.co.nz/search?idiom=\&phrase=\&proverb=\&loan=\&histLoanWords=\&keywords=tu akana

http://maoridictionary.co.nz/search?idiom=\&phrase=\&proverb=\&loan=\&histLoanWords=\&keywords=te ina

${ }^{15}$ http://health.tki.org.nz/Key-collections/Exploring-te-ao-kori/Planning-learning-experiences/Teachingmethods
} 
Since we are of similar ages, my working relationship with my supervising music therapist, Alison, has very little to do with age and more to do with who has the requisite knowledge at any point in proceedings. I generally defer to Alison, as my tuakana, with regards to the knowledge that she has and imparts to me. There are times, however, when she benefits from my knowledge and experience - especially so with songs that she is less familiar with than I am. Our ability to learn from each other, in some ways switching our tuakana/teina roles, adds depth to our relationship and the way we work together.

AT: Important now I think for me to assist just when invited - so that the onus is on Jenny to manage this. Perhaps think about the more likely future scenario that you might have a musician-volunteer to direct.

(1.1 CBRC 14.05.18)

AT: Today we had specific songs to lead - and I took some photos during one of Jenny's songs. We also supported one another with accompaniment and singing - I found this particularly helpful when I went astray in Today is Monday - thank you! J

(1.3 CBRC 28.05.18)

These concepts of 'ako' and the tuakana / teina model of teaching and learning flow through to the relationships within the singing groups. There is a real sense of whanaungatanga (relationships formed from mutual respect and caring as could be found families) in the groups. One online definition defines whanaungatanga as, "1. (noun) relationship, kinship, sense of family connection - a relationship through shared experiences and working together which provides people with a sense of belonging. It develops as a result of kinship rights and obligations, which also serve to strengthen each member of the kin group. It also extends to others to whom one develops a close familial, friendship or reciprocal relationship, (Maori Dictionary.co.nz ${ }^{16}$ ).

\begin{abstract}
AT: I was thinking during this session about the choir as a supportive family/whanau - individual relationships within the bigger structure ...l'm also mindful that in a large group - especially with a new MTS (and for different reasons with a locum RMTh) - the relationships within the group (of people with different strengths, challenges, roles, personality, gender, age) are as important as the therapist-client relationship.

(1.1 CBRC 14.05.18)
\end{abstract}

16

http://maoridictionary.co.nz/search?idiom=\&phrase=\&proverb=\&loan=\&histLoanWords=\&keywords=w hanaungatanga 
At times members have advised, modelled and led various activities and discussions as they, at that time, were the tuakana. Such is the way these groups operated.

Plan: Sirens but more extensive than at the start. See if would like to LEAD. JG: was very obliging.

AT: Good - enjoys this role and ... understands what to do as well as creating some humour! (1.1 CBRC 14.05.18)

JG: Very interesting that $\square$ felt able to bring her expertise of Maori language and pronunciation to the group (Figure 19). It is lovely seeing her come out of her shell, share her knowledge and engage in this. (3.1 SUR 04.10.18)

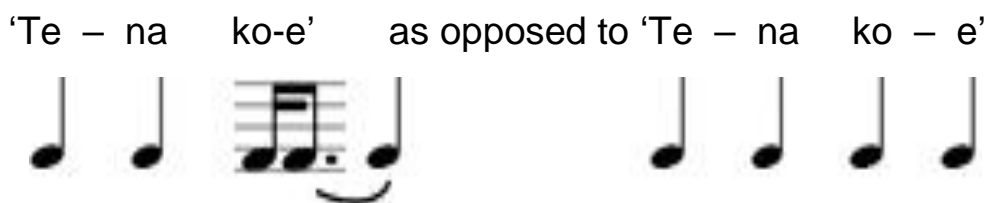

FIGURE 19 - TENA KOE

Aside from the three main themes, Gearing for Positivity, Maintaining the Feel-good Factor, and Managing my Skills and Vulnerabilities mentioned in pages $29-64$, there were two factors regarding the development and use of repertoire with these groups that were important but did not fit into the three main themes. These were issues around copyright and safety.

\subsubsection{Copyright}

Copyright is an important issue to consider when using songs. Particularly so when the context is a public one. Filming events occurred in both groups on my placement with them and we needed to be careful that we had permission to use songs or they were in the public domain.

JG: The repertoire considerations -we needed to have songs in the PUBLIC DOMAIN as it seemed quite difficult to get RECORDING PERMISSIONS for certain songs ... The public domain songs are very old (pre 1923 or 70-90 years after the death of the composer).

AT: I felt most people were very focused, interested in the filming process, and accepted the choice of (public domain) repertoire. It has highlighted for me how many of the choir enjoy projects and performances - as well as research!

(2.2 CBRC 13.08.18) 
Applying for permission to use a song in copyright can be a lengthy, time consuming process. We noted that, should we want to use a copyrighted song in the future, we would allow plenty of time to get the permissions.

AT: ... so if this is required at any time in the future, we will need to plan well ahead! (2.2 CBRC 13.08.18)

\subsubsection{Safety First!}

Although this topic appears last in my findings it is by no means the least important. On the contrary, hence the name of the code.

JG: (Regarding the singing of an up-beat song). I noticed having a good 'dance' in his chair and wondered if we could do the Hokey Tokey. I asked the group and, after a short silence, (a volunteer from the start of this group) suggested doing it in our chairs. Great. $\quad$ (2.1 SUR 09.08.18)

I was running the session on my own for the first time, in Alison's absence. It seemed to be going well and for a moment there I felt I got a little carried away with the excitement. Thank goodness common-sense and experience prevailed. I hope to always consider safety first in the future.

\subsubsection{Summary of Findings}

Initially, at least, I considered ways I could 'perform' my role, as support person for the groups, better. This focussed on being more musical (singing and accompanying better), being clearer, and being more supportive by clever and considered cueing. In the beginning I was not so comfortable if I was not able to assuage my performance anxiety through rehearsal and preparation. As I came to know the participants, as individuals, I began to stop thinking of my work with them as a performance, but more as a process. Both groups, and Alison, were inviting and encouraging from the beginning but this was a learning I had to come to in my own time. 
Critique of anyone or anything is a difficult skill to acquire. Even after many years of teaching $\mid$ found it hard to judge students' work summatively ${ }^{17}$. Formative assessment ${ }^{18}$ was easier in teaching sense. There was always the next education 'hurdle to get over' or the next 'hill to climb' as identified in the curriculum documents. With these groups I am not sure what the next hurdles or hills to climb are. Individually it may be clearer, but as a group the goal posts are a mirage in the desert for me wavering in the distance and ill-defined. There seems much to learn, and it will be ongoing. I will continue to learn and be the best music therapist that I can be for those allow me to work with them.

\footnotetext{
${ }^{17}$ Usually regarded as high stakes - a final performance, test, exam that results in a grade or mark according to a marking schedule that can be quantified.

${ }^{18}$ Regarded as low stakes. Helpful to students and faculty to determine, What the students know? What are the next steps for the students? How can the faculty help students get there?
} 


\section{VIGNETTE}

This vignette shows the communicative power of music. It triggered memories in one for whom memory is an issue, allowing notions of her identity to regenerate and her abilities to flourish. Music brought two people together allowing them to connect through shared memories and common interest.

Madeleine ${ }^{19}$ is sitting directly across the circle from me today. She has a sweet face which, at the singing group sessions at least, has a look of anticipation of impending joy on it - bright eyes, chin slightly forward and tilted up, and mouth with a hint of a smile.

It is time to sing our final song of the session. I have chosen the chorus of 'See you Later, Alligator', for simplicity, figuring that many people would know the tune and possibly the chorus lyrics which we repeated a few times. Our arrangement included guitar accompaniment and backing vocables for the horn line - "See you later, Alligator - Do Do Do Do" (Figure 20), for those inclined (they may like the rhythm of the harmony of the part), or for whom the lyrics may have been difficult. As I begin to introduce the idea of singing it as a farewell and closing song to the group, she has the same sweet look on her face. Then her husband says, "See you later, Alligator" in high falsetto (mimicking the start of the Bill Haley and His Comets, 1956, version of the song). Her whole face changes in a flash and becomes animated and excited. I think she recognises the song from his mimic. She shifts in her chair slightly, moving her bottom back in the seat as though preparing to sing.

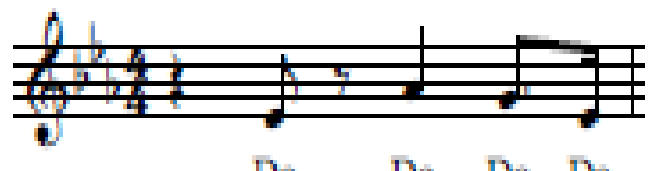

Dọ Dọ Do Do

Figure 20 - Horn line for "See You later Aligator"

The song is sung by the group with gusto, getting stronger each repeat as lyrics and words become remembered more surely and our arrangement firms up. I am glad of the co-therapy nature of working with this group because the co-therapist has taken the vocables part and leads this clearly while I play guitar and lead the main melody and lyrics, allowing many of the group early and full access to participation. Feet begin to tap, arms are raised slightly, and people are moving in their chairs. There's a whole lot o' shakin' goin' on! It is difficult to bring the song to a close. Partly because we did not pre-determine how many times would repeat the chorus but also, I think, because we are enjoying it.

${ }^{19}$ Names have been changed to protect the participants' privacy 
After the session has ended, while people are putting chairs away, I move across the space between us and say to her and her husband of more than fifty years, Ron, "I bet you two can dance the jitter-bug". He replies, "Oh yes! She's a marvellous dancer". I start singing the chorus again, looking at her. Madeleine stands and moves from side to side as if she's dancing by herself. I check with Ron that she's safe and not likely to fall. He confirms for me that she is sure on her feet. Ron takes both Madeleine's hands in his and joins her in the side-to-side motion. I wonder if he gathers her hands to make sure she does not fall or if he wants to hold her hands and join her in the dance. We continue to hum and sing the rest of the chorus. Suddenly he scoops her into his arms in the waltz tradition and she follows easily where he leads, complete with dainty twirl under his arm, holding his fingers. Madeleine takes her hand off his shoulder, as if to move away while still holding Ron's hand. Her feet are finding the 'jitterbug' steps off to his side one moment and then she is back in his arms the next. They seem happy. Madeleine is smiling broadly. (July 2018)

This couple have been married for over fifty years. She has Alzheimer's disease. She has strong, vibrant memories of her childhood but she has lost some procedural memory, so she is no longer able to do some things, like cooking, on her own. However, she can still sing and remembers many sets of lyrics, and intricate tunes and rhythms. I feel she depends on him for most things and seems highly tuned into what he says and does. It's as though, if he is near, she feels safe and secure. They both have had a life-long interest in music - particularly singing. They attend a weekly singing group for people living with neurological conditions and their partners or carers.

Group singing opportunities allow for the formation of social relationships as well as positive physiological changes (Clift, 2012). Living with dementia and experiencing significant memory problems can precede social isolation as interactions and communication become challenging. The singing group provides one of the places and activities that these two are able to connect, not only with each other, but with others, in a broader social setting.

Those who were still around after the session seemed to get some enjoyment from watching them dance. Some people even stopped putting chairs away and generally tidying up and came nearer. Perhaps we all wanted 'what they were having'!

It was a joy to see these two interact and I absolutely loved it. So, while it is supposed to be all about them, it can also benefit me. 


\section{DISCUSSION}

The findings in this research represent a coalescence of my experiences, and reflections thereof, around developing and delivering repertoire to two singing groups of people living with neurological conditions, and their carers, while on placement as a student music therapist. The three cycles of action research have provided data that has been discussed in three broad themes - Gearing for Positivity, Maintaining the Feel-Food Factor, and Managing My Skills and Vulnerabilities. The data collected did not capture every thought or eventuality and, consequently, more questions have been raised, while some points need further clarification and warrant further discussion. These are: multi-tasking and 'Flow'; the point of critique; some clinical/technical aspects regarding speech pitch/frequencies, song keys, and Aphasia friendly guidelines; and, finally notions of a quality music experience.

\subsection{Multi-tasking and 'Flow'}

Upon writing up my findings and considering things at length, I began to wonder if, perhaps, my multi-tasking confusion (page 59) was much the same as theirs? It feels like it's all new and hard to pull off ... must be similar for them when they're dealing with acquired neurological conditions, whether sudden or gradual, as well as the associated psychosocial difficulties. It's a new way of being and it takes some managing. With me, so new to this field of work, does this level the playing field, at least for a while?

\subsection{The Point Of Critique}

I found that I was open to being critiqued by Alison and yet I found it very difficult to critique the singing groups. Alison mentioned that she admired how well I managed her appraisal of me. I am grateful that she was able to make some comments that I might have found challenging to make, in the interests of furthering my skills and learnings during my practicum. Why did I find it so difficult to afford the groups the same consideration? One might well wonder why I would need to critique the groups and why would they need to be better? This is something I will continue to work on because, if I do begin to critique effectively, and we work further on certain aspects of 
our sound, who is to say that the enjoyment would not be greater from that different sound or experience as a result?

\subsection{Speech / Singing Pitches and Aphasia Friendly Printing}

When considering the best keys in which to sing the songs during my time with the singing groups, (per my findings, "Choosing the Key" p. 35), we worked off the premise that speech pitches were approximately $A_{3}-A_{4}$. This was earlier on in my time with the choir. Further along the track, I considered my own speech pitches although I was not working on that, per se, in my research.

In Henton, (1989), (Figure 21), the following pitch ranges were shown.

\begin{tabular}{|l|c|c|}
\hline & Frequencies & Scientific Pitch Notation \\
\hline Men & $93-131$ & $\mathrm{~F}^{\#_{2}} / \mathrm{G}^{b}{ }_{2}-\mathrm{C}_{3}$ \\
\hline Women & $155-216$ & $\mathrm{D}^{\#_{3} / \mathrm{E}^{b}}{ }_{3}-\mathrm{A}_{3}$ \\
\hline
\end{tabular}

\section{Figure 21 - Speech Pitches (Henton, 1989)}

These are lower pitches than what I was aiming at for the singing groups. There might be different considerations for men and women in singing groups. There might be marked differences in what is comfortable people to be speaking and singing. Currently, most music therapists are women and I wonder if this has a bearing on the optimum pitch range. These are possible topics for further enquiry.

Another topic for further enquiry could be regarding the 'Aphasia Friendly Guidelines' currently available. Due to the differences in types and variance in severity of people with aphasia, it could be that there needs to be multiple options of 'Aphasia Friendly Guidelines'. When I asked some of the people with aphasia that I worked with individually whether this resource (following 'Aphasia Friendly Guidelines') was easier to read than the other, it didn't make any difference to them. This in itself means nothing but it prompts me to consider this as a topic for further enquiry. 


\subsection{Quality Music Experiences}

I found that when we were singing rounds it was easier for me to concentrate by turning my back on one group and focussing on the group I was leading. This was only possible when we were in a co-therapy situation and the other group(s) had good support from Alison and volunteers. This did allow us to achieve more technically difficult music activities but did not occur often because it sometimes excluded some of the participants due to the difficulty.

\subsection{Summary of Discussion}

Some of my findings raised further questions, some needed more explanation and clarity, and others warranted, in my opinion, further research. Multi-tasking and 'Flow' asked "was my newness to working in this field somewhat of a 'field-leveller'? I also wondered why I was so averse to giving critique when I valued it be given to me. A standard, or universally understood, notion of 'quality musical experience' still eludes me and, like learning to sensibly and sensitively critique, are things I will continue to work on. These last two notions may warrant further research, but they are both difficult to quantify. Things warranting further research, that are possible to quantify, are further checks on speech frequencies/ranges and Aphasia Friendly Guidelines for public health information purposes at least. ${ }^{20}$

\section{Strengths and Limitations}

This research, since I inhabited the dual role of researcher and practitioner, has little generalisability due to its subjectivity. While I considered ways and means of improving my own practice during this research, the findings may or may not be valid for others' situations, characters and contexts. While this research is 'about me' it does, however, implicate others by association and although I have tried to be as true

\footnotetext{
${ }^{20}$ Here I fall on my sword. Since early in my practicum Alison forwarded me the Aphasia Friendly guidelines as noted above. I mis-read the font description (sans serif) and have printed all my resources during this placement in SERIF font of 'Calisto MS'. I even started formatting this exegesis in that same font until I re-checked the document online. I am hoping that some members of the singing groups will be interested enough to want to read this - hence the Non-serif font and left margin alignments.
} 
to the tenets of research, by including all relevant information, there may have been times when I thought some information too sensitive to others to disclose. There were times when I immersed myself so fully in the practitioner side of my role that I neglected the researcher side. Consequently, I may not have allowed enough time to reflect and write notes leading to possible gaps in the data.

There are, I'm sure, a multitude of ways that this data could have been construed, given unlimited resources of time and energy. Within the constraints I what I could do at the time, I recognise that this is only one facet of what must surely be a maze a mirrors if time were of no consequence.

The insights provided in these findings might be of use to music therapy with neurological singing groups in New Zealand.

\section{CONCLUSION}

There were times when I was concerned about my ability to be able to carry out the myriad of actions and processes I thought attributed to the task of building and delivering repertoire, whilst being a student music therapist working with singing groups of people living with neurological conditions. All the things discussed earlier in 'Gearing For Positivity', 'Maintaining the Feel-Good Factor' and 'Managing My skills and Vulnerabilities', which were challenging at first as a new practitioner seemed to be important to bring together in order to support the community singing groups helpfully.

By reflecting in three action cycles and building a thematic analysis of my reflections in a systematic way, I learnt to develop a broad base of skills (cueing, modelling, musicality, building and maintaining the feel-good factor as well as recognising and managing my own vulnerabilities) to keep a positive enjoyable musical focus to our sessions. I learned, through my reflections, that enjoyment and flow were such a 
valuable part of the experience and I began to welcome the humanising link this had with our singing group members.

I became aware that I, too, am a vulnerable person while learning new skills and I wondered if this made me more aware of the participants' vulnerabilities? At times it was difficult balancing the mastery of skills and delivery techniques while still maintaining the therapeutic mode of being that I deemed to be important. I reminded myself to stay positive. This was well reinforced by the wonderful support and encouragement I received.

As I came to know the participants more comprehensively, (names, conditions, and their preferences), I found it easier, once I was with them, to 'give in to just being with them'. I realised that it is not necessarily all about the songs or the singing of them, it was more about the encounters with people and, indeed, the whole experience that truly matters. 


\section{References}

Aigen, K. (2012). Community Music Therapy. In G. E. McPherson \& G. F. Welch (Eds.), The Oxford Handbook of Music Education (Vol. 2): Oxford University Press. Retrieved from http://www.oxfordhandbooks.com/view/10.1093/oxfordhb/9780199928019.001 .0001/oxfordhb-9780199928019-e-10. doi:10.1093/oxfordhb/9780199928019.013.0010

Ansdell, G. (2002). Community Music Therapy and the winds of change. Voices: $A$ World Forum for Music Therapy, 2(2). doi:10.15845/voices.v2i2.83

Baker, F., \& Ballantyne, J. (2012). "You've got to accentuate the positive": Group songwriting to promote a life of enjoyment, engagement and meaning in aging Australians. Nordic Journal of Music Therapy, 22(1), 7-24. doi:10.1080/08098131.2012.678372

Baker, F., \& Tamplin, J. (2006). Music therapy methods in neurorehabilitation: A clinician's manual. London, UK: Jessica Kingsley.

Braun, V., \& Clarke, V. (2006). Using thematic analysis in psychology. Qualitative Research in Psychology, 3(2), 77-101. doi:10.1191/1478088706qp063oa

Bruscia, K. E. (1998). Defining music therapy (2nd ed.). Gilsum, NH: Barcelona Publishers.

Cevasco-Trotter, A. M., Vanweelden, K., \& Bula, J. A. (2014). Music therapists' perception of top ten popular songs by decade (1900s-1960s) for three subpopulations of older adults. Music Therapy Perspectives, 32(2), 165-176. doi:10.1093/mtp/miu028

Clarke, V., \& Braun, V. (2016). Thematic analysis. The Journal of Positive Psychology, 12(3), 297-298. doi:10.1080/17439760.2016.1262613

Clift, S. (2010). Singing for health: a musical remedy. British Journal of Wellbeing, 1(6), 14-16. doi:10.12968/bjow.2010.1.6.78577

Clift, S. (2012). Singing, wellbeing, and health. In R. MacDonald, G. Kreutz, \& L. Mitchell (Eds.), Music, health, and wellbeing (pp. 113-124): Oxford Scholarship Online.

Coghlan, D. (2008). Authenticity as first person practice: An exploration based on Bernard Lonergan. Action Research, 6(3), 351-366. doi: $10.1177 / 1476750308094649$

Daveson, B. (2008). A Description of a Music Therapy Meta-Model in NeuroDisability and Neuro-Rehabilitation for Use with Children, Adolescents and Adults. The Australian Journal of Music Therapy, 19, 70-85.

Daykin, N., Mansfield, L., Meads, C., Julier, G., Tomlinson, A., Payne, A., . . Victor, C. (2018). What works for wellbeing? A systematic review of wellbeing outcomes for music and singing in adults. Perspectives in Public Health, 138(1), 39-46. doi:10.1177/1757913917740391

Durham, C. (2002). Music therapy and neurology. In L. Bunt \& S. Hoskyns (Eds.), The Handbook of Music Therapy (pp. 115-131). Hove, England: Routledge. 
Elefant, C., Baker, F. A., Lotan, M., Lagesen, S. K., \& Skeie, G. O. (2012). The Effect of Group Music Therapy on Mood, Speech, and Singing in Individuals with Parkinson's Disease - A Feasibility Study. Journal of music therapy, 49(3), 278-302. doi:10.1093/jmt/49.3.278

Henton, C. G. (1989). Fact and fiction in the description of female and male pitch. Language and Communication, 9(4), 299-311. doi:10.1016/02715309(89)90026-8

Istvandity, L. (2017). Combining music and reminiscence therapy interventions for wellbeing in elderly populations: A systematic review. Complementary Therapies in Clinical Practice, 28, 18-25. doi:10.1016/j.ctcp.2017.03.003

Kennedy, M., \& Bourne, J. (2013). The Oxford Dictionary of Music.

Keown, P., Parker, L., \& Tiakiwai, S. (2005). Values in the New Zealand curriculum: A literature review on values in the curriculum. Wellington.

Livesey, L., Morrison, I., Clift, S., \& Camic, P. (2012). Benefits of choral singing for social and mental wellbeing: Qualitative findings from a cross-national survey of choir members. Journal of Public Mental Health, 11(1), 10-26. doi:10.1108/17465721211207275

Pagad, S. (2014). What Is the Role of A Student Music Therapist in a Community Music Setting? In D. Rickson (Ed.): Victoria University of Wellington.

Papinczak, Z. E., Dingle, G. A., Stoyanov, S. R., Hides, L., \& Zelenko, O. (2015). Young people's uses of music for well-being. Journal of Youth Studies, 18(9), 1-16. doi:10.1080/13676261.2015.1020935

Pavlicevic, M. (2013). Music, musicality, and musicking: Between therapy and everyday life. Matatu, 44(1), 67-84. doi:10.1163/9789401210546 007

Rickson, D. (2009). Researching Ones Own Clinical Practice: Managing Multiple Roles in an Action Research Project. Voices: A World Forum for Music Therapy, 9(1), NP. doi:10.15845/voices.v9i1.364

Rolvsjord, R. (2010). Resource-oriented music therapy in mental health care. Gilsum, N.H.: Barcelona Publishers.

Rose, T., Worrall, L., Hickson, L., \& Hoffman, T. (2014). Aphasia-friendly health information: Text formatting facilitators and barriers.

Seligman, M. E., \& Csikszentmihalyi, M. (2000). Positive psychology. An introduction. The American psychologist, 55(1), 5-14.

Silverman, M. J. (2017). Staff and administrators' perceptions of music therapy with acute care mental health inpatients: A qualitative investigation. Journal of Creativity in Mental Health, 13(2), 1-14. doi:10.1080/15401383.2017.1360815

Silverman, M. J., Letwin, L., \& Nuehring, L. (2016). Patient preferred live music with adult medical patients: A systematic review to determine implications for clinical practice and future research. The Arts in Psychotherapy, 49, 1-7. doi:10.1016/j.aip.2016.05.004

Small, C. (1999). Musicking - the meanings of performing and listening. A lecture. Music Education Research, 1(1), 9-22. doi:10.1080/1461380990010102 
Stige, B. (2015). Community Music Therapy. In B. L. Wheeler (Ed.), Music Therapy Handbook (pp. 233-245). New York, NY: Guildford Publications.

Stige, B., \& Aarø, L. E. (2012). Invitation to community music therapy. New York, NY: Routledge.

Stige, B., \& McFerran, K. S. (2016). Action Research. In B. L. Wheeler \& K. M. Murphy (Eds.), Music therapy research (3rd ed., pp. 429-440). Dallas, TX: Barcelona Publishers.

Talmage, A., Ludlam, S., Leão, S., Fogg-Rogers, L., \& Purdy, S. (2013). Leading the CeleBRation Choir: The Choral Singing Therapy protocol and the role of the music therapist in a social singing group for adults with neurological conditions. New Zealand Journal of Music Therapy, 11, 7-50.

Tamplin, J., \& Grocke, D. (2008). A Music therapy treatment protocol for acquired dysarthria rehabilitation. Music Therapy Perspectives, 26(1), 23-30. doi:10.1093/mtp/26.1.23

Thaut, M. H., \& Wheeler, B. L. (2010). Music Therapy. In P. Juslin \& J. Sloboda (Eds.), Handbook of music and emotion: Theory, research, applications. (pp. 819-848): Oxford University Press.

Theorell, T., \& Kreutz, G. (2012). Epidemiological studies of the relationship between musical experiences and public health. In R. Macdonald, G. Kreutz, \& L. Mitchell (Eds.), Music, health, and wellbeing (pp. 424-435). New York: Oxford Scholarship Online.

Vanweelden, K., \& Cevasco, A. (2010). Recognition of geriatric popular song repertoire: A comparison of geriatric clients and music therapy students. Journal of music therapy, 47(1), 84-99.

VanWeelden, K., \& Cevasco, A. M. (2007). Repertoire recommendations by music therapists for geriatric clients during singing activities. Music Therapy Perspectives, 25(1), 4-12. doi:10.1093/mtp/25.1.4

VanWeelden, K., \& Cevasco, A. M. (2009). Geriatric clients' preferences for specific popular songs to use during singing activities. Journal of music therapy, 46(2), 147-159. doi:10.1093/jmt/46.2.147

Wall, G. (2010). Enhancing psychological wellbeing for people with long-term neurological conditions. British Journal of Wellbeing, 1(7), 25-29. doi:10.12968/bjow.2010.1.7.79416

Wheeler, B. L. (Ed.) (2015). Music therapy handbook. New York, NY: Guilford Press. 


\section{APPENDICES}

Appendix 1: Two Requests for permission to conduct research

Appendix 2: Information Sheet for participants

Appendix 3: Consent Form for participants

Appendix 4: Consent Form for Alison Talmage

Appendix 5: Cycle 1 Results

Appendix 6: Cycle 2 Results

Appendix 7: Cycle 3 Results 


\title{
Appendix 1: Two Requests for permission to conduct research
}

\author{
WVICTORIA \\ New zeNunD soiocl or muac

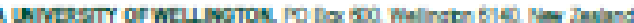

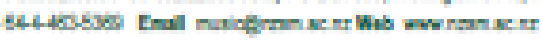

15 May 2018

Allson Taimage

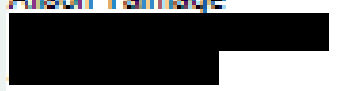

Dear Alson

\section{APPLICATION FOR PERMISSION TO CONDUCT RESEARCH}

I wish to apply for your permission to conduct action research on my own music therapy practice whlle I am a student muslc theraplst working under your direction with the CeleBRation and Sing Up Rodney! Choirs. This research is part of the requirements for a Master of Music Therapy which I am currently undertaking through NZ School of Music - Te KoKT and Victoria University of Wellington.

My research question is "How do I develop and delver a repertoire for use in muslc therapy with adults and oider adults who are experiencing neurological issues?* While I will seek to protect the anonymity of the choir members in this study, I would like to acknowledge the CeleBRation Choir, The Centre for Brain Research, The Unlversity of Auckiand, and SIng Up Rodney! Choir for their part in this research if you so wish.

I have recelved approval for this proposal from the NZSM Postgraduate Committee and the research will operate under an ethical template for student research for NZSM 526 Casework 8 Research gained by my lecturers, Approval \#: 22131 dated 15 July 2015. I have attached a copy of my research proposal for further information to the emall I have sent you. If you have any questions about this research, please contact my supervisor: Assoc. Professor, Sarah Hoskyns,

Please sign the form below and give me a copy at your convenlence. I hope to proceed with this study from $14^{\text {th }}$ May 2018.

KInd regards Jenny Gordon

I give permission for Jenny Gordon to conduct action research on her own music therapy practice whlle she is a student music theraplst working under my direction with the CeleBRation and Sing Up Rodney! Choirs.

\section{Alson Talmage}

I give permission for Sing Up Rodney! to be named in the acknowledgements of the final exegesis. 
15 May 2018

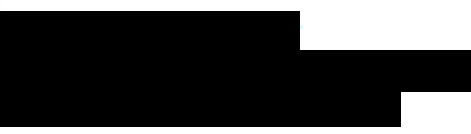

Dear

\section{APPLICATION FOR PERMISSION TO CONDUCT RESEARCH}

I wish to apply for your permission to conduct action research on my own music therapy practice while I am a student music therapist working under the direction of Alison Talmage with the CeleBRation Choir. This research is part of the requirements for a Master of Music Therapy which I am currently undertaking through NZ School of Music - Te Koki and Victoria University of Wellington.

My research question is "How do I develop and deliver a repertoire for use in music therapy with adults and older adults who are experiencing neurological issues?" While I will seek to protect the anonymity of the choir members in this study. I would like to acknowledge the CeleBRation Choir. the Centre for Brain Research and the University of Auckland for their part in this research if you so wish.

I have received approval for this proposal from the NZSM Postgraduate Committee and the research will operate under an ethical template for student research for NZSM 526 Casework \& Research gained by my lecturers, Approval \#: 22131 dated 15 July 2015 . I have attached a copy of my research proposal for further information to the email I have sent you. If you have any questions about this research, please contact my supervisor. Assoc. Professor, Sarah Hoskyns ant this research, pleas

Please sign the form below

I hope to proceed with this study from 14: May 2018.

Kind regards Jenny Gordon

I give permission for Jenny Gordon to conduct action research on her own music therapy practice while she is a student music therapist working under the direction of Alison Talmage with the CeleBRation Choir.

Date.

I give permission to use the CeleBRation Choir and the University of Auckland to be named in the acknowledgements of the final exegesis.

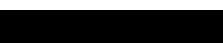

Date. 


\section{Appendix 2: Information Sheet for singing group participants}

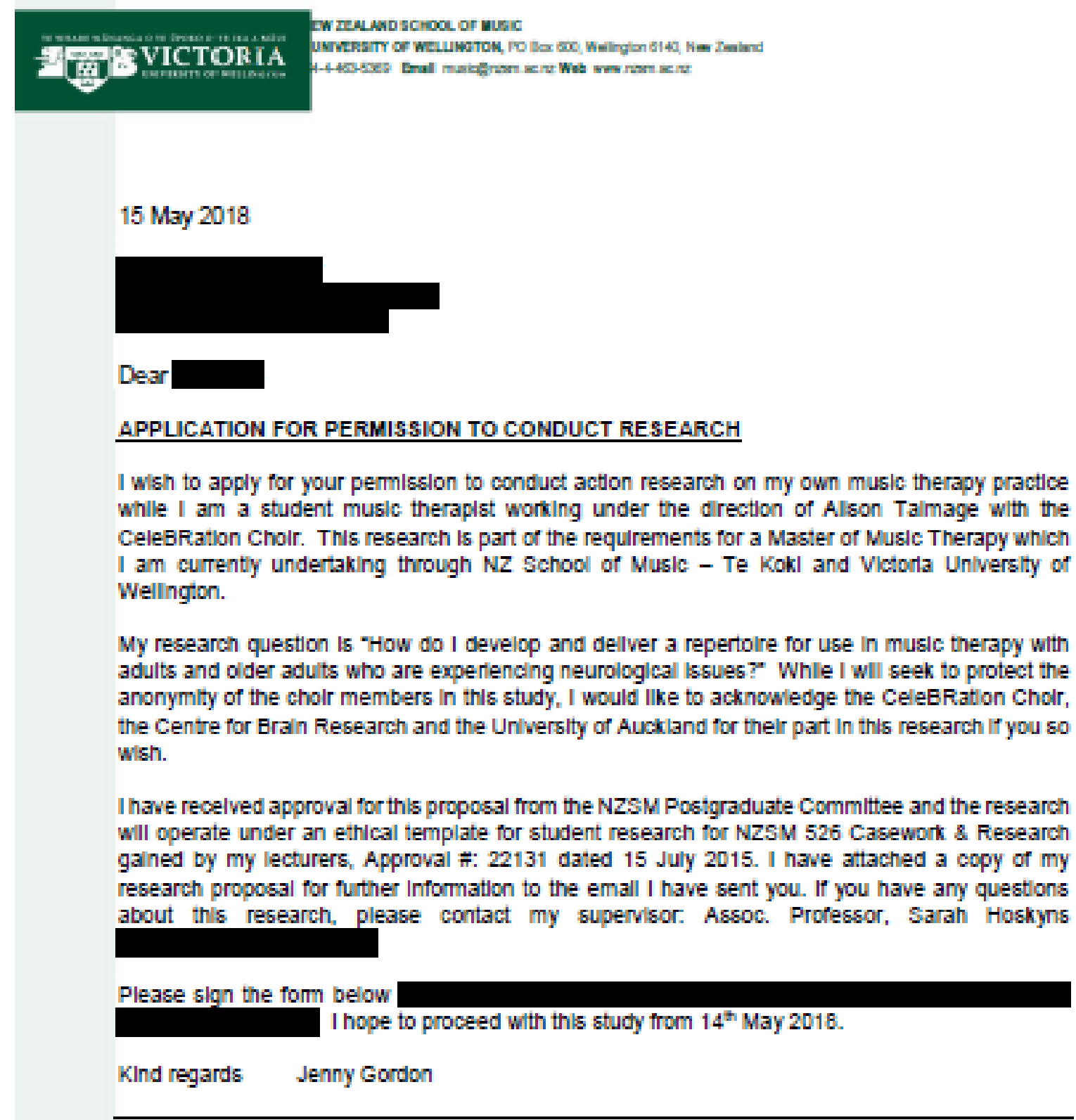

I give permission for Jenny Gordon to conduct action research on her own music therapy practice whlle she is a student music therapist working under the direction of Alson Talmage with the CeleBRation Choir.

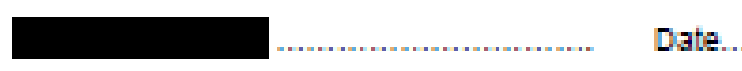

I give permission to use the CeleBRation Choir and the Unlversity of Auckiand to be named In the acknowledgements of the inal exegesis.

Date. 


\section{INFORMATION SHEET for Informed Consent}

\section{Research by Jenny Gordon}

"How do I develop and deliver a repertoire for use in group singing with people living with a neurological condition, and their caregivers?"

\section{$\underline{\text { MyResearch }}$}

My name is Jenny Gordon and I have generously been given permission to work with this choir as part of my practical for this year. This is a requirement for my Master of Music Therapy degree at the New Zealand School of Music - Te Köki at Victoria University of Wellington.

I will also be researching my practice with the choir to see how I develop and use repertoire in this work because I believe that the right music can not only bring people together but be a powerful tool to help people. I am seeking your consent to be able to write about us for this research, but you do not have to say yes.

This research that I am doing is called 'action research' and I will be focusing on my own practice. This means that I am looking to improve what I do in my practice of trying to help you reach the goals you set yourself when you joined this choir. This can help me become a better music therapist.

\section{Vignettes}

I will write some vignettes (real examples of my work with you). These can be used to show how my practice has improved. You will not be required to do anything 'special' for the research. It is important to note that I will be focusing on and researching what I do and not what you do.

If you sign the attached consent form giving me permission to write about you and our work in this choir, I will be using a pseudonym instead of your real name to protect your anonymity. I will, however, be naming the choir and the University of Auckland in the acknowledgments of my report.

\section{Andio and Video Recording}

From time to time I would like to be able to record some of our work together to check what it is that I am doing in our sessions. I will also use these recordings to transcribe 
some of the music we create together. Once again, there will be nothing that will distinguish you as individuals although the choir will be named in the acknowledgements. These recordings will be deleted once the music is transcribed.

\section{Your Rights to Refuse or Withdraw}

- You do not have to give your consent to take part in my research.

- If you do give your consent, you can change your mind and withdraw it up to August 31 2018.

\section{After the Research is Finished}

Once I have finished the research, I will be able to tell you about what I have written and show you any vignette I have written about you specifically. Data from the research will be stored in a locked cabinet at the NZSM- Te Koki for a period of 5 years. The report will be available for people to look at through the Victoria University of Wellington library. I will be sharing my research in private with my supervisors and examiners throughout this process. I may also decide to share my research with others through professional journals.

\section{What do you need to do?}

- Please feel free to ask me or my supervisor any questions if you have any.

- If you do consent, then please fill out the attached consent form by June $30^{\text {th }} 2018$ and bring it to choir when you next come.

- If you do not give your consent, then do not fill in a consent form.

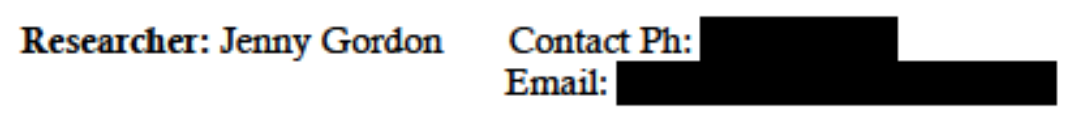

Supervisor: Sarah Hoskyns, Associate Professor, Director of Music Therapy Programme New Zealand School of Music - Te Köki at Victoria, University of Wellington

\section{Ethical Approval}

This project has been reviewed and approved by the New Zealand School of Music Postgraduate Committee. The VUW Human Ethics committee has given generic approval for music therapy students to conduct studies of this type. The music therapy projects have been judged to be low risk and, consequently, are not separately reviewed by any Human Ethics Committees. The supervisor named above is responsible for the ethical conduct of this research. If you have any concerns about the conduct of this research, please contact the supervisor, or if you wish to raise an issue with someone other than the researcher or supervisor, please contact the Victoria University of Wellington Human Ethics Convenor, A. Prof. Susan Corbett email: 


\section{Appendix 3: Consent Form for singing group participants}

\section{CONSENT FORM for Informed Consent}

\section{Research by Jenny Gordon}

"How do I develop and deliver a repertoire for use in group singing with people living with neurological condition, and their caregivers?"

$\square$ I have read and understand the Information Sheet.

$\square$ I was able to ask questions and I understood the answers.

I know that I can ask questions at any time.

$\square$ I know that my real name will not be used but that the choir will be named in the acknowledgements of the report.

$\square$ I know that I can see the report when it is completed.

I have had time to make my decision.

I I understand that I am not obligated to give my consent and that, if I do then I can withdraw it up until $31^{\text {st }}$ August 2018.

- I consent to a vignette about me being used in Jenny's research

$$
\text { (please circle one) YES / NO }
$$

- I consent to audio and video recordings being made to help the researcher with accuracy about musical details

$$
\text { (please circle one) YES / NO }
$$

Full Name (printed)

Please tick which choir you belong to

\section{CeleBRation Choir}

Sing Up Rodney!

Signed:

Date: 


\section{Appendix 4: Consent Forms for Alison Talmage}

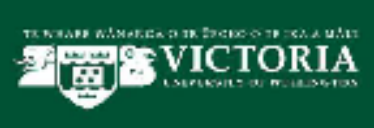

TE KÖKI NEW ZEALAND SCHOOL OF MUSIC

VICTORIA UNINERSITY OF WELINGTON, PO Bor 600, Wellinglon 6140, New Zealand

Phone +64-4-463-5369 Email musicgnzzm.sc.nz Web www.rzsm.ac.nz

\section{CONSENT FORM for Informed Consent}

\section{Research by Jenny Gordon}

"How do I develop and deliver a repertoire for use in group singing with people living with neurological condition, and their caregivers?"

I have read and understand the Information Sheet.

I was able to ask questions and I understood the answers.

$\square$ I know that I can ask questions at any time.

$\square \quad$ I know that my real name will be used and that the choirs will be named in the acknowledgements of the report.

I know that I can see the report when it is completed.

$\square$ I have had time to make my decision.

$\square$ I understand that I am not obligated to give my consent and that, if I do then I can withdraw it up until $31^{\text {st }}$ August 2018.

- I consent to a vignette about me being used in Jenny's research

$$
\text { (please circle one) YES / NO }
$$

- I consent to audio and video recordings being made to help the researcher with accuracy about musical details

$$
\text { (please circle one) YES / NO }
$$

Full Name (printed)

Please tick which choir you belong to

CeleBRation Choir

Sing Up Rodney!

Signed:

Date: 


\section{Appendix 5: Cycle 1 Results}

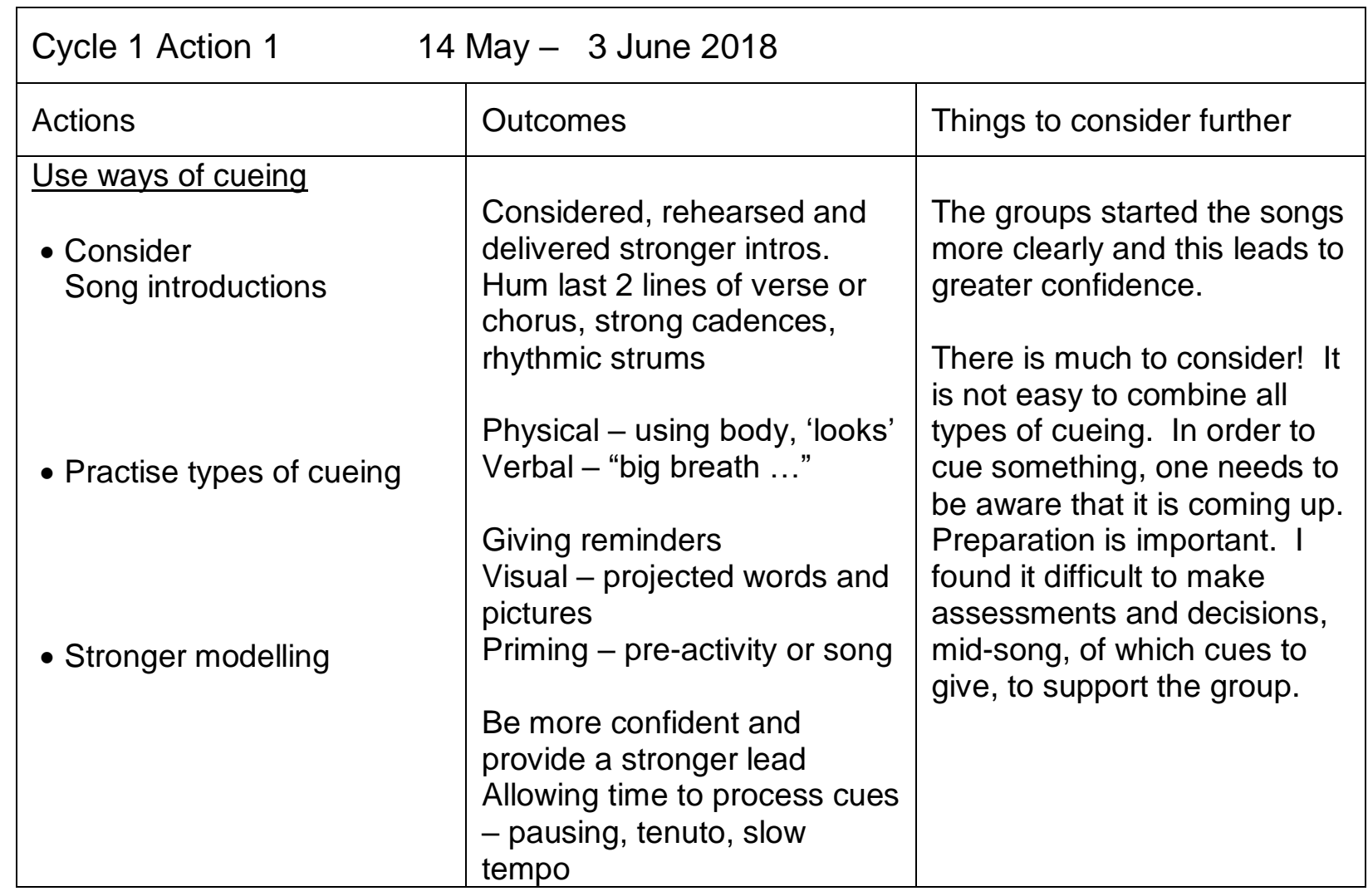

\begin{tabular}{|c|c|c|}
\hline \multicolumn{3}{|c|}{14 May - 3 June 2018} \\
\hline Actions & Outcomes & Things to consider further \\
\hline $\begin{array}{l}\frac{\text { Create exercises from }}{\text { familiar and fun songs and }} \\
\text { tunes } \\
\text { - Consider target areas } \\
\text { - Matching elements of a } \\
\text { song to the target area } \\
\text { - Create and deliver to group } \\
\text { Be-Bop-A-Lula } \\
\text { Blueberry Hill } \\
\text { Little Brown Jug } \\
\text { William Tell Overture }\end{array}$ & $\begin{array}{l}\text { These are generally speech } \\
\text { production (Phonation, } \\
\text { Respiration, Articulation, } \\
\text { Resonance and Prosody) } \\
\text { issues and word retrieval. } \\
\text { Parts of songs and melodies } \\
\text { to practise set target areas. }\end{array}$ & $\begin{array}{l}\text { The spectrum of the group in } \\
\text { terms of needs and goals, } \\
\text { preferences, prior knowledge } \\
\text { - it can be difficult to create } \\
\text { experiences that are } \\
\text { meaningful to all at once. } \\
\text { Don't labour the exercise as } \\
\text { the fun goes out of it. } \\
\text { A familiar song may be } \\
\text { unknown to some and hence } \\
\text { the exercise became a } \\
\text { learning issue } \\
\text { Keeping the ideas flowing so } \\
\text { there are new, fresh } \\
\text { exercises is burdensome. } \\
\text { Possibly the notion of having } \\
\text { many different exercises that } \\
\text { target the same things and } \\
\text { thus being able to rotate the } \\
\text { use of them might be helpful? }\end{array}$ \\
\hline
\end{tabular}




\begin{tabular}{|c|c|c|}
\hline \multicolumn{3}{|c|}{14 May - 3 June 2018} \\
\hline Actions & Outcomes & Things to consider further \\
\hline $\begin{array}{l}\text { Considering appropriate song } \\
\underline{\text { keys }} \\
\text { - Consider speech range }\end{array}$ & $\begin{array}{l}A_{3}-A_{4}(A \text { below \& above } \\
\text { middle } C \text { ) } \\
\text { This is often extended to } G_{3} \\
\text { or } F_{3} \text { and up to } C_{5} \\
\\
\text { I prefer to play different keys } \\
\text { on different instruments. } \\
\text { Practising helps. }\end{array}$ & $\begin{array}{l}\text { There is little else to } \\
\text { consider. It is possible to go } \\
\text { outside this range but } \\
\text { extremities of pitch confound } \\
\text { other problems such as word } \\
\text { retrieval and articulation } \\
\text { processes as the singers are } \\
\text { concentrating on high or low } \\
\text { pitches. } \\
\text { Some songs are aesthetically } \\
\text { more pleasing in some keys } \\
\text { rather than others }\end{array}$ \\
\hline
\end{tabular}


Appendix 6: Cycle 2 Results

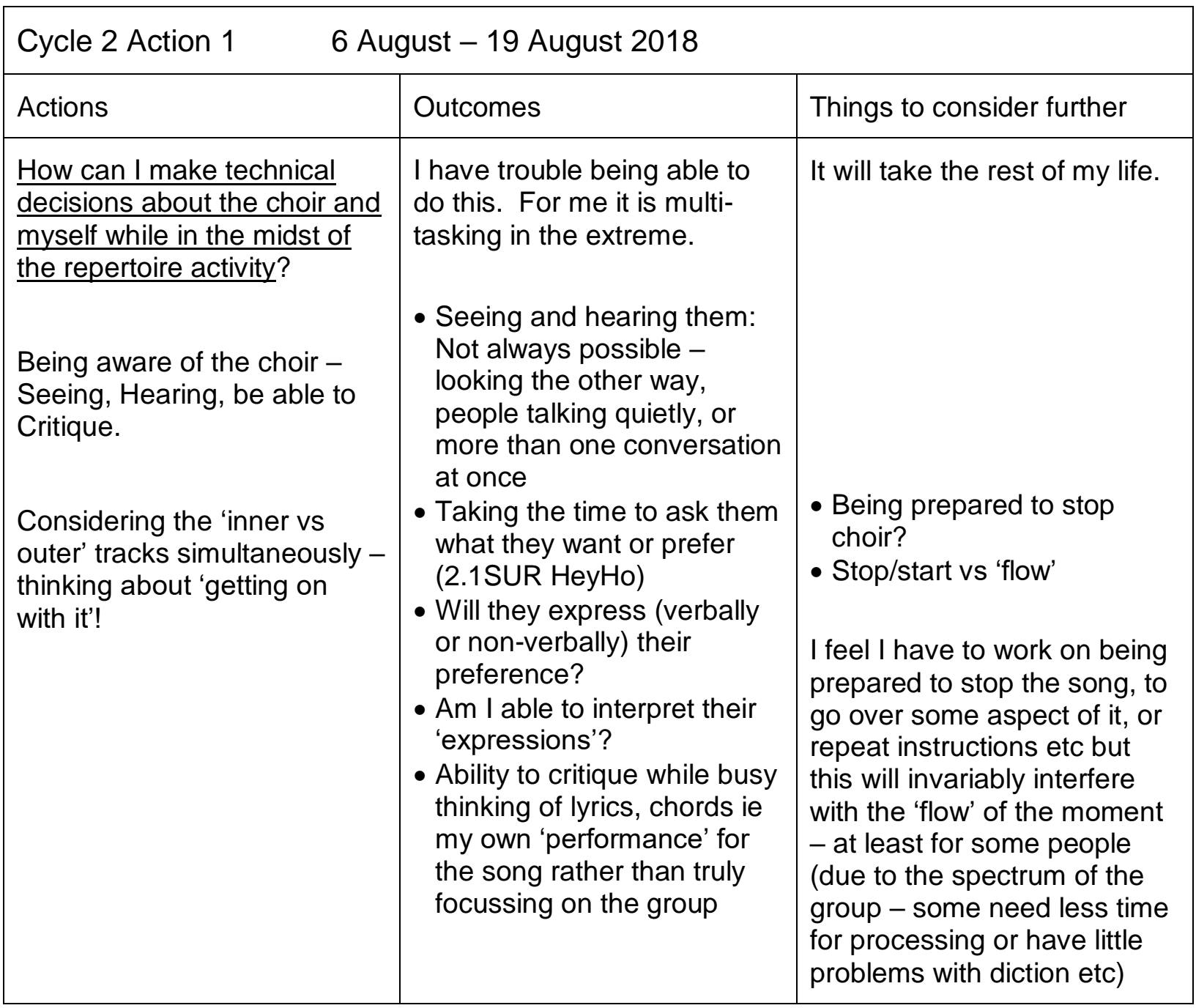

\begin{tabular}{|c|c|c|}
\hline \multicolumn{3}{|c|}{6 August - 19 August 2018} \\
\hline Actions & Outcomes & Things to consider further \\
\hline $\begin{array}{l}\text { How can I dispel unhelpful } \\
\text { anxieties to fully allow me to } \\
\text { be a natural and open } \\
\text { therapeutic presence while } \\
\text { making technical decisions in } \\
\text { the moment? }\end{array}$ & $\begin{array}{l}\text { Preparation and rehearsal } \\
\text { lead to a certain confidence } \\
\text { in delivery. I find I don't mind } \\
\text { making mistakes or 'not } \\
\text { knowing' when the session is } \\
\text { in progress, it's the pre- } \\
\text { session that I need to get a } \\
\text { handle on and it's not always } \\
\text { possible to do all the }\end{array}$ & $\begin{array}{l}\text { I did begin to manage my } \\
\text { anxiety more successfully } \\
\text { during impromptu parts of the } \\
\text { sessions (where a song was } \\
\text { selected that I was } \\
\text { unrehearsed for). I got more } \\
\text { self confidence in this as my } \\
\text { practice/practise progressed. } \\
\text { As I came to know the } \\
\text { participants more } \\
\text { comprehensively, (names, } \\
\text { conditions, and them } \\
\text { personally), I found it easier } \\
\text { once I was with them to 'give } \\
\text { in to just being with them'. I }\end{array}$ \\
\hline
\end{tabular}




\begin{tabular}{|l|l|l|}
\hline & $\begin{array}{l}\text { rehearsal necessary to gain } \\
\text { the 'performance confidence'. }\end{array}$ & $\begin{array}{l}\text { realised that it is not } \\
\text { necessarily all about the } \\
\text { songs or the singing of them, } \\
\text { it was more about the } \\
\text { encounters and the whole } \\
\text { experience. }\end{array}$ \\
\hline
\end{tabular}

Appendix 7: Cycle 3 Results

\begin{tabular}{|c|c|c|}
\hline \multicolumn{3}{|c|}{17 Sept - 7 October 2018} \\
\hline Actions & Outcomes & Things to consider further \\
\hline $\begin{array}{l}\frac{\text { How can I simultaneously }}{\text { facilitate quality musical }} \\
\frac{\text { experiences of the repertoire }}{\text { while responding to the }} \\
\frac{\text { needs of individual }}{\text { participants? }} \\
\text { Things to consider: } \\
\text { 1. What is a quality musical } \\
\text { experience? My own or } \\
\text { their notion of quality } \\
\text { musical experience? } \\
\text { 2. Managing the technical } \\
\text { aspects of the music: } \\
\text { - Give careful and } \\
\text { thoughtful instructions } \\
\text { / back to cueing etc } \\
\text { Break the activity } \\
\text { down } \\
\text { Start simple and build } \\
\text { complexity }\end{array}$ & $\begin{array}{l}\text { Struggling a bit with what is } \\
\text { teaching them my 'my } \\
\text { version' or instructing them } \\
\text { rather than just offering the } \\
\text { song and letting them sing it } \\
\text { 'their' way. This could } \\
\text { potentially detract from the } \\
\text { experience due to different } \\
\text { versions of the song and } \\
\text { some may not know the song } \\
\text { well, if at all. I have offered } \\
\text { the chance to split up and } \\
\text { some do basslines or drones } \\
\text { etc while others in the group } \\
\text { sing the melody. They tell } \\
\text { me they prefer just to sing the } \\
\text { words and in unison as } \\
\text { opposed to learning } \\
\text { harmonies. Is it that it is } \\
\text { harder work and to them not } \\
\text { worth the effort? I think these } \\
\text { things add to my experience, } \\
\text { but it seems that for } \\
\text { some/most of them just } \\
\text { singing the lyrics and melody } \\
\text { to the best of their abilities } \\
\text { (includes energy levels and } \\
\text { how they are feeling at the } \\
\text { time) is the EXPERIENCE } \\
\text { that they desire? }\end{array}$ & $\begin{array}{l}\text { This leads to notions of what } \\
\text { kind of therapist am I } \\
\text { intending to be (I've been } \\
\text { reading Aigen's identity of the } \\
\text { music therapist (Aigen, 2012) } \\
\text { - musician doing } \\
\text { therapy/therapist using } \\
\text { music; and Sidarth Pagad } \\
\text { (Pagad, 2014) re music } \\
\text { produced in CoMT "While } \\
\text { music serves as the vehicle } \\
\text { and the means by which this } \\
\text { is achieved, the music is not } \\
\text { the end goal or purpose of } \\
\text { the group "Pg } 27\end{array}$ \\
\hline
\end{tabular}

